\title{
Functionalized Layered Double Hydroxides for Innovative Applications
}

Received 00th January 20xx, Accepted 00th January 20xx DOI: $10.1039 / x 0 x \times 00000 x$

\author{
Minwang Laipan, ${ }^{a, b, c, d}$ Jingfang Yu, ${ }^{e}$ Runliang Zhu, ${ }^{c, d, *}$ Jianxi Zhu, ${ }^{c, d}$ Andrew T. Smith, ${ }^{a, b}$ Hongping \\ $\mathrm{He}^{\mathrm{c}, \mathrm{d}}{ }^{\text {Dermot O’Hare, }}{ }^{\mathrm{e}, *}$ Luyi Sun ${ }^{\mathrm{a}, \mathrm{b}, \mathrm{f}, *}$
}

\begin{abstract}
Two-dimensional layered double hydroxides (LDHs) are currently a topic of significant interest due to their extraordinary physiochemical properties. LDHs are potentially useful in a wide range of applications, particularly in environmental, energy, catalysis, and biomaterials related fields. Despite the unique intrinsic properties of LDHs, various functionalization strategies have been applied to LDHs that yield even more exciting performance opportunities, offering guides to design novel functional nanomaterials. In this review, we address how these strategies can improve the various properties of LDHs. We provide an overview of the functionalizing strategies of intercalation, surface modification, hybridization, layered compositions regulation, size and morphology control, and defect creation. These strategies contribute significantly to the enhancement of the performance of LDHs, across a diverse range of areas such as adsorptive, catalytic, electronic, electrochemical, and optical. As a result, functionalized LDHs exhibit great potential in a wide range of applications in the environmental and energy domains. We have comprehensively highlighted their emerging potential in the environmental, energy, catalysis, and biomaterials related fields, including heavy metal removal, radionuclide capture, organic contaminants purification, oil pollution elimination, hydrogen generation, supercapacitors, batteries, solar cells, catalysis, and biomaterial fabrication.
\end{abstract}

\section{Introduction}

Two-dimensional (2D) layered materials are currently a topic of significant interest due to their extraordinary physiochemical properties. ${ }^{1}$ Their unique anisotropic structural characteristics make them potentially useful in a wide range of applications, such as optoelectronics, photonics, catalysis, piezoelectric devices, environmental pollution control, energy storage and conversion, and biomaterials. ${ }^{1-3}$ Layered double hydroxides (LDHs), previously known as anionic clays, are one family of $2 \mathrm{D}$ materials that have attracted significant interest in recent years. LDHs comprise of positively charged edge-shared octahedral coordinated metal hydroxide layers sandwiched by charge compensating interlayer anions with optional solvation eg. water. The general formula of an $\mathrm{LDH}$ is $\left[\mathrm{M}^{a+}{ }_{1-x} \mathrm{M}^{\prime b+}{ }_{x}(\mathrm{OH})_{2}\right]^{y^{+}}\left[\mathrm{A}^{c-}{ }_{y / c}\right]^{y+} \cdot \mathrm{zH}_{2} \mathrm{O} ; y=a(1-x)+b x-2 ; \mathrm{A}^{c-}$ is an interlayer anion; $\mathrm{M}$ and $\mathrm{M}^{\prime}$ are metal cations. Most frequently $\mathrm{LDHs}$ conform to the formula $\left[\mathrm{M}^{2+}{ }_{1-x} \mathrm{M}^{\prime 3+}{ }_{x}(\mathrm{OH})_{2}\right]^{x+}\left[\mathrm{Ac}^{\mathrm{c}-} \times{ }_{x}\right]^{x+} \cdot \mathrm{zH}_{2} \mathrm{O}$ (where $\mathrm{M}^{2+}$ and $\mathrm{M}^{\prime 3+}$ are divalent and trivalent metal cations typically of $\mathrm{Mg}^{2+}$ and $\mathrm{Al}^{3+}$ respectively; $\mathrm{A}^{c-}$ are inorganic or organic anions)

a.Polymer Program, Institute of Materials Science, University of Connecticut, Storrs, CT 06269, USA

E-mail: luyi.sun@uconn.edu

b.Department of Chemical and Biomolecular Engineering, University of Connecticut, Storrs, CT 06269, USA

c.CAS Key Laboratory of Mineralogy and Metallogeny/Guangdong Provincial Key Laboratory of Mineral Physics and Materials, Guangzhou Institute of Geochemistry, Chinese Academy of Sciences, Guangzhou 510640, China.

E-mail: zhurl@gig.ac.cn

d.Institutions of Earth Science, Chinese Academy of Sciences

e. Chemistry Research Laboratory, Department of Chemistry, University of Oxford,

12 Mansfield Road, Oxford, OX1 3TA, UK.

E-mail: dermot.ohare@chem.ox.ac.uk

f.Department of Biomedical Engineering, University of Connecticut, Storrs, CT 06269, USA.
(Figure 1). ${ }^{4,5,6,7}$ In a few special cases the $\mathrm{M}^{2+}$ site can be substituted by $\mathrm{Li}^{+}$and the $\mathrm{M}^{3+}$ site can be substituted by $\mathrm{M}^{4+}$ cations. ${ }^{8}$ In this review, an LDH containing the metal components, $\mathrm{M}^{1 / 2+}$ and $\mathrm{M}^{\prime 3 / 4+}$ are abbreviated as $\mathrm{MM}^{\prime}-\mathrm{LDH}$. LDHs became the focus for both fundamental research and practical applications due to their unique structures, tunable chemical compositions, and a wide variety of material properties. ${ }^{6,9-13}$ Despite the unique intrinsic properties of LDHs, various functionalization strategies have been applied to LDHs that yield even more exciting performance opportunities. That is, functionalization can drastically improve the performance of LDHs or develop new properties for use in a wide range of applications. For instance, the fabrication of threedimensional hierarchical nano-architecture of an NiFe-LDH remarkably facilitated its rate of electron transport and channel diffusion for catalytic water splitting. ${ }^{14}$ Hybridizing with conductive textile fibers made NiCo-LDH a promising candidate for highperformance pseudocapacitors. ${ }^{15}$ Intercalation of polysulfide developed the potential of MgAl-LDH for highly selective and efficient capture of radionuclide, e.g., uranium. ${ }^{3}$ Hybridization of LDHs with semiconductors to form heterojunction can markedly inhibit the recombination of charge carriers, and thus significantly enhance photocatalytic activity. ${ }^{16,17}$

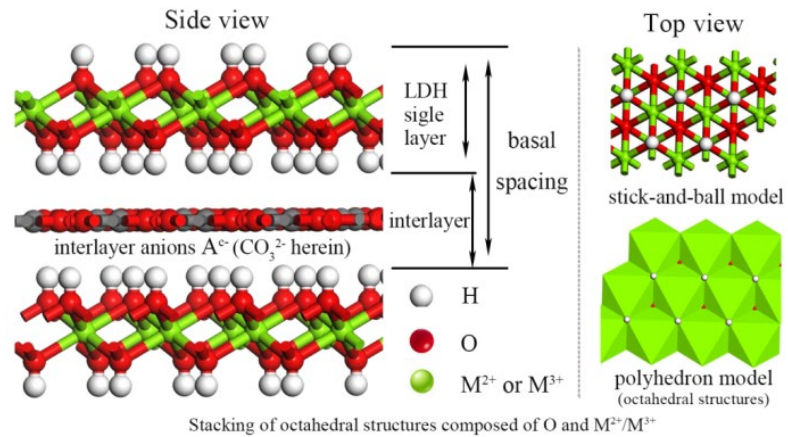


Figure 1. Representative structure of an $\mathrm{LDH} ;\left[\mathrm{M}^{2+}{ }_{1-x} \mathrm{M}^{\prime 3+}{ }_{x} \times(\mathrm{OH})_{2}\right]\left[\mathrm{A}^{c-} \times / c^{-}\right]$ where $\mathrm{M}^{2+}$ and $\mathrm{M}^{\prime 3+}$ are divalent and trivalent metal cations, respectively; $\mathrm{A}^{\mathrm{c}-}$ is an interlayer anion.

Functionalization of LDHs is a process involving the control and manipulation of their surface zone, shape, size, and composition to activate them, or introduction of foreign species or defects on LDHs to enhance or create new functions. ${ }^{1}, 9,18-20$ The modification of surface zone includes intercalation of functional species and alteration of surface functional groups. Introduction of foreign species emphasizes anchoring functional substances onto the surface of LDHs to generate LDH-based hybrids. Apart from the modification of surface zone and introduction of functional species, LDHs can also be functionalized by manipulation of layer composition including the type, ratio, and chemical valence of the metal components, by regulation of the size and morphology of $\mathrm{LDHs}$, and by creation of defects resulting from surface and layered composition regulation. Herein, we summarize the common functionalization strategies that have been developed for LDHs in the following major categories: (1) intercalation,2, 3 (2) surface modification, ${ }^{21,} 22$ (3) hybrid assembly, ${ }^{23,} 24$ (4) layer composition tuning, ${ }^{25}, 26$ (5) size and morphology regulation, ${ }^{14,} 27$ (6) defect introduction, ${ }^{26,28}$ among others. Each of these functionalization strategies demonstrates that with the appropriate modification LDHs can deliver novel and/or enhanced features, e.g., enhanced photoelectronic, $^{23}, 29$ magnetic, $^{30}$ catalytic, $^{29}, 31,32$ and energy storage ${ }^{15}, 33,34$ properties, offering unique perspectives and advantages for both fundamental and applied research

The fundamentals why these strategies can effectively functionalize LDHs are outlined in this review article. For example, the reasons that intercalation is such a versatile and effective approach in tuning the properties of LDHs are: (1) intercalation provides the highest possible doping and/or phase change to the pristine LDHs; (2) the intercalation process, and the concomitant changes in the properties of LDHs is typically reversible; (3) intercalation is controllable; (4) changes in intercalated LDHs during material preparation can be monitored in situ and in real time; (5) intercalation can induce structural changes, such as lattice expansion or even phase changes, for improved or new physiochemical properties; (6) intercalation adds a new degree of freedom for tuning LDHs, which can be combined with other modification methods. ${ }^{1}$ The modification of surface functional groups of LDHs can be one of the most common strategies in altering the surface properties of LDHs, because the introduction of foreign functional groups renders LDHs to possess different or enhanced functions. For instance, the introduction of amine terminal groups onto MgAl-LDH makes the MgAl-LDH a potential biomaterial without causing any hemolysis, 35,36 and enhances its functions in the environmental field. ${ }^{37}$ The reason that the introduction of functional materials onto LDHs can alter the properties of LDHs is ascribed to the fact that it can combine the strength of each component in the structure and functions. I $n$ addition, the components in hybrids may even generate synergies, which will result in the enhancement of the properties. ${ }^{19,} 20,3423,24$ 38 For example, in the electrochemical field, LDHs have been reported to be promising electrode materials for the nextgeneration supercapacitors, but the relatively low conductivity of LDHs constrains their performance. ${ }^{39}, 40$ It's suggested that the electrochemical properties of LDHs can be further improved by the hybridization with conductive materials. ${ }^{29}$ This is because the conductive materials, e.g., graphene, can significantly enhance the electrical conductivity and accelerate the electron transfer, resulting in excellent charge and discharge capability. $41-45$ Many other reasons for the enhanced or newly created functions of LDHs produced by various functionalization strategies are summarized in Section 2.

In this review, we focus on the functionalization strategies for LDHs, and highlight the significance of functionalization in tuning the physiochemical properties of $\mathrm{LDH}$ and their subsequent applications particularly in the environmental, energy, catalysis, and biomaterials sectors. We also provide some insights into the challenges and future opportunities of LDHs.

\section{Strategies to functionalize LDHs}

In general, functionalization of LDHs can be achieved by modifying their surface zone, assembling hybrids, and regulating layer composition, size and morphology. The modification of surface zone includes intercalation of functional species and alteration of surface functional groups. Hybrid assembly emphasizes anchoring functional substances onto the surface of LDHs to generate LDH-based hybrids. The assembly usually occurs at the interface between LDHs and the loaded functional substances. Manipulation of layer composition focuses on the regulation of type, ratio, and chemical valence of the metal components. The size and morphology section highlights the impact of size and morphology on the properties of LDHs. Apart from the above aspects, other factors such as creation of defects resulted from surface and layered composition regulation can also be utilized to functionalize LDHs.

\subsection{Intercalation}

The phenomenon of intercalation was first discovered ca. 600700 A.D. in China. ${ }^{46}$ At that time, alkali metal ions were intercalated into natural minerals, such as kaolin, to make porcelain. ${ }^{47}$ The first intercalation phenomenon in the literature was reported by Schafhäutl in 1840, in which the authors attempted to dissolve graphite in sulphuric acid.48 The modern era of intercalation research was initiated in 1926 by Fredenhagen et al., in which the uptake of potassium vapor into graphite was reported. ${ }^{49}$ Over the subsequent decades, intercalation strategies for 2D materials have significantly advanced and various mechanisms have been clarified. ${ }^{18}, 50-63$ Exploring the benefits of intercalation in 2D materials for various applications remains a very active contemporary field of research.

The intercalation of 2D LDHs is a process of inserting a foreign species between the edge-shared metal hydroxide layers of the LDHs (Figure 2). In many instances, intercalation can lead to drastically improved performance for the LDHs. For example, incorporation of homogeneous catalysts (e.g., inorganic anions, organic acid/base, organic complexes) into LDH interlayer space offers the chance to heterogenize the homogeneous reaction process over LDH-based catalysts with enhanced lifetime and thermal stability, as well as facile separation/purification. ${ }^{9}$ Intercalation can also make LDHs more favorable for the use of energy storage and conversion. In one example, the intercalation of bistrifluoromethane sulfonamide into galleries of CoTi-LDH endowed CoTi-LDH with the ability in making up low-overpotential $\mathrm{Li}^{-} \mathrm{O}_{2}$ batteries with superior cycling stability. ${ }^{64}$ Herein, we summarize some common LDHs and intercalants reported in recent years, and the benefits of the intercalation in improving various performances of LDHs (Table 1). The data suggests that different combinations of $\mathrm{LDHs}$ and intercalants can offer different 
performances, and intercalation is indeed a promising means to functionalize LDHs and to expand their applications. The reasons that intercalation is such a versatile and effective approach in tuning the properties of 2D LDHs are: (1) intercalation provides the highest possible doping and/or phase change to the pristine LDHs; (2) the intercalation process, and the concomitant changes in the properties of LDHs is typically reversible; (3) intercalation is controllable; (4) changes in intercalated LDHs during material preparation can be monitored in situ and in real time; (5) intercalation can induce structural changes, such as lattice expansion or even phase changes, for improved or novel physiochemical properties; (6) intercalation adds a new degree of freedom for tuning LDHs, which can be combined with other

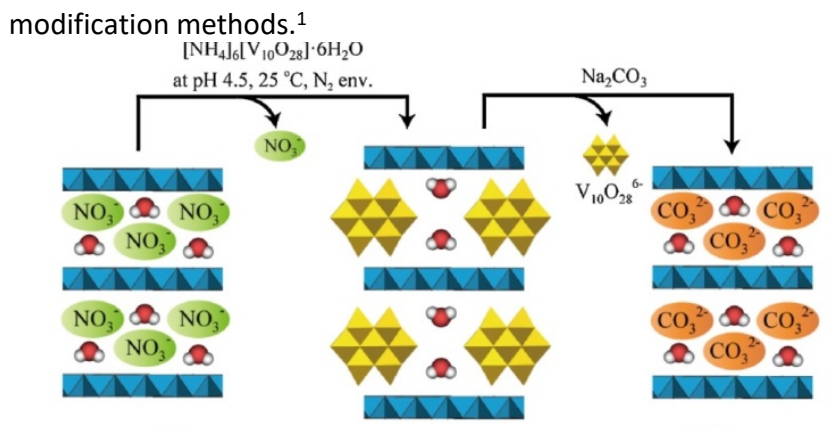

$\left[\mathrm{Zn} 2 \mathrm{Al}(\mathrm{OH})_{6}\right] \mathrm{NO}_{3} \cdot 2 \mathrm{H}_{2} \mathrm{O}$

$\left[\mathrm{Zn}_{2} \mathrm{Al}(\mathrm{OH})_{6}\right]\left[\mathrm{V}_{10} \mathrm{O}_{28}\right] \cdot n \mathrm{H}_{2} \mathrm{O}$

$\left[\mathrm{Zn} 2 \mathrm{Al}(\mathrm{OH})_{6}\right] \mathrm{CO}_{3} \cdot 2 \mathrm{H}_{2} \mathrm{O}$ Figure 2. Schematic illustration of the intercalation of $\mathrm{ZnAl}-\mathrm{LDH} .65$ Reproduced with permission from ref. ${ }^{65}$, Copyright 2014, Elsevier.

Table 1. Representative examples reported in recent years of LDH intercalation, and the benefits of the intercalation in improving various performances of LDHs.

\begin{tabular}{|c|c|c|c|}
\hline LDH & Intercalant & $\begin{array}{l}\text { Performance } \\
\text { vs. } \\
\text { the pristine LDH }\end{array}$ & Ref. \\
\hline MgAl & Polysulfide & Highly selective and efficient for radionuclide $\left(\mathrm{UO}_{2}{ }^{2+}\right)$ sequestration & 3 \\
\hline MgAl & $\mathrm{MoS}_{4}^{2-}$ & $\begin{array}{l}\text { Highly selective and efficient for heavy metals and radionuclides removal; 5-8 folds increase of the capture } \\
\text { capacities }\end{array}$ & 2,66 \\
\hline MgAl & $\begin{array}{l}\text { Hydroxyl ammonium } \\
\text { ionic liquids }\end{array}$ & $\sim 6$ folds higher adsorptive capacity towards organic contaminants & 67 \\
\hline MgAl & $\mathrm{Fe}(\mathrm{CN})_{6}{ }^{4-} / \mathrm{S}^{2-}$ & Endowed LDH with an ability of rapid detection of heavy metal ions & 68 \\
\hline MgAl & $\begin{array}{l}\text { Keggin } \\
\text { polyoxometalate }\end{array}$ & $\begin{array}{l}\text { Highly efficient catalytic activity; produced the highest turnover number reported in Knoevenagel } \\
\text { condensation of benzaldehyde with ethyl cyanoacetate }\end{array}$ & 69,70 \\
\hline $\begin{array}{l}\text { Silylate } \\
\text { d MgAl }\end{array}$ & $\mathrm{MnO}_{2}$ nanowires & High catalytic activity, stability, and reusability & 71 \\
\hline MgAl & $\mathrm{MnO}_{2}$ & Enhanced electrocatalytic activity; excellent stability, selectivity, and reproducibility & 72 \\
\hline MgAl & $\begin{array}{l}\text { Ruthenium } \\
\text { polypyridine complex }\end{array}$ & High thermal and photo stability; enhanced luminescence efficiency and lifetime & 73 \\
\hline MgAl & Decavanadate & Enhanced corrosion-resistant properties, especially long-term corrosion resistance & 74 \\
\hline MgAl & $\mathrm{CO}_{3}{ }^{2-} / \mathrm{NO}_{3}{ }^{-}$ & Tunable electronic transport properties by changing intercalated ions & 75 \\
\hline $\mathrm{NiCr}$ & $\begin{array}{l}\text { Diphenylamine-4- } \\
\text { sulfonate }\end{array}$ & Highly selective and efficient for heavy metal removal & 76 \\
\hline $\mathrm{NiFe}$ & Cobalt & Significantly enhanced catalytic activity for water splitting; long term stability & 77 \\
\hline $\mathrm{NiCo}$ & $\begin{array}{l}\text { n-alkylsulfonate } \\
\text { anions }\end{array}$ & Tunability of magnetic properties, enhanced coercivity & 78 \\
\hline $\mathrm{NiCo}$ & Ethylene glycol & Ultrahigh specific capacitance and excellent cycling stability & 79 \\
\hline NiMn & $\mathrm{MnO}_{2}$ & Greatly improved supercapacitor behavior & 80 \\
\hline
\end{tabular}

\subsection{Surface modification}

Modification and control of surface properties of LDHs are of crucial importance in the functionalization of LDHs. There are numerous studies focusing on the surface modification of LDHs by hybridizing functional materials onto the surface of LDHs. For example, surfactants are the most popular functional species to be anchored onto the LDH surface to functionalize an LDH. ${ }^{18,19}$ In this section, we focus on the regulation of the properties of LDHs by the introduction of various functional groups.

The modification of surface hydroxyl groups of LDHs can be one of the most common strategies in altering the surface properties of LDHs. For example, Oh et al. modified the surface hydroxyl groups of $\mathrm{MgAl}-\mathrm{LDH}$ by grafting aminopropyltriethoxysilane, which introduced amine terminal groups onto the surface of MgAl-LDH without affecting the LDH layered structure (Figure 3a). ${ }^{81}$ The amine terminal groups could be utilized as an active site for further modification to render MgAl-LDH as an effective drug-delivery carrier. ${ }^{81} \mathrm{Hu}$ et al. found that the functionalized MgAl-LDH with amine terminal groups (functionalized through a three-step surface grafting process) possessed enhanced blood compatibility, which made it a potential biomaterial without causing any hemolysis. ${ }^{35,36}$. Besides the applications in the medical field, amine groups functionalized LDHs can also be used in the environmental field. For example, Ezeh et al. found that after amine modification, MgAl-LDH 
presented an enhanced physical adsorption of $\mathrm{CO}_{2}$, and with an increase of amine loading, the adsorption of $\mathrm{CO}_{2}$ was further enhanced. ${ }^{37}$ In another example, Li et al. introduced various functional groups including phenolic hydroxyl groups, alcoholic hydroxyl groups, and carboxyl groups onto the surface of ZnAl-LDH by loading fulvic acid. ${ }^{82}$ The fulvic acid anchored ZnAl-LDH showed a great ability to simultaneously remove organic dyes and heavy metal cations. In addition to the functional groups derived from organic compounds, functional groups from inorganic substances can also functionalize LDHs. For instance, Lima et al. prepared fluorinated $\mathrm{MgAl}-\mathrm{LDH}$ by using $\mathrm{NaAlF}_{6}$, and found that the introduction of surface $\mathrm{F}$ terminal groups onto MgAl-LDH could significantly modify the physicochemical, thermal, and adsorptive properties. ${ }^{83}$

Apart from the above discussed functional groups, many other groups have been grafted onto the surface of LDHs, such as epoxide group, disulfide bonds, $\mathrm{Br}$ groups, and silanol groups, 7,18 , 36 which led to remarkable improvement in a range of physical properties of the LDHs. a
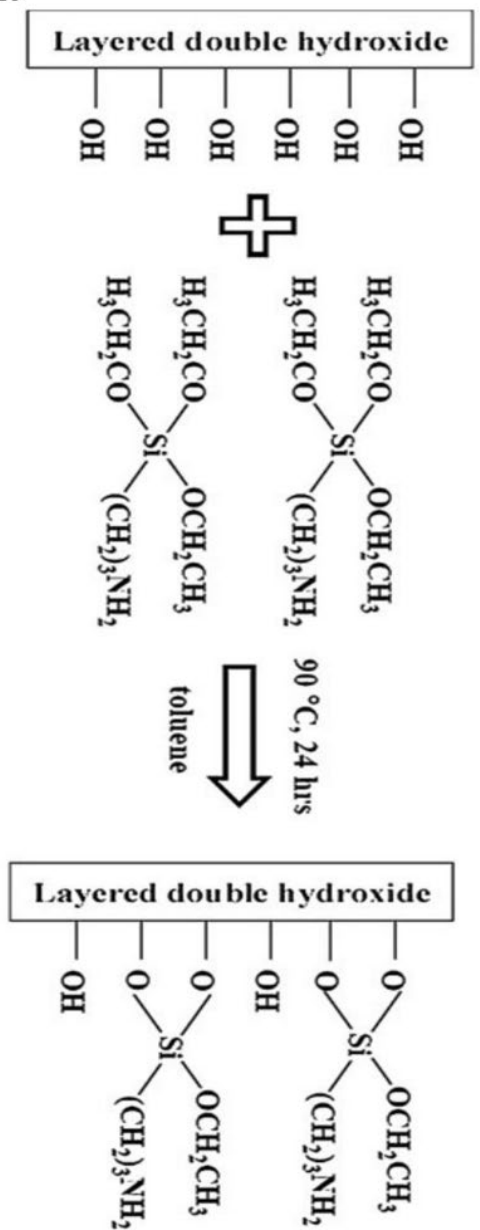

b
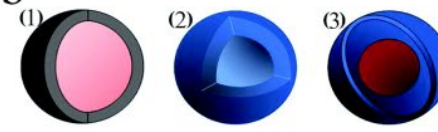

(4)

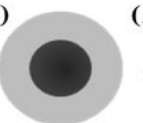

(5)

(7)
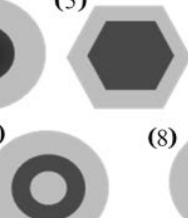

(6)

(8)

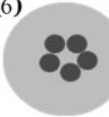

-

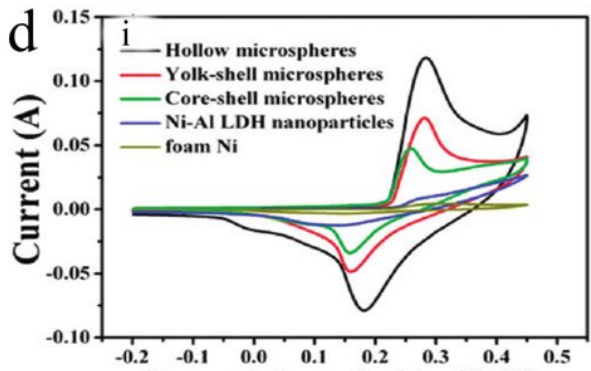

Potential vs. Ag/AgCl (V)

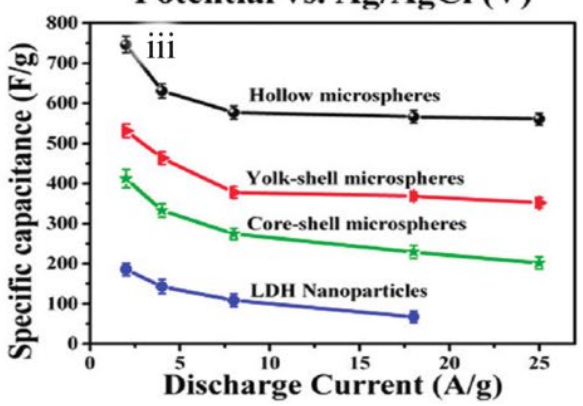

C

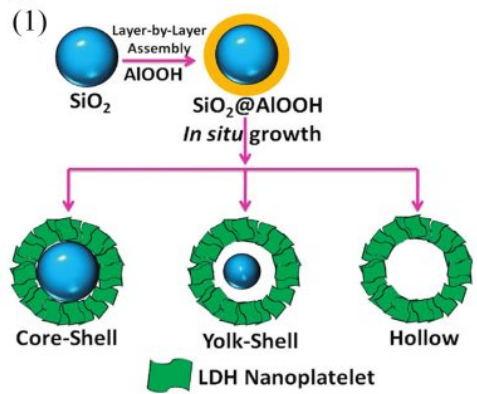

Figure 3. (a) Schematic illustration of aminopropyltriethoxysilane (amine terminal groups) grafting onto the surface of MgAl-LDH. ${ }^{81}$ Reproduced with permission from ref. ${ }^{81}$, Copyright 2009, WILEY-VCH Verlag GmbH \& Co. KGaA, Weinheim. (b) Schematic illustration of (1) core-shell; (2) hollow core-shell; (3) yolk or rattle core-shell nanostructures; (4) spherical core-shell nanoparticles; (5) hexagonal core-shell nanoparticles; (6) multiple small core materials coated by single shell material; (7) nanomatryushka material; (8) movable core within hollow shell material. ${ }^{84}$ Reproduced with permission from ref. ${ }^{84}$, Copyright 2016, The Royal Society of Chemistry. (c) Schematic illustration of preparation of LDH microspheres with tunable interior architecture from coreshell to hollow structure. (d) Cyclic voltammograms (CVs) curves (i); galvanostatic (GV) discharge curves (ii); current density dependence of the specific capacitance (iii); Nyquist plots of the electrochemical impedance spectroscopy for the hollow, yolk-shell, core-shell LDH microspheres, and LDH nanoparticles (reference sample) (iv). ${ }^{85}$ Reproduced with permission from ref. ${ }^{85}$, Copyright 2012, American Chemical Society.

\subsection{Hybridization}

The combination of two or more distinct properties into a unique composite is an exciting direction for the fabrication of novel multifunctional materials. Construction of LDH-based hybrids, especially one with a nanostructure, by interacting LDHs with other materials (e.g., silica nanoparticles, magnetic nanoparticles, semiconductors, rare earth and noble metal elements), is an emerging active research vector which may serve various fields, such as environmental remediation, energy conversion and storage. ${ }^{23}, 24,38$ The introduction of functional materials onto LDH can alter the properties of LDHs, offering various enhanced or new functions to LDHs. Hybrid assembly provides the advantages of combining the strength of each component in the structure and functions. In addition, the components in hybrids may generate synergies. The resultant 
hybrids may exhibit new properties depending on the interactions between the different components. Herein, we mainly highlight the construction of LDH-based hybrids by the fabrication of coreshell structure and the loading of conductive materials, semiconductors, and rare earth elements or noble metals onto LDHs to enhance or extend the functions of LDHs. Notably, some LDH-based hybrids can be grouped into different sections. These materials will be discussed only in one of the sections below.

\subsubsection{Introduction of a "core" or "shell"}

The terminology of "core-shell" was first adopted in the early 1990s when researchers attempted to synthesize concentric multilayer semiconductor nanoparticles to improve the property of semiconductor materials. ${ }^{86}$ Figure $3 \mathrm{~b}$ shows different types of core-shell structures. The general concept of core-shell presents two materials with two functions in one structure (Figure $3 b-1$ ). When the core is removed, hollow core-shell structural material will be created (Figure $3 b-2$ ). And by combining the above two types of core-shell structures, the yolk or rattle core-shell architecture which has a core@void@shell configuration (Figure $3 b-3)$ is generated. ${ }^{86}$ Generally, core-shell nanoparticles are wellknown for better stability, for being able to protect the core material from the surrounding environment, for improved physiochemical properties, for improved semi-conductive properties, for easy biofunctionalization. The shell could change the functions and properties of the original core, ${ }^{84}$ and the core could also modify the functions and properties of the original shell. ${ }^{87}$ In other words, the core/shell can exhibit new chemical or physical properties with shell/core formation. In addition, coreshell composites may have properties that are synergistic between the core and the shell and/or offer new properties depending on the interactions between the core and the shell. 87,88

Thanks to the above highlighted merits, the construction of core-shell composites has become an effective avenue to functionalize LDHs. For instance, to enhance the supercapacitor behavior of NiAl-LDH, Shao et al. fabricated core-shell LDH microspheres with tunable interior architecture using $\mathrm{SiO}_{2}$ as a core. ${ }^{85}$ Via the regulation of interior architecture, core-shell, hollow core-shell, and yolk core-shell types of NiAl-LDHs were produced (Figure 3c), and variations in specific surface area and pore-size distribution were achieved. Moreover, the prepared core-shell microspheres, especially the hollow ones, exhibited excellent pseudocapacitance performance, including high specific capacitance and rate capability, high charge/discharge stability, and long-term cycling life (Figure $3 \mathrm{~d}$ ). The improvement of the supercapacitor performance of NiAl-LDH was due to the greatly improved faradaic redox reaction and mass transfer. In another example, Han et al. used CoAl-LDH as the core to produce flexible CoAI-LDH@poly(3,4-ethylenedioxythiophene) core-shell nanoplatelets for high-performance energy storage. ${ }^{87}$ The synthesized material exhibited high specific capacitance, excellent rate capability, and long-term cycling stability, which were superior to those of the conventional supercapacitors and the CoAl-LDH without the shell of poly(3,4-ethylenedioxythiophene). The largely enhanced pseudocapacitor performance of the prepared material was related to the synergistic effect of its individual components: the LDH nanoplatelet core provided abundant energy-storage capacity, while the highly conductive poly(3,4-ethylenedioxythiophene) shell and the porous architecture facilitated the electron/mass transport in the redox reaction. LDH-based core-shell materials have growing applications because of the multifunctionality that is achieved through the tailoring of core/shell materials. Table 2 summarizes some representative LDH-based core-shell composites in the past three years and the significance of fabrication of a core-shell structure. Clearly, novel physiochemical properties, such as medical, magnetic, catalytic, electrochemical, and electronic characteristics can be imparted to LDHs through the formation of a core-shell structure.

Table 2. Representative LDH-based core-shell hybrids reported in the past three years.

\begin{tabular}{|c|c|c|c|}
\hline \multirow[b]{2}{*}{ Core/Shell } & \multirow[b]{2}{*}{ Synthesis method } & \multicolumn{2}{|l|}{ Performance } \\
\hline & & $\begin{array}{l}\text { vs. } \\
\text { the pristine } L D H\end{array}$ & Ref. \\
\hline $\mathrm{Fe}_{3} \mathrm{O}_{4} / \mathrm{CuAl}-\mathrm{LDH}$ & $\begin{array}{l}\text { Hydrothermal and co- } \\
\text { precipitation }\end{array}$ & $\begin{array}{l}\text { Endowed magnetism; endowed high sensitivity, good reproducibility, and long-term stability } \\
\text { as electrochemical sensors; endowed real-time monitoring for live cancer cells }\end{array}$ & 89 \\
\hline $\begin{array}{l}\mathrm{Fe}_{3} \mathrm{O}_{4} / \text { enrofloxacin } \\
\text { intercalated MgAl-LDH }\end{array}$ & $\begin{array}{l}\text { Delamination- } \\
\text { reassembly }\end{array}$ & $\begin{array}{l}\text { Endowed magnetism; enhanced stability; potential magnetic targeting drug delivery- } \\
\text { controlled-release system }\end{array}$ & 90 \\
\hline $\begin{array}{l}\mathrm{Fe}_{3} \mathrm{O}_{4} /(\mathrm{Zn}, \mathrm{Mg}, \mathrm{Ni}) \mathrm{Al}- \\
\mathrm{LDH}\end{array}$ & Co-precipitation & Endowed high superparamagnetism for easy separation & 91 \\
\hline $\mathrm{CO}_{3} \mathrm{O}_{4} / \mathrm{NiCOAI}-\mathrm{LDH}$ & $\begin{array}{l}\text { Two-step } \\
\text { hydrothermal } \\
\text { synthesis }\end{array}$ & $\begin{array}{l}\text { Enhanced electrochemical performance: exhibited high specific capacitance ( } 1104 \mathrm{~F} \mathrm{~g}^{-1} \text { at } 1 \\
\left.\mathrm{~A} \mathrm{~g}^{-1}\right) \text {, adequate rate capability and cycling stability ( } 87.3 \% \text { after } 5000 \text { cycles) }\end{array}$ & 92 \\
\hline $\mathrm{NiCO}_{2} \mathrm{O}_{4} / \mathrm{NiCoAl-LDH}$ & $\begin{array}{l}\text { Hydrothermal } \\
\text { synthesis and a step- } \\
\text { by-step in situ }\end{array}$ & $\begin{array}{l}\text { Enhanced specific capacitance of } 1814.24 \mathrm{Fg}^{-1} \text { at a current density of } 1 \mathrm{Ag}^{-1} \text { and } 93 \% \\
\text { retention after } 2000 \text { cycles at } 10 \mathrm{Ag}^{-1} \text {. }\end{array}$ & 93 \\
\hline $\mathrm{ZnO} / \mathrm{CuZnAl-LDH}$ & $\begin{array}{l}\text { structure fabrication } \\
\text { Deposition- } \\
\text { Precipitation }\end{array}$ & Enhanced activity in photoreduction of $\mathrm{CO}_{2}$ to hydrocarbons & 94 \\
\hline $\mathrm{CuO} / \mathrm{CoFe}-\mathrm{LDH}$ & $\begin{array}{l}\text { Calcination and } \\
\text { electrodeposition }\end{array}$ & $\begin{array}{l}\text { Largely improved specific capacitance, high rate capability and long cycling lifespans; } \\
\text { exhibited excellent supercapacitive performances with a high energy density ( } 1.857 \mathrm{mWh} \\
\left.\mathrm{cm}^{-3}\right) \text { and long-term cycling stability }(99.5 \% \text { device capacitance retention after } 2000 \text { cycles) }\end{array}$ & 95 \\
\hline $\mathrm{TiO}_{2} / \mathrm{CoNi}-\mathrm{LDH}$ & Electrodeposition & Remarkably enhanced performance for photoelectrochemical water splitting & 96 \\
\hline $\mathrm{ZnO}$ and $\mathrm{CdS} / \mathrm{CoNi}-\mathrm{LDH}$ & Electrodeposition & Efficient solar water oxidation & 97 \\
\hline
\end{tabular}




$\mathrm{Cu}_{2} \mathrm{O} / \mathrm{ZnCr}-\mathrm{LDH}$
$\mathrm{MnO}_{2} / \mathrm{NiFe}-\mathrm{LDH}$ on $\mathrm{Ni}$
foam
$\mathrm{WO}_{3} / \mathrm{NiFe}-\mathrm{LDH}$
$\mathrm{BiVO}_{4} /(\mathrm{Ni}, \mathrm{Co}) \mathrm{Fe}-\mathrm{LDH}$
$\mathrm{SiO}_{2} / \mathrm{DNA}$ intercalated
$\mathrm{Niln}^{-\mathrm{LDH}}$
$\mathrm{SiO}_{2} / \mathrm{MgAl}-\mathrm{LDH}$

Zeolites/MgFe-LDH

Nickel phosphide

/NiCo-LDH

$\mathrm{Fe} / \mathrm{MgAl}-\mathrm{LDH}$

$\mathrm{Cu} / \mathrm{CoFe}-\mathrm{LDH}$

$\begin{array}{ll}\begin{array}{l}\text { Porous graphitized } \\ \text { carbon/NiFe-LDH One-step } \\ \text { Hollow carbon }\end{array} & \begin{array}{l}\text { hydrothermal } \\ \text { nanospheres }\end{array} \\ \end{array}$

NiCo-LDH

Graphene-

encapsulated

carbon/NiAl-LDH

ZnAl-LDH/ZIF-8 (one of

the zeolitic imidazolate

frameworks)

NiCo-LDH/reduced

graphene oxide

NiCoAl-LDH

/carbonaceous aerogel

Carborane intercalated

MgAl-LDH

/magnesium ferrite

$\mathrm{NiFe}$-LDH

/NiFe-borate

$\mathrm{NiFe-LDH/Au}$

nanoarrays on $\mathrm{Ni}$ foam

Hydrothermal
$\mathrm{Cu} / \mathrm{NiFe}-\mathrm{LDH}$
In situ crystallization-

selective etching

method

Hydrothermal

Electrodeposition

Layer-by-Layer

assembly

Co-precipitation

Co-precipitation

Phosphorization of $\mathrm{Ni}$ foam and subsequent electrodeposition

Co-precipitation

Electrodeposition

Electrostatic-induced assembly

In situ grown on the ZnAl-LDH

One-pot hydrothermal method

Hydrothermal

Direct mixing

Hydrothermal

Hydrothermal and chemical deposition
Largely enhanced visible-light-driven water splitting efficiency: with a $\mathrm{H}_{2}$ and $\mathrm{O}_{2}$ production rate of 0.90 and $0.44 \mu \mathrm{mol} \mathrm{h}{ }^{-1}$, respectively, without any sacrificial agent and co-catalyst, which is among the highest of the reported photocatalysts under the same conditions Enhanced supercapacitor performance: high capacitance of $4274.4 \mathrm{mF} \mathrm{cm}^{-2}$ at $5 \mathrm{~mA} \mathrm{~cm}^{-2}$ and a capacitance retention of $95.6 \%$ after 1000 cycles from a traditional three-electrode system

Enhanced photoelectrochemical water splitting

Greatly enhanced photocatalysis for the oxygen evolution reaction

Low infrared emissivity

Tunable size and morphology

Solved the problem of the application of powdered LDH in constructed rapid infiltration system

Significantly enhanced electrochemical performances: high specific capacitance, and excellent cycling stability

High adsorption of organic contaminants

Afforded small overpotentials of $171 \mathrm{mV}$ for the hydrogen evolution reaction and $240 \mathrm{mV}$ for the oxygen evolution reaction at a current density of $10 \mathrm{~mA} \mathrm{~cm}^{-2}$, along with Tafel slopes of 36.4 and $44.4 \mathrm{mV} \mathrm{dec}{ }^{-1}$ for the hydrogen evolution reaction and oxygen evolution reaction, respectively

Exhibited outstanding oxygen evolution reaction activity as well as excellent hydrogen evolution reaction performance in an alkaline medium

Excellent oxygen evolution reaction properties with a low onset potential and a lower overpotential; superior catalytic activity; enhanced electrocatalyst

Remarkable electrochemical properties: much higher of the specific capacitances and outstanding rate capability

Exhibited high specific capacitance; high energy density with an excellent rate capability as well as a robust long-term cycling stability

Enhanced $\mathrm{CO}_{2}$ capture

112

Significantly enhanced electrochemical performance: high performance asymmetric supercapacitors with remarkable cycling stability

High specific capacitances; excellent cycling stability

Potential to be used in Boron Neutron Capture Therapy (BNCT) and magnetically targetedBNCT applications

Produced highly efficient water oxidation electrocatalysis in near-neutral media with a strong electrochemical durability

According to the previous studies, a number of factors are important role in deciding the physical and chemical properties of core-shell materials, such as (a) ligand effect, which involve the interactions between the core and the shell due to atomic proximity affecting the charge transfer between the components; (b) ensemble effect, which is governed by the material's adsorption on the surface due to the presence of distinct atomic groups, and (c) geometric effect, originating from the difference in reactivity of the surface atoms because of their three dimensional structural constraints (e.g., surface strain). ${ }^{88}$

\subsubsection{Hybridization with conductive materials}

LDHs are emerging as potential candidates in electrochemical, photo-electrochemical, and photochemical applications due to the facile tunability of their chemical composition, many transition metal ions across a range of oxidations states possess ionic radii that can be accommodated within the octahedral sites. Their electrochemical, photo-electrochemical and photochemical properties can be further improved by the hybridization with conductive materials. ${ }^{29}$ In the electrochemical field, for example, LDHs were reported to be promising electrode materials for the next-generation supercapacitors. ${ }^{39,} 118$ However, the relatively low conductivity of LDHs constrains electron transfer, resulting in poor charge and discharge capability that adversely affects the performance of electrode materials. ${ }^{39}, 40$ Hybridization LDHs with conductive materials has been demonstrated to be a feasible and effective approach to enhance the electron conductivity. ${ }^{119}$ ${ }^{121}$ For instance, Zhang et al. designed and synthesized a hybrid of CoAl-LDH and graphene, they found that the loading of conductive graphene endowed CoAl-LDH with a high specific capacitance that was much higher than the pure CoAl-LDH. In addition, the obtained hybrid showed a high cycle stability of 93.9\% of the specific capacitance retained at $3 \mathrm{Ag}^{-1}$ after 2000 cycles. ${ }^{39}$ The improved electrochemical performance benefited from the anchoring electroactive graphene onto the surface of LDH. Liu et al. anchored conductive carbon nanoparticles onto 
the surface of NiAl-LDH, and manifested the resulting supercapacitor to exhibit excellent capacitive performance, including a high specific capacitance, good cycling capability and high energy density. The enhanced electrical conductivity that resulted from the incorporation of carbon nanoparticles contributed to the improved capacitance and rate capability. ${ }^{122}$ Yang et al. designed a graphene oxide (GO) surface-confined strategy to fabricate NiCo-LDH-graphene nanosheet composites (Figure 4). By this strategy, ultrathin 2D nanosheets with a thickness of 1.7-1.8 $\mathrm{nm}$ that are duplicated from the GOs in terms of both the lateral dimensions and the shape can be prepared. The as-obtained NiCo-LDH-graphene nanosheets exhibited a superior electrocatalytic activity for oxygen evolution reaction, evidenced by a small overpotential of $0.337 \mathrm{~V}$ (@10 $\mathrm{mA} \cdot \mathrm{cm}^{-2}$ in $0.1 \mathrm{M} \mathrm{KOH}$ electrolyte), and a high charge storage capability of $1489 \mathrm{~F} \cdot \mathrm{g}^{-1}$ as electrodes for supercapacitors. The authors pointed out that the relatively wide interlayer distance, ultrathin and highly tortuous structures, large specific surface area, multilevel pore structure, and high electrical conductivity benefited from graphene resulted in the high activity.

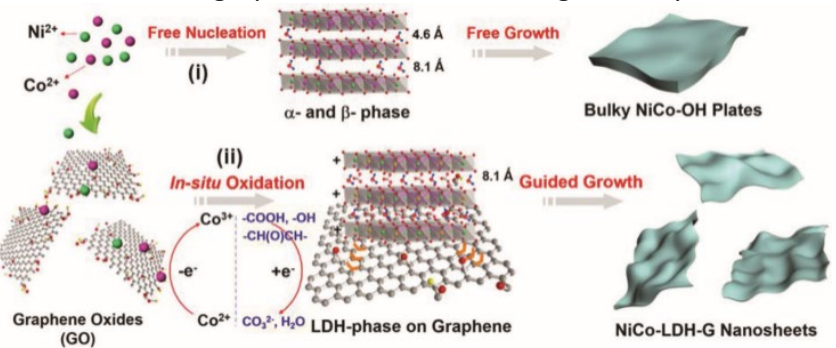

Figure 4. Schematic of the fabrication routes of the NiCo-LDH-graphene nanosheets (NiCo-LDH-G). i) Growth process of NiCo-hydroxide (NiCo-OH) in the absence of $\mathrm{GO}$, leading to the bulky and rigid $\mathrm{NiCo-OH}$ plates with the main interlayer spacing of $\approx 4.6 \AA \AA$; ii) GO surface-guided growth of NiCo-LDH nanosheets, yielding ultrathin and highly tortuous NiCo-LDH-G nanosheets with an interlayer distance of $\approx 8.1 \AA$. Reproduced with permission from ref. ${ }^{123}$, Copyright 2018, WILEY-VCH Verlag GmbH \& Co. $\mathrm{KGaA}$, Weinheim

In photocatalysis, hybridization of LDHs with conductive materials brings similar benefits. The ease in electron-hole recombination for many LDH photocatalysts restrains their applications in photocatalysis. The hybridization with electron accepting species provides a powerful approach to further enhance the photocatalytic efficiency of the LDH material by the timely conduction of electrons to prolong the lifetime of electron and hole. Gunjakar et al. assembled a highly effective photocatalyst by combining $\mathrm{ZnCr}-\mathrm{LDH}$ with graphene nanosheets (Figure 5a). ${ }^{29}$ The coupling of graphene with $\mathrm{ZnCr}-\mathrm{LDH}$ gave a remarkable depression of the photoluminescence signal, and an unusually high photocatalytic activity for visible light-induced $\mathrm{O}_{2}$ generation with a rate of ca. $1.20 \mathrm{mmol} \mathrm{h}^{-1} \mathrm{~g}^{-1}$, which was far superior to that of the pristine $\mathrm{ZnCr}-\mathrm{LDH}$ (ca. $0.67 \mathrm{mmol} \mathrm{h}^{-1} \mathrm{~g}^{-1}$; note that pristine $\mathrm{ZnCr}$-LDH is one of the most effective visible light photocatalysts for $\mathrm{O}_{2}$ production with an unusually high quantum efficiency of $61 \%$ at $410 \mathrm{~nm}$ wavelength). The loading of graphene gave rise to a remarkable depression of electronhole recombination by the timely conduction of electrons. Figure $5 b-2$ shows a schematic illustration of electronic coupling between $\mathrm{ZnCr}$-LDH and graphene, showing how graphene takes effect.
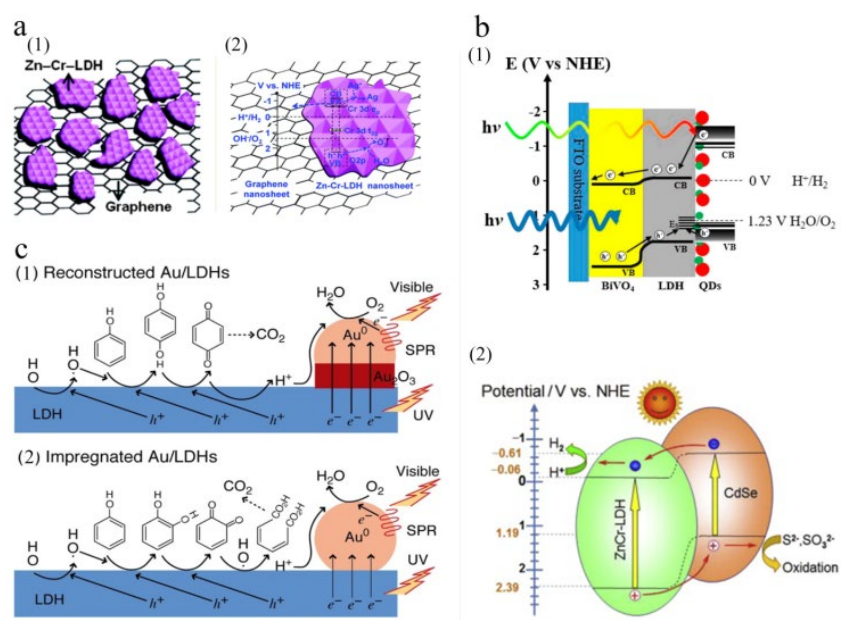

Figure 5. (a): (1) Structural model for the self-assembled nanohybrids of $\mathrm{ZnCr}$-LDH-graphene; (2) schematic illustration of electronic coupling between $\mathrm{ZnCr}$-LDH and graphene under light irradiation. ${ }^{29}$ Reproduced with permission from ref. ${ }^{29}$, Copyright 2013, The Royal Society of Chemistry; (b): (1) schematic illustration of $\mathrm{BiVO}_{4} / \mathrm{CoAl}-\mathrm{LDH}$ heterojunction in electron (-) and hole $(+)$ separation and transport under light irradiation, ${ }^{124}$ Reproduced with permission from ref. ${ }^{124}$, Copyright 2016, American Chemical Society; (2) schematic illustration of CdSe/ZnCr-LDH heterojunction in electron $(-)$ and hole $(+)$ separation and transport under visible light irradiation, ${ }^{125}$ Reproduced with permission from ref. ${ }^{125}$, Copyright 2015, Elsevier; (c) proposed reaction mechanism (charge transfer between gold nanoparticles and ZnAl-LDH and surface plasmon resonance (SPR) effect of gold) of photocatalytic phenol decomposition on gold species formed on ZnAl-LDH: (1) $\mathrm{Au}^{3+}-\mathrm{Au}^{0}-\mathrm{ZnAl}-\mathrm{LDH}$, and (2) $\mathrm{Au}^{0}-\mathrm{ZnAl}-$ LDH. ${ }^{126}$ Reproduced with permission from ref. ${ }^{126}$, Copyright 2016, Elsevier.

Table 3 summarizes the LDH-based hybrids anchored with various conductive materials in recent years. LDHs containing $\mathrm{Ni}^{2+}, \mathrm{Co}^{2+/ 3+}, \mathrm{Fe}^{2+/ 3+}, \mathrm{Mn}^{2+/ 4+}, \mathrm{Zn}^{2+}, \mathrm{Ti}^{4+}$, and $\mathrm{Al}^{3+}$ are the most frequently studied in the electrochemical field, carbon-based materials and metals such as nickel are the most common conductive materials hybridized with LDH. Clearly, anchoring conductive materials with LDH is a promising avenue to functionalize $\mathrm{LDH}$ and expand their application as functional electronic materials. 
Table 3. Representative LDH-based hybrids anchored with conductive materials in recent years.

\begin{tabular}{|c|c|c|c|c|}
\hline \multirow{2}{*}{ LDH } & \multicolumn{2}{|l|}{ Anchoring materials } & \multirow{2}{*}{$\begin{array}{l}\text { Performance } \\
\text { vs. } \\
\text { pristine LDH }\end{array}$} & \multirow{2}{*}{ Ref. } \\
\hline & material & Type & & \\
\hline $\mathrm{NiCo}$ & $\begin{array}{l}\text { Reduced } \\
\text { graphene oxide }\end{array}$ & $\begin{array}{l}\text { Conductive } \\
\text { material }\end{array}$ & $\begin{array}{l}\text { Greatly enhanced rate of electron and mass transfer; exhibited excellent supercapacitive } \\
\text { properties: high specific capacitance, extraordinary rate capability, and good cycling stability }\end{array}$ & 111 \\
\hline NiCo & $\begin{array}{l}\text { Carbon } \\
\text { nanofibers }\end{array}$ & $\begin{array}{l}\text { Conductive } \\
\text { material }\end{array}$ & $\begin{array}{l}\text { Provided not only more active sites for electrochemical reaction but also more efficient pathways } \\
\text { for electron transport; enhanced supercapacitors performance }\end{array}$ & 112 \\
\hline $\mathrm{NiCo}$ & $\begin{array}{l}\text { Nitrogen-Doped } \\
\text { Carbon Nanofiber }\end{array}$ & $\begin{array}{l}\text { Conductive } \\
\text { material }\end{array}$ & Exhibited significantly enhanced specific capacitance and excellent cycling stability & 113 \\
\hline $\mathrm{NiCo}$ & Nickel foam & $\begin{array}{l}\text { Conductive } \\
\text { material }\end{array}$ & Displayed a high specific capacitance and a unique cyclability & $\begin{array}{l}114, \\
115\end{array}$ \\
\hline $\mathrm{NiCo}$ & $\begin{array}{l}\text { Nickel foam and } \\
\text { reduced graphene } \\
\text { oxide }\end{array}$ & $\begin{array}{l}\text { Conductive } \\
\text { material }\end{array}$ & Exhibited an enhanced specific capacitance, excellent rate capability, and long cyclic life & 116 \\
\hline $\begin{array}{l}\mathrm{NiCoF} \\
\mathrm{e}\end{array}$ & $\begin{array}{l}\text { Carbon } \\
\text { nanofibers and } \\
\text { activated carbon }\end{array}$ & $\begin{array}{l}\text { Conductive } \\
\text { material }\end{array}$ & Higher specific capacitance and rate capability; excellent long-time cycle life & 117 \\
\hline $\mathrm{NiFe}$ & Graphene oxide & $\begin{array}{l}\text { Conductive } \\
\text { material }\end{array}$ & $\begin{array}{l}\text { Excellent electrocatalyst for oxygen evolution reaction; exhibiting small overpotential and low Tafel } \\
\text { slope }\end{array}$ & $\begin{array}{l}118 \\
119\end{array}$ \\
\hline $\mathrm{NiFe}$ & Carbon nanotubes & $\begin{array}{l}\text { Conductive } \\
\text { material }\end{array}$ & Achieving stable and efficient water oxidation & 120 \\
\hline $\mathrm{NiFe}$ & $\begin{array}{l}\text { Reduced } \\
\text { graphene oxide }\end{array}$ & $\begin{array}{l}\text { Conductive } \\
\text { material }\end{array}$ & $\begin{array}{l}\text { Showed superior oxygen evolution reaction performance compared to pristine NiFe-LDH and } \\
\text { reference } \mathrm{IrO}_{2}\end{array}$ & 121 \\
\hline $\mathrm{NiFe}$ & $\mathrm{Ni}$ & $\begin{array}{l}\text { Conductive } \\
\text { material }\end{array}$ & Exhibit a superior specific capacitance of $2708 \mathrm{Fg}^{-1}$ at $5 \mathrm{Ag}^{-1}$ & 122 \\
\hline NiAl & $\begin{array}{l}\text { Au, single-walled } \\
\text { carbon } \\
\text { nanotubes, and } \\
\text { graphene }\end{array}$ & $\begin{array}{l}\text { Conductive } \\
\text { material }\end{array}$ & $\begin{array}{l}\text { Enhanced electrical conductivity and more electron transfer passages; showed good reproducibility, } \\
\text { repeatability, stability, and anti-interference property as non-enzymatic sensor }\end{array}$ & 123 \\
\hline NiAl & Carbon nanotubes & $\begin{array}{l}\text { Conductive } \\
\text { material }\end{array}$ & $\begin{array}{l}\text { Carbon nanotubes improved the electrical conductivity and decreased the electrochemical } \\
\text { polarization of the composite; much better electrochemical performance than pure NiAl-LDH }\end{array}$ & $\begin{array}{l}124, \\
125\end{array}$ \\
\hline NiAl & Nickel foam & $\begin{array}{l}\text { Conductive } \\
\text { material }\end{array}$ & $\begin{array}{l}\text { Enhanced electrochemical performance: higher specific capacity and cycling stability than those of } \\
\text { NiAl-LDH }\end{array}$ & 126 \\
\hline NiAl & $\begin{array}{l}\text { Reduced } \\
\text { graphene oxide }\end{array}$ & $\begin{array}{l}\text { Conductive } \\
\text { material }\end{array}$ & Enhanced supercapacitor performance & 127 \\
\hline NiAl & $\begin{array}{l}\text { Nickel foam and } \\
\text { graphene }\end{array}$ & $\begin{array}{l}\text { Conductive } \\
\text { material }\end{array}$ & $\begin{array}{l}\text { Resulted in better electrode stability at high current density; exhibited higher energy and power } \\
\text { densities; but leading to a decrease in specific capacity and the rate performance of the electrode }\end{array}$ & 128 \\
\hline NiAl & Carbon cloth & $\begin{array}{l}\text { Conductive } \\
\text { material }\end{array}$ & Highly sensitive electrochemical sensors & 129 \\
\hline NiAl & MXenes & $\begin{array}{l}\text { Conductive } \\
\text { material }\end{array}$ & Enhanced supercapacitor performance & 130 \\
\hline $\begin{array}{l}\text { CoNiA } \\
\text { I }\end{array}$ & $\begin{array}{l}\text { Reduced } \\
\text { graphene oxide }\end{array}$ & $\begin{array}{l}\text { Conductive } \\
\text { material }\end{array}$ & Enhanced charge conductivity and electrochemical performance & $\begin{array}{l}131, \\
132\end{array}$ \\
\hline $\mathrm{NiMn}$ & Nickel foam & $\begin{array}{l}\text { Conductive } \\
\text { material }\end{array}$ & $\begin{array}{l}\text { Largely enhanced supercapacitor behavior: high specific capacitance, excellent rate capability, high } \\
\text { coulombic efficiency and long-term cycling life }\end{array}$ & $\begin{array}{l}133, \\
134\end{array}$ \\
\hline $\mathrm{NiMn}$ & Porous carbon & $\begin{array}{l}\text { Conductive } \\
\text { material }\end{array}$ & $\begin{array}{l}\text { Largely enhanced supercapacitor behavior: much better specific capacitance, and long-term cycling } \\
\text { life }\end{array}$ & 135 \\
\hline NiMn & $\begin{array}{l}\text { (Reduced) } \\
\text { graphene oxide }\end{array}$ & $\begin{array}{l}\text { Conductive } \\
\text { material }\end{array}$ & $\begin{array}{l}\text { Showed much higher efficiency as electrocatalyst, and the overpotential could be decreased to as } \\
\text { small as } 0.26 \mathrm{~V} \text {; higher electrochemical activities }\end{array}$ & $\begin{array}{l}136- \\
138\end{array}$ \\
\hline $\begin{array}{l}\text { NiMn } \\
\text { CoMn }\end{array}$ & $\begin{array}{l}\text { Reduced } \\
\text { graphene oxide }\end{array}$ & $\begin{array}{l}\text { Conductive } \\
\text { material }\end{array}$ & Improved the capacitance and cyclic stability of the hybrid materials & 139 \\
\hline CoAl & 3D graphene & $\begin{array}{l}\text { Conductive } \\
\text { material }\end{array}$ & $\begin{array}{l}\text { Exhibited excellent catalytic activity and stability for oxygen evolution reaction in alkaline solution, } \\
\text { which was comparable or even better than the state-of-art LDH-related oxygen evolution reaction } \\
\text { electrocatalysts }\end{array}$ & 140 \\
\hline CoAl & Graphene & $\begin{array}{l}\text { Conductive } \\
\text { material }\end{array}$ & Enhanced capacitive performance for supercapacitors & $\begin{array}{l}105, \\
141\end{array}$ \\
\hline CoAl & $\begin{array}{l}\text { Fluorinated } \\
\text { graphene }\end{array}$ & $\begin{array}{l}\text { Conductive } \\
\text { material }\end{array}$ & Enhanced capacitive performance for supercapacitors & 142 \\
\hline CoAl & $\begin{array}{l}\text { Reduced } \\
\text { graphene oxide }\end{array}$ & $\begin{array}{l}\text { Conductive } \\
\text { material }\end{array}$ & Enhanced electrochemical performance & 143 \\
\hline CoFe & Graphene & $\begin{array}{l}\text { Conductive } \\
\text { material }\end{array}$ & $\begin{array}{l}\text { Highly efficient electrocatalyst for oxygen evolution reaction; created well-interconnected } \\
\text { conductive networks within the electrode matrix, leading to a low overpotential }\end{array}$ & 144 \\
\hline CoFe & Carbon fiber cloth & $\begin{array}{l}\text { Conductive } \\
\text { material }\end{array}$ & Enhanced electrochemical performance; delivered an improved capacitance & 145 \\
\hline $\mathrm{ZnTi}$ & $\mathrm{C} 60$ & $\begin{array}{l}\text { Conductive } \\
\text { material }\end{array}$ & Enhanced photocatalytic activity for organic contaminant degradation & 8 \\
\hline
\end{tabular}




\subsubsection{Hybridization with semiconductors}

Transition metal-containing LDHs have been reported to exhibit highly-efficient catalytic performance, of most note is their activity in water splitting, and oxidation and reduction of environmental contaminants. Although transition metal containing LDHs show high catalytic performance, hybridizing semiconductors onto $\mathrm{LDH}$ s can generally further enhance the catalytic activity of LDHs. Taking the application of LDHs in photocatalysis as an example, anchoring semiconductors on LDHs will commonly result in the formation of heterojunction, which can increase the separation efficiency of the excited electrons and holes to improve the photocatalytic activity by inhibiting the recombination of charge carriers (i.e., the photo-generated holes and electrons). For example, Ao et al. found that the hybrid of $\mathrm{BiOBr}$ and CoNi-LDH exhibited much higher adsorptive and photocatalytic degradation of organic contaminants (organic dyes and phenol) than either $\mathrm{BiOBr}$ or CoNi-LDH under UV-light irradiation. ${ }^{16}$ The excellent photocatalytic activity is because of the formed heterojunction between the $\mathrm{BiOBr}$ and the CoNi-LDH, which inhibits the recombination of charge carriers, and thus more holes or electrons can be captured to induce the photocatalytic reaction. Figure $5 b$ shows schematic illustrations of different types of semiconductor/LDH heterojunctions in electron-hole separation and transport and photocatalytic activity under visible or solar light irradiation. ${ }^{124,125}$ Clearly, the photo-generated electrons and holes can transfer between LDH and the hybridized semiconductors, which are significantly beneficial to the extension of the lifetime of electrons and holes, and thus increasing the photocatalytic activities.

Anchoring semiconductors onto the surface of LDHs can also improve the electrochemical and photoelectrochemical catalytic activity of the LDHs. For instance, Hu et al. hybridized $\mathrm{MoS}_{2}$ onto NiCo-LDH and demonstrated a dramatic enhancement of hydrogen evolution reaction kinetics in base media compared to either $\mathrm{MoS}_{2}$ or NiCo-LDH. ${ }^{159}$ The resultant $\mathrm{MoS}_{2} / \mathrm{NiCo}-\mathrm{LDH}$ hybrid exhibited extremely low hydrogen evolution reaction overpotential of $78 \mathrm{mV}$ at $10 \mathrm{~mA} / \mathrm{cm}^{2}$ and a low Tafel slope of 76.6 $\mathrm{mV} / \mathrm{dec}$ in $1 \mathrm{M} \mathrm{KOH}$ solution. Benefiting from the desirable structural characteristics, the $\mathrm{MoS}_{2} / \mathrm{NiCo}-\mathrm{LDH}$ interfaces synergistically favor the chemisorption of $\mathrm{H}\left(\right.$ on $\mathrm{MoS}_{2}$ ) and $\mathrm{OH}$ (on $\mathrm{LDH}$ ), and can thus effectively accelerate the water dissociation step and the overall hydrogen evolution reaction. Zhang et al. hybridized $\mathrm{TiO}_{2}$ with $\mathrm{ZnFe}-\mathrm{LDH}$, and found that $\mathrm{TiO}_{2} / \mathrm{ZnFe}-\mathrm{LDH}$ photoanode exhibited a largely enhanced photoelectrochemical water splitting performance. ${ }^{160}$ The study revealed that the photogenerated holes of $\mathrm{TiO}_{2}$ tended to travel to $\mathrm{ZnFe}-\mathrm{LDH}$, which enhanced the bulk charge separation, and thus the surface water oxidation reaction. Table 4 summarizes the representative LDHbased hybrids anchored with various semiconducting materials, the table highlights that the anchoring of semiconductors significantly enhances the catalytic activities of LDHs.

\subsubsection{Hybridization with noble metals or rare earth elements}

Table 5 summarizes the noble metals and rare earth elements that have been anchored on LDHs and the impacts these elements have on enhancing the properties of LDHs. Noble metals such as $\mathrm{Au}, \mathrm{Ag}, \mathrm{Pt}, \mathrm{Pd}$, and $\mathrm{Ru}$, and rare earth elements of $\mathrm{Ce}, \mathrm{Tb}$, and La are the most prevalent elements to be anchored onto LDHs. Loading noble metals and rare earth elements on LDHs can dramatically improve the photocatalytic performance with enhanced light absorption, charge transport properties, interfacial kinetics, ${ }^{171}$ and the adsorptive abilities for reactants. ${ }^{171,}{ }^{172}$ Noble metals and rare earth elements improve the properties of LDHs owing to one or several of the following aspects: $40,126,171,172$ (1) noble metals and rare earth elements are electron-abundant species which possess prominent electron donating abilities; (2) noble metals and rare earth elements have strong coordination abilities; that is, when integrated into LDH, they can serve as adsorptive sites; (3) noble metals and rare earth elements can conduct electrons promptly; (4) the loading of noble metals and rare earth elements may create lattice distortions which can be active sites; (5) photoresponsive characteristics, e.g., surface plasmon resonance, of noble metals and rare earth elements. Taking the applications of LDHs in photocatalysis as an example, LDHs have emerged as highly active photocatalysts due to their unique structure, large specific surface area and semiconductive properties. However, the slow interfacial kinetics and fast charge recombination (due to the poor charge mobility) are the major obstacles which limit the performance of LDH-based photocatalysts. Fu et al. demonstrated the incorporating terbium onto $\mathrm{ZnCr}$-LDH could significantly inhibit the recombination of photo-induced charge carriers and increase the charge injection efficiency simultaneously, and thus largely enhanced the visible light photocatalytic performance for oxygen evolution (about a 2 fold increase compared with that of the pristine $\mathrm{ZnCr}-\mathrm{LDH}$ ). ${ }^{171} \mathrm{~Tb}$ provided a prompt conduction of the photo-induced electrons and the injection of electrons of $\mathrm{Tb}$ accelerated the target reactions. In another example, Mikami et al. found that anchoring gold nanoparticles on ZnAl-LDH could remarkably enhance photocatalytic degradation of phenol under solar light irradiation. ${ }^{126}$ The specific charge transfer between the gold nanoparticles and the ZnAl-LDH and the surface plasmon resonance of gold particles contributed significantly to the enhanced photocatalytic response (Figure $5 c$ ). 
Table 4. Representative LDH-based hybrids anchored with semiconductors in recent years.

\begin{tabular}{|c|c|c|c|c|}
\hline \multirow{2}{*}{ LDH } & \multicolumn{2}{|c|}{ Anchoring materials } & \multirow{2}{*}{$\begin{array}{l}\text { Performance } \\
\text { vs. } \\
\text { the pristine LDH }\end{array}$} & \multirow{2}{*}{ Ref. } \\
\hline & Material & type & & \\
\hline MgFe & Molybdate & Semiconductor & Enhanced photocatalytic activity for organic contaminant & 161 \\
\hline ZnAl & $\mathrm{g}-\mathrm{C}_{3} \mathrm{~N}_{4} / \mathrm{CuO}$ & Semiconductor & Enhanced photodegradation activity toward phenol & 162 \\
\hline ZnAl & $\mathrm{ZnS}$ & Semiconductor & Exhibited a large enhancement of the photocatalytic degradation activity for organic dyes & 163 \\
\hline ZnAl & $\mathrm{TiO}_{2}$ & Semiconductor & $\begin{array}{l}\text { Improved overall photocatalytic performance; enhanced antibacterial performances in water } \\
\text { purification processes }\end{array}$ & $\begin{array}{l}164, \\
165\end{array}$ \\
\hline ZnFe & $\mathrm{TiO}_{2}$ & Semiconductor & Largely promoted performances in the photoelectrochemical water splitting & 160 \\
\hline $\mathrm{ZnCr}$ & CdSe & Semiconductor & $\begin{array}{l}\text { Remarkably suppressed the photogenerated electron-hole recombination; significantly enhanced } \\
\text { photocatalytic activity for } \mathrm{H}_{2} \text { generation }\end{array}$ & 125 \\
\hline $\mathrm{NiFe}$ & $\begin{array}{l}\mathrm{TiO}_{2} \text { and } \\
\text { reduced } \\
\text { graphite } \\
\text { oxide }\end{array}$ & $\begin{array}{l}\text { Conductive } \\
\text { Material and } \\
\text { semiconductor }\end{array}$ & Simultaneously enhanced the charge separation and water oxidation efficiency & 23 \\
\hline $\mathrm{NiFe}$ & $\begin{array}{l}\text { g- } \mathrm{C}_{3} \mathrm{~N}_{4} \text { and } \\
\mathrm{N} \text {-doped } \\
\text { graphene }\end{array}$ & $\begin{array}{l}\text { Conductive } \\
\text { Material and } \\
\text { semiconductor }\end{array}$ & Enhanced solar-driven photoelectrochemical water oxidation & 166 \\
\hline $\mathrm{NiFe}$ & $\mathrm{g}-\mathrm{C}_{3} \mathrm{~N}_{4}$ & Semiconductor & Enhanced photocatalytic activity towards water oxidation and reduction reaction & 167 \\
\hline $\mathrm{NiFe}$ & $\mathrm{BiOCl}$ & Semiconductor & Enhanced photo-degradation of dye & 168 \\
\hline $\mathrm{NiFe}$ & $\mathrm{NiCO}_{2} \mathrm{O}_{4}$ & Semiconductor & Highly efficient overall water-splitting activity & 169 \\
\hline $\mathrm{NiCo}$ & $\mathrm{MoS}_{2}$ & Semiconductor & $\begin{array}{l}\text { Exhibited an extremely low hydrogen evolution reaction overpotential of } 78 \mathrm{mV} \text { at } 10 \mathrm{~mA} / \mathrm{cm}^{2} \\
\text { and a low Tafel slope of } 76.6 \mathrm{mV} / \mathrm{dec} \text { in } 1 \mathrm{M} \mathrm{KOH} \text { solution; more stable }\end{array}$ & 159 \\
\hline $\mathrm{CoNi}$ & $\mathrm{BiOBr}$ & Semiconductor & $\begin{array}{l}\text { Showed much higher adsorption and photocatalytic properties for organic dyes and phenol } \\
\text { under UV-light irradiation }\end{array}$ & 16 \\
\hline CoAl & $\begin{array}{l}\mathrm{CdTe} \\
\mathrm{BiVO}_{4}\end{array}$ and & Semiconductor & Highly enhanced photoelectrochemical water oxidation efficiency & 124 \\
\hline
\end{tabular}


Table 5. Representative LDH-based hybrids anchored with rare earth elements and noble metals.

\begin{tabular}{|c|c|c|c|c|}
\hline \multirow{2}{*}{ LDH } & \multicolumn{2}{|c|}{ Anchoring materials } & \multirow{2}{*}{$\begin{array}{l}\text { Performance } \\
\text { vs. } \\
\text { pristine LDH }\end{array}$} & \multirow{2}{*}{ Ref. } \\
\hline & material & type & & \\
\hline $\mathrm{ZnSn}$ & $\mathrm{CeO}_{2}$ & $\begin{array}{l}\text { Semiconductor and } \\
\text { Rare earth element }\end{array}$ & Enhanced photocatalytic performance for phenol photodegradation under UV light & 173 \\
\hline $\mathrm{MgAl}$ & $\mathrm{CeO}_{2}$ & $\begin{array}{l}\text { Semiconductor and } \\
\text { Rare earth element }\end{array}$ & Enhanced photocatalytic activity for $\mathrm{H}_{2}$ production & 174 \\
\hline $\mathrm{MgAl}$ & $\mathrm{Tb}$ & Rare earth element & Exhibited strong green emission response to L-lysine (L-lysine sensor) & 175 \\
\hline MgAl & $\mathrm{Pd}$ & Noble metal & $\begin{array}{l}\text { Excellent catalyst for selective synthesis of primary anilines from cyclohexanone } \\
\text { oximes with high yields }\end{array}$ & 176 \\
\hline MgAl & Ru & Noble metal & $\begin{array}{l}\text { Displayed significant catalytic } \\
\text { activity for selective } \mathrm{CO}_{2} \text { hydrogenation to produce formic acid }\end{array}$ & 172 \\
\hline MgAl & Pt & Noble metal & Effective and stable catalyst for glycerol steam reforming & 177 \\
\hline $\begin{array}{l}\text { MgAl } \\
\text { and } \\
\text { MgAlCe }\end{array}$ & $\mathrm{Au}$ & Noble metal & Highly efficient reductive degradation of organic contaminants & 178 \\
\hline MgZnAl & Au-Pd & Noble metal & Enhanced photocatalytic degradation of organic dye & 179 \\
\hline $\mathrm{MgCaAl}$ & $\begin{array}{l}\text { AuPd and } \\
\text { La }\end{array}$ & $\begin{array}{l}\text { Rare earth element } \\
\text { and noble metal }\end{array}$ & $\begin{array}{l}\text { Highly efficient bimetallic catalysts with the enhanced stability for a wide range of } \\
\text { base-free aerobic oxidation of organic contaminants in water }\end{array}$ & 180 \\
\hline ZnAl & $\mathrm{Ce}$ & Rare earth element & $\begin{array}{l}\text { Enhanced phenol catalytic decomposition: } \mathrm{Ce}^{4+} \text { acted as electron scavenger, } \\
\text { facilitating the electron transfer toward adsorbed } \mathrm{O}_{2} \text { and an accumulation of holes, } \\
\text { increasing the generation of radicals } \mathrm{OH} \text {. }\end{array}$ & 181 \\
\hline ZnAl & $\mathrm{Au}$ & Noble metal & Enhanced phenol catalytic decomposition under solar light & 126 \\
\hline $\mathrm{ZnCr}$ & $\mathrm{Tb}$ & Rare earth element & $\begin{array}{l}\text { Largely enhanced visible light photocatalytic performance: effective separation of } \\
\text { photo-induced charge carriers and high charge injection efficiency }\end{array}$ & 171 \\
\hline $\mathrm{ZnTi}$ & $\mathrm{Ag}$ & Noble metal & Much higher photocatalytic activity and photochemical stability & 182 \\
\hline ZnGa & $\mathrm{Ag}$ or $\mathrm{Au}$ & Noble metal & Much higher photocatalytic activity and selectivity for conversion of carbon dioxide & 183 \\
\hline CoAl & $\mathrm{Ag}$ & Noble metal & Highly sensitive flexible piezoresistive materials & 184 \\
\hline
\end{tabular}

\subsection{Regulation of layer composition}

The LDH structure type is very accommodating to changing the metal components, their molar ratios, and oxidation states. The ionic radii of the two metal cations is the principal guiding concept to assess the feasibility of a particular metal cation combination for the hydroxide layers.$^{185}$ As a result the physical properties of an LDHs can be greatly controlled by this very flexible chemical composition space. ${ }^{186}$

\subsubsection{Regulation of metal components}

The flexible LDH structural platform offers an effective means to adjust the chemical, coordination, and oxidation states within an $\mathrm{LDH}$. Adding and reducing metal component(s), or replacing the metal component(s) with different metal(s) regulates the properties of LDHs. ${ }^{26,114,187-189}$ For example, Parida et al. prepared MgAlFe-LDH by the incorporation of $\mathrm{Fe}^{3+}$ into MgAl-LDH framework with the aim of investigating the role of iron in photocatalytic activity for $\mathrm{H}_{2}$ generation. ${ }^{189}$ The sample with the highest concentration of iron in the LDH layer was found to be the most effective catalyst towards hydrogen evolution under visible light irradiation. Wang and coworkers also found that the incorporation of iron could enhance the electrochemical performance of LDHs for oxygen evolution reaction. ${ }^{114}$ In another example, Liu et al. demonstrated that the electrocatalytic activity of NiFe-LDHs for oxygen evolution reaction in alkaline conditions could be notably increased by aluminum substitution, because the introduction of trivalent $\mathrm{Al}$ ions could adjust the ratio of low- coordinated $\mathrm{Ni}$ and Fe atoms. ${ }^{26}$ Furthermore, the number of active sites (defects) could also be greatly increased by the partial etching of Al species in strong alkaline solution, which further increased the activity toward oxygen evolution reaction. ${ }^{26}$ However, when investigating the performance of NiAICo-LDH in rechargeable NiZn battery, Gong and coworkers found that the existence of the element Co could slightly inhibit the performance (e.g., capacity) of NiAICo-LDH compared to that of NiAl-LDH. ${ }^{25}$ This is probably because $\mathrm{Co}^{2+}$ can suppress the oxidation of $\mathrm{Ni}^{2+}$ to a higher oxidation state. Therefore, the addition of new metal components may also present suppression in improving performances of LDHs; in other word, the reduction of some preexisting metal elements in certain LDHs may also improve the properties of LDHs. The above examples demonstrate that the incorporation of new metal component(s) into LDH framework and reduction of metal component(s) from LDH can alter various properties of LDHs.

By replacing the metal component(s) with different metal element(s) of $\mathrm{LDH}$, the properties of LDHs can also be tuned. In one instance, Li et al. prepared NiAl, CoAl, MnAl, NiCo, NiMn, and CoMn-LDH to investigate the synergistic effect between different metal components on the electrochemical behaviors of LDHs. ${ }^{188} \mathrm{It}$ was demonstrated that the LDHs with dual transition metals possessed lower band-gap energies and higher conductivities than mono-transition metal-based samples. The reduced band-gap energy and enhanced conductivity should be ascribed to the hybridization between $3 \mathrm{~d}$-orbitals of different transition metal atoms. As a result, the LDHs with dual transition metals exhibited lower charge transfer resistances and redox potentials as well as longer electron lifetime, thus they could be oxidized or reduced 
more easily during the redox process. According to their results, NiMn-LDH possessed the lowest charge transfer resistance and longest electron lifetime, which signified that the synergistic effect between $\mathrm{Ni}^{2+}$ and $\mathrm{Mn}^{4+}$ was the best.

Table 6 presents representative examples of altering properties of LDHs by the regulation of metal component(s). As one can observe, on one hand, the regulation of metal component(s) can significantly improve various performances of LDHs, which can be ascribed to several reasons, including endowing LDHs with the specific characteristic of a certain metal ion, modifying surface structure and crystallinity, increasing specific surface area, improving electronic structure and conductivity, adjusting bandgap, and creating defects. On the other hand, tuning the metal component(s) by introducing improper metals may also inhibit the performance of LDHs.

Table 6. Representative examples of the regulation of metal components: regulation types, performance or characteristics, and reasons for the changes of properties.

\begin{tabular}{|c|c|c|}
\hline $\begin{array}{l}\text { Pristine } \\
\text { LDH }\end{array}$ & $\begin{array}{l}\text { Regulation } \\
\text { types }\end{array}$ & $\begin{array}{c}\text { Performance } \\
\text { or } \\
\text { characteristic }\end{array}$ \\
\hline $\mathrm{MgAl}$ & $\begin{array}{l}\text { Addition of } \mathrm{Fe}^{2+} \text { in } \\
\text { layers }\end{array}$ & $\begin{array}{l}\text { Endowed the LDH with the ability to reduce } \\
\text { hexavalent chromium }\end{array}$ \\
\hline MgAl & $\begin{array}{l}\text { Addition of } \mathrm{Fe}^{3+} \text { in } \\
\text { layers }\end{array}$ & $\begin{array}{l}\text { Enhanced hydrogen evolution activity under } \\
\text { visible light irradiation }\end{array}$ \\
\hline $\begin{array}{l}\text { (Mg or } \\
\mathrm{Zn}) \mathrm{Al}\end{array}$ & $\begin{array}{l}\text { Metal composition } \\
\text { replacement } \\
\text { (between } \mathrm{Mg} \text { and } \\
\mathrm{Zn} \text { ) }\end{array}$ & $\begin{array}{l}\text { MgAl-LDH possessed a much higher electric } \\
\text { conductivity than that of ZnAl-LDH }\end{array}$ \\
\hline $\mathrm{NiAl}$ & $\begin{array}{l}\text { Addition of } \mathrm{Co}^{3+} \text { in } \\
\text { layers }\end{array}$ & $\begin{array}{l}\text { Slightly inhibited the performance in NiZn } \\
\text { battery }\end{array}$ \\
\hline NiFe & $\begin{array}{l}\text { Addition of } \mathrm{Mn}^{4+} \\
\text { in layers }\end{array}$ & Superior oxygen evolution activity \\
\hline NiFe & $\begin{array}{l}\text { Addition of } \mathrm{A}^{\mathrm{l}^{3+}} \text { in } \\
\text { layers and partial } \\
\text { etching/dissolutio } \\
\mathrm{n} \text { of the } \\
\text { incorporated } \mathrm{Al}^{3+}\end{array}$ & $\begin{array}{l}\text { Higher activity and stability than NiFe-LDH } \\
\text { for oxygen evolution reaction }\end{array}$ \\
\hline NiCo & $\begin{array}{l}\text { Addition of } \mathrm{Fe}^{3+} \text { in } \\
\text { layers }\end{array}$ & $\begin{array}{l}\text { The Fe-incorporation significantly enhanced } \\
\text { the electrochemical performance of the } \\
\text { material for oxygen evolution reaction } \\
\text { Superior specific capacitance of } 1153 \mathrm{Fg}^{-1} \text { at }\end{array}$ \\
\hline $\begin{array}{l}\mathrm{NiCo}, \\
\mathrm{NiCoFe}\end{array}$ & $\begin{array}{l}\text { Addition of } \mathrm{Al}^{3+} \text { in } \\
\text { layers }\end{array}$ & $\begin{array}{l}6 \mathrm{Ag}^{-1} \text {, and excellent cycling stability (ca. } \\
92.97 \% \text { capacitance retention after } 3000 \\
\text { cycles). }\end{array}$ \\
\hline $\begin{array}{l}\text { NiAl, } \\
\text { CoAl, } \\
\text { MnAl, } \\
\text { NiCo, } \\
\text { NiMn, } \\
\text { CoMn }\end{array}$ & $\begin{array}{l}\text { Metal composition } \\
\text { replacement }\end{array}$ & $\begin{array}{l}\text { LDH with dual transition metals possessed } \\
\text { lower band-gap energies and higher } \\
\text { conductivities than mono-transition metal- } \\
\text { based samples }\end{array}$ \\
\hline $\mathrm{ZnCr}$ & $\begin{array}{l}\text { Addition of } \mathrm{La}^{3+} \text { in } \\
\text { layers }\end{array}$ & $\begin{array}{l}\text { Enhanced photo catalytic activity for organic } \\
\text { contaminant degradation under visible light } \\
\text { irradiation }\end{array}$ \\
\hline ZnAl & $\begin{array}{l}\text { Addition of } \mathrm{Co}^{2+} \text { or } \\
\mathrm{Cu}^{2+} \text { in layers }\end{array}$ & $\begin{array}{l}\text { Enhanced photocatalytic activities for } \\
\text { organic contaminants degradation }\end{array}$ \\
\hline $\mathrm{MgAl}$ & $\begin{array}{l}\text { Regulation } \\
\text { molar ratios }\end{array}$ & $\begin{array}{l}\mathrm{HAsO}_{4}{ }^{2-} \text { uptake amounts on } \mathrm{LDH} \text { varied with } \\
\mathrm{Mg} / \mathrm{Al} \text { ratio }\end{array}$ \\
\hline MgAl & $\begin{array}{l}\text { Regulation } \\
\text { molar ratios }\end{array}$ & $\begin{array}{l}\text { LDH with higher } \mathrm{Al}^{3+} \text { content exhibited } \\
\text { better adsorption performance for } \\
\text { norfloxacin both in adsorption rate and } \\
\text { adsorption capacity }\end{array}$ \\
\hline MgAl & $\begin{array}{l}\text { Regulation } \\
\text { molar ratios }\end{array}$ & $\begin{array}{l}\text { MgAl-LDH with different } \mathrm{Mg} / \mathrm{Al} \text { ratios had } \\
\text { different surface physical properties, } \\
\text { crystallinities, and } \mathrm{CO}_{2} \text { adsorption capacities }\end{array}$ \\
\hline MgAl & $\begin{array}{l}\text { Regulation } \\
\text { molar ratios }\end{array}$ & $\begin{array}{l}\text { Antimonate uptake amounts increased as } \\
\text { the } \mathrm{Mg} / \mathrm{Al} \text { molar ratio decrease from } 4 \text { to } 2\end{array}$ \\
\hline MgCaAl & $\begin{array}{l}\text { Regulation } \\
\text { molar ratios }\end{array}$ & $\begin{array}{l}\text { LDH with different } \mathrm{Mg} / \mathrm{Ca} / \mathrm{Al} \text { ratios had } \\
\text { different surface physical properties and } \\
\text { adsorption capacities for fluoride and } \\
\text { protein }\end{array}$ \\
\hline
\end{tabular}

Reasons for the changes of properties

Ref.

The reducing activity of $\mathrm{Fe}^{2+}$

The enhanced performance was attributed to the favorable surface structure and higher crystalline nature of 189 hydrotalcites

The difference in electric conductivity is due to the differing ionic radii and electronic structures of the intralayer metal cations, as well as the different degrees of distortion of the $\mathrm{MO}_{6}$ octahedron in the 2D LDH layers.

This could be due to Co suppressing the oxidation of $\mathrm{Ni}^{2+}$ to a higher

oxidation state

The addition of $\mathrm{Mn}^{4+}$ can modify the electronic structure and improve the conductivity of the electrocatalyst

Al substitution increased the concentration of $\mathrm{Ni}$ active sites on the catalyst surface. Besides, low-coordinated $\mathrm{Ni}$ and $\mathrm{Fe}$ atoms and defects were formed by partial etching/dissolution of $\mathrm{Al}^{3+}$ in alkaline solution, further increasing the activity towards oxygen evolution reaction

This was ascribed to the enhanced conductivity and improved intrinsic catalytic activity, a large surface area, and a high porosity structure of the material

The corporation of $\mathrm{Al}^{3+}$ led to the improvement of the electrochemical performance; $\mathrm{Al}^{3+}$ could regulate the crystallinity, hydrophilicity and nanosheets stacking of LDH

The reduced band-gap energy and enhanced conductivity should be ascribed to the hybridization between $3 \mathrm{~d}$-orbitals of different transition atoms

\section{The increased surface area and light harvesting ability}

Well-crystallized structure; the homogenously dispersed Co suppressed the recombination of holes and electrons and improved charge transfer in the ZnAl-LDH framework

The amount of $\mathrm{Al}^{\mathrm{l}+}$ affected the charge density, basal spacing, and the exchange of interlayered anions of MgAl-LDH

Higher charge density gave a reinforced electrostatic attraction between LDH and anionic species

The changes of surface porosity, surface area, and crystallinities

Thanks to the increasing excess of positive charge of LDH sheets and the expanding interlayer spacing

190




\begin{tabular}{|c|c|c|c|}
\hline ZnAl & $\begin{array}{l}\text { Regulation } \\
\text { molar ratios }\end{array}$ & of & $\begin{array}{l}\text { The crystallinity of } \mathrm{LDH} \text { were found to } \\
\text { improve as } \mathrm{Zn} / \mathrm{Al} \text { molar ratio decreased; } \\
\text { band gaps were affected by the variation of } \\
\text { the } \mathrm{Zn} / \mathrm{Al} \text { ratio }\end{array}$ \\
\hline ZnAl & $\begin{array}{l}\text { Regulation } \\
\text { molar ratios }\end{array}$ & of & $\begin{array}{l}\text { Low } \mathrm{Zn} / \mathrm{Al} \text { molar ratios showed limited } \\
\text { influence to the morphology and surface } \\
\text { area; high } \mathrm{Zn} / \mathrm{Al} \text { molar ratios decreased the } \\
\text { surface area }\end{array}$ \\
\hline ZnTi & $\begin{array}{l}\text { Regulation } \\
\text { molar ratios }\end{array}$ & of & $\begin{array}{l}\text { All the } \mathrm{ZnTi}-\mathrm{LDH} \text { with } \mathrm{Zn} / \mathrm{Ti} \text { molar ratio of } \\
2: 1 \text {, } 3: 1 \text { and } 4: 1 \text { displayed high } \\
\text { photocatalytic activity under visible-light } \\
\text { irradiation with the } 3: 1 \text { one being the most } \\
\text { active }\end{array}$ \\
\hline $\mathrm{NiTi}$ & $\begin{array}{l}\text { Regulation } \\
\text { molar ratios }\end{array}$ & of & $\begin{array}{l}\text { The NiTi-LDH with a Ni/Ti molar ratio of } 4: 1 \\
\text { displayed the highest photocatalytic } \mathrm{H}_{2} \\
\text { production activity, in comparison with a } \\
\text { LDH with a Ni/Ti ratio of } 2: 1,3: 1 \text {, and } 5: 1\end{array}$ \\
\hline $\mathrm{NiFe}$ & $\begin{array}{l}\text { Regulation } \\
\text { molar ratios }\end{array}$ & of & $\begin{array}{l}\text { The NiFe-LDH with different } \mathrm{Ni} / \mathrm{Fe} \text { molar } \\
\text { ratio showed different electrocatalytic } \\
\text { activities }\end{array}$ \\
\hline $\mathrm{NiCo}$ & $\begin{array}{l}\text { Regulation } \\
\text { molar ratios }\end{array}$ & of & $\begin{array}{l}\text { As the content of nickel increased, the } \\
\text { hydroxides tended to have a higher specific } \\
\text { capacitance with a gradually deteriorative } \\
\text { rate capability }\end{array}$ \\
\hline NiMn & $\begin{array}{l}\text { Regulation } \\
\text { molar ratios }\end{array}$ & of & $\begin{array}{l}\mathrm{Ni} / \mathrm{Mn} \text { molar ratio affected the oxygen } \\
\text { evolution reaction activity of } \mathrm{NiMn}-\mathrm{LDH} \text {; } \\
\mathrm{NiMn}-\mathrm{LDH} \text { with a Ni/Mn ratio of } 3 \text { showed } \\
\text { the best performance (highly active and } \\
\text { stable) }\end{array}$ \\
\hline CoFe & $\begin{array}{l}\text { Regulation } \\
\text { molar ratios }\end{array}$ & of & $\begin{array}{l}\text { LDH with different molar ratio presented } \\
\text { different adsorption abilities toward organic } \\
\text { contaminants, and CoFe-LDH with a Co/Fe } \\
\text { ratio of } 4 \text { showed the highest affinity to } \\
\text { organic dye methyl orange }\end{array}$ \\
\hline $\begin{array}{l}\mathrm{Co}\left(\mathrm{Fe}^{2+}\right. \\
\left., \mathrm{Fe}^{3+}\right)\end{array}$ & $\begin{array}{l}\text { Regulation } \\
\text { molar ratios }\end{array}$ & of & $\begin{array}{l}\text { Co/Fe molar ratio affected the capacitive } \\
\text { properties of the CoFe-LDH }\end{array}$ \\
\hline $\mathrm{ZnCo}$ & $\begin{array}{l}\text { Partial oxida } \\
\text { of } \mathrm{Co}^{2+} \text { to } \mathrm{Co}^{3+}\end{array}$ & & $\begin{array}{l}\text { The oxidation of } \mathrm{Co}^{2+} \text { affected the magnetic } \\
\text { susceptibility of } \mathrm{ZnCo}-\mathrm{LDH}\end{array}$ \\
\hline $\mathrm{NiCo}$ & $\begin{array}{l}\text { Partial oxida } \\
\text { of } \mathrm{Co}^{2+} \text { to } \mathrm{Co}^{3+}\end{array}$ & & Enhanced electrochemical performance \\
\hline $\mathrm{NiCoFe}$ & $\begin{array}{l}\text { Partial oxida } \\
\text { of } \mathrm{Co}^{2+} \text { to } \mathrm{Co}^{3+}\end{array}$ & & $\begin{array}{l}\text { Significantly enhanced both oxygen } \\
\text { reduction reaction and oxygen evolution } \\
\text { reaction activity }\end{array}$ \\
\hline $\mathrm{NiFe}$ & $\begin{array}{l}\text { Partial oxida } \\
\text { of } \mathrm{Ni}^{2+} \text { to } \mathrm{Ni}^{3+}\end{array}$ & & High catalytic activity in water splitting \\
\hline $\mathrm{NiTi}$ & $\begin{array}{l}\text { Partial oxida } \\
\text { of } \mathrm{Ni}^{2+} \text { to } \mathrm{Ni}^{3+}\end{array}$ & & $\begin{array}{l}\text { Significantly improved supercapacitive } \\
\text { performance }\end{array}$ \\
\hline \multicolumn{4}{|l|}{$\mathrm{NiFe}$} \\
\hline $\begin{array}{l}\mathrm{NiCo} \\
\mathrm{CoFe} \\
\mathrm{NiCoFe}\end{array}$ & $\begin{array}{l}\text { Reduction of } \\
\text { Fe, and Co }\end{array}$ & $\mathrm{Ni}$ & $\begin{array}{l}\text { Dramatically promoted the overall water } \\
\text { splitting performance }\end{array}$ \\
\hline
\end{tabular}

The decreased crystallinity was attributed to the distortion of the hydroxide layer networks of the LDH crystal by the larger difference in ionic radii of $\mathrm{Zn}^{2+}$ and $\mathrm{Al}^{3+}$; the formation of the low crystalline phases $\left(\mathrm{ZnO}\right.$ and $\left.\mathrm{ZnAl}_{2} \mathrm{O}_{4}\right)$ affected the band gaps

Lower band gap, hierarchical microsphere structure, as well as high specific surface; $\mathrm{ZnTi}-\mathrm{LDH}$ with $\mathrm{Zn} / \mathrm{Ti}$ ratio of 3:1 had the strongest absorption in the visible light region

$\mathrm{Ni} / \mathrm{Fe}$ molar ratio affected the crystallinity of $\mathrm{NiFe}-\mathrm{LDH}$; too small or large amounts of Fe will not form the NiFe-LDH phase properly

The addition of $\mathrm{Ni}$ could increase the conductivity of $\mathrm{Ni}-\mathrm{Co}$ binary hydroxides

$\mathrm{NiMn}-\mathrm{LDH}$ with a Ni/Mn ratio of 3 exhibited a high degree of crystallinity, large interlayer spacing, large surface area, and highly porous structure

Different porous structures

$\mathrm{Co} / \mathrm{Fe}$ molar ratio had a significant influence on the phase and structure of the products

The co-existence of high spin $\mathrm{Co}^{2+}$ and low spin $\mathrm{Co}^{3+}$

The partial conversion of $\mathrm{Co}^{2+}$ to $\mathrm{Co}^{3+}$ state, which stimulated the charge transfer to the catalyst surface

The generation of effective $\mathrm{Ni}^{3+}$ sites on NiFe-LDH

The decrease in the conductive resistance of the materials caused by the introduction of $\mathrm{Ni}^{3+}$; that is, $\mathrm{Ni}^{3+}$ served as more conductive species

The reduced metals could finely tune the surface electronic 212 state

\subsubsection{Regulation of ratio of metal components}

The properties of LDHs can be fine-tuned by adjusting the molar ratio of the metal components. For example, Zhao et al. found that the molar ratio of $\mathrm{Ni} / \mathrm{Ti}$ could significantly affect the catalytic activities of NiTi-LDH. ${ }^{202}$ The NiTi-LDH with a Ni/Ti molar ratio of $4: 1$ displays the highest photocatalytic activity in $\mathrm{H}_{2}$ production, in comparison with the $\mathrm{LDH}$ with a $\mathrm{Ni} / \mathrm{Ti}$ ratio of $2: 1$, $3: 1$, and 5:1. Sumboja et al. also revealed that the molar ratio of LDHs greatly influenced their catalytic activity. ${ }^{205}$ In their study, they demonstrated that NiMn-LDH with the optimized $\mathrm{Ni} / \mathrm{Mn}$ molar ratio (3:1) had good crystallinity, large interlayer spacing, and large surface area, all of which were beneficial to enhance their catalytic activity. Apart from the catalytic performances, regulation of the molar ratios of metal components of LDHs can also tune other properties. For instance, Zhang et al. found that the electrochemical performance of NiCo-LDH was closely related to the molar ratio of $\mathrm{Ni} / \mathrm{Co}^{204}$ As the content of nickel was increased, the sample tended to have a higher specific capacitance. Their electrochemical data demonstrated that the binary hydroxide with a $\mathrm{Ni} / \mathrm{Co}$ molar ratio of $7: 3$ could deliver the maximum specific capacitance of $1803.6 \mathrm{Fg}^{-1}$, while the binary hydroxide with a $\mathrm{Ni} / \mathrm{Co}$ molar ratio of $3: 7$ exhibited a high rate capability. These results indicated that increasing the amount of $\mathrm{Ni}$ could increase the conductivity of Ni-Co binary hydroxides. On the other hand, different $\mathrm{Ni} / \mathrm{Co}$ ratios would result in different basal spacing of NiCo-LDH. The experimental results also gave a clue 
that the charge storage stability and rate capability of these hydroxides highly depended on the basal spacing of NiCo-LDH. A higher basal spacing corresponds to a better electrochemical performance. In another example, Kim et al. systematically investigated the effect of $\mathrm{Mg} / \mathrm{Al}$ molar ratio (between 3 and 30) on the adsorption of $\mathrm{CO}_{2}$ by MgAl-LDHs. ${ }^{196}$ When the $\mathrm{Mg} / \mathrm{Al}$ molar ratio was between 12 and 30, these MgAl-LDHs showed a unique two-step $\mathrm{CO}_{2}$ adsorption behavior: low $\mathrm{CO}_{2}$ loading initially followed by a gradual transition to very high $\mathrm{CO}_{2}$ loading. The $\mathrm{CO}_{2}$ adsorption capacity for the MgAl-LDH with an $\mathrm{Mg} / \mathrm{Al}$ molar ratio of 20 exhibited the highest reported value. The different adsorption behaviors may be ascribed to the different pore structures, surface areas, and crystallinities resulted from the different $\mathrm{Mg} / \mathrm{Al}$ molar ratios. ${ }^{196}$

Table 6 presents examples of how altering the molar ratio of metal components may alter the properties of LDHs. As shown in Table 6 , by regulating the molar ratio of the metal components in LDHs, one can generally adjust the crystallinity, basal spacing, charge density, surface area, porous structure, distortion of layers, electron conductivity of layers, and/or band-gap structure of LDHs, and subsequently obtain LDHs with tunable properties.

\subsubsection{Regulation of chemical valence of metal components}

Generally, regulating chemical valence state of the metal components of LDHs can modify the electronic structure of individual components, thus changing the properties of LDHs. ${ }^{27,209 \text {, }}$ 210,212 In a particular instance, Gou et al. reported that tuning the valence state of $\mathrm{Co}$ in NiCo-LDH could be an effective method to significantly improve the rate performance of NiCo-LDH, which was realized through a facile in situ chemical treatment of phosphites. ${ }^{209}$ The specific capacitance of the obtained rosette $\mathrm{NiCo}-\mathrm{LDH}$ electrode was $1425 \mathrm{Fg}^{-1}$ at $20 \mathrm{Ag}^{-1}$, which was $83.9 \%$ of $1698 \mathrm{Fg}^{-1}$ at $1 \mathrm{Ag}^{-1}$. Meanwhile, a moderate cycling stability with an efficiency of $80.6 \%$ after cycling 4000 times at a current density of $10 \mathrm{Ag}^{-1}$ was obtained. Moreover, an energy density of 40.1 Whkg- ${ }^{-1}$ at a power density of $801.2 \mathrm{Wkg}^{-1}$ was achieved in an assembled aqueous asymmetric supercapacitor, using NiCo-LDH as the positive electrode material and activated carbon as the negative electrode material. Their study showed that the chemical treatment evoked morphology and phase transformation and induced partial $\mathrm{Co}^{2+}$ conversion to a more conductive $\mathrm{Co}^{3+}$ state. The electrochemical performance is also highly related to the valence state of Cobalt. Qian and coworkers demonstrated that tuning the valence state of a metal component of LDH could notably enhance the performance of the LDH. ${ }^{210}$ In their research, the $\mathrm{Co}^{2+}$ in NiCoFe-LDH was partially oxidized to $\mathrm{Co}^{3+}$ by $\mathrm{H}_{2} \mathrm{O}_{2}$, which significantly enhanced both oxygen reduction reaction and oxygen evolution reaction activity of NiCoFe-LDH. This phenomenon was attributed to the partial conversion of $\mathrm{Co}^{2+}$ to $\mathrm{Co}^{3+}$ state in the pre-oxidation step, which stimulated the charge transfer to the catalyst surface.

Table 6 presents typical examples of the changes the chemical valence states of the metal components of LDHs. In these examples, transition metals such as $\mathrm{Ni}, \mathrm{Co}$, and Fe are the most common metals to be regulated. The change of valence state of the metal components within LDHs is commonly a key factor to enhancing catalytic activities and electrochemical performances (e.g., supercapacitor performance) of LDHs.

\subsection{Size and morphology control}

Since the decrease of particle size, thickness and the diversification of morphologies of LDHs have a significant impact on their electronic, catalytic, and adsorption properties and thus potential applications, ${ }^{213-216}$ considerable efforts have been focused on tuning the particle size and thickness, as well as the morphology of LDHs in the past decade. ${ }^{6,213-218}$

\subsubsection{Size refinement}

Downsizing LDHs (i.e., lowering particle size or thickness of LDH layers) offers a significant opportunity to enhance a range of $\mathrm{LDH}$ properties that are attributed to factors such as more coordinatively unsaturated metal cations (i.e., defect-rich structures which serve as active centers), more available exposed active sites, larger specific surface area, and higher electronic conductivity than the bulk LDHs. ${ }^{27,214,215,219-222}$ For example, Zhao et al. found that the decrease of the size of NiTi-LDH by in situ preparing monolayer LDH nanosheets contributed greatly to the improvement of its supercapacitor performance. ${ }^{27}$ It was reported that the NiTi-LDH nanosheets exhibited a maximum specific capacitance of $2310 \mathrm{Fg}^{-1}$ (at $1.5 \mathrm{Ag}^{-1}$ ), which is unprecedented and 6 times higher than that of the bulk counterpart $\left(377 \mathrm{Fg}^{-1}\right)$. Furthermore, it could maintain a remarkable rate capability and high durability. The NiTi-LDH nanosheets with highly exposed chemically reactive sites and a large specific surface area ensured an efficient supercapacitive reaction. Zhao et al. also found that the coordinatively unsaturated metal ions in ultrathin ZnAl-LDH contributed significantly to the photocatalytic activity in $\mathrm{CO}_{2}$ reduction. ${ }^{215}$ Due to the dramatic enhancement of various properties of LDHs via decreasing size or thickness, huge innovative efforts have been devoted to advance the approaches of preparation of ultrafine or ultrathin LDHs.

The methods to prepare ultrafine or ultrathin LDHs are mainly based on two pathways, i.e., bottom-up and top-down strategies. ${ }^{6}$ The bottom-up strategy is to prepare ultrafine or ultrathin LDHs from initial metal salts, while the top-down pathway is to decrease the particle size or thickness of the preexisting LDHs. Generally, controlling or separating the nucleation and crystallization processes of LDHs, such as using limited space under controlled reaction conditions to induce the formation of LDHs, is an effective bottom-up means to prepare ultrafine or ultrathin LDH (Figure 6A-D). ${ }^{27,} 223$ For example, $\mathrm{Hu}$ and $\mathrm{O}^{\prime}$ Hare were the first to utilize a water-in-oil reverse microemulsion as a LDH synthesis microreactors providing only limited space and nutrients for the proceeding reactions to prepare ultrafine MgAlLDH. ${ }^{224}$ By limiting the available space and nutrients the nucleation and crystallization processes could be very precisely controlled, and the prepared MgAl-LDH possessed uniform nanometer sizes typically with a diameter of $40-50 \mathrm{~nm}$ and a thickness of $c a .10 \mathrm{~nm}$. Wang et al. also reported a method by using a continuous-flow hydrothermal reactor to prepare ultrafine CaAl-LDH and MgAl-LDH. ${ }^{225}$ In this method, the nucleation and aging time can be controlled to be very short (e.g., 4 s), which prevents the growth of the LDH nanosheets. These examples indicate that the control of nucleation and crystallization (under aging state) is highly important in bottom-up strategy to prepare ultrafine LDH. Sun and coworkers developed a unique approach to prepare LDH single-layer nanosheets by growing LDH in formamide, which serves as an effective blocking agent to selectively block the growth of the LDH in the thickness direction. ${ }^{217,} 218$ Their preparing procedures are shown in Figure 5E. 

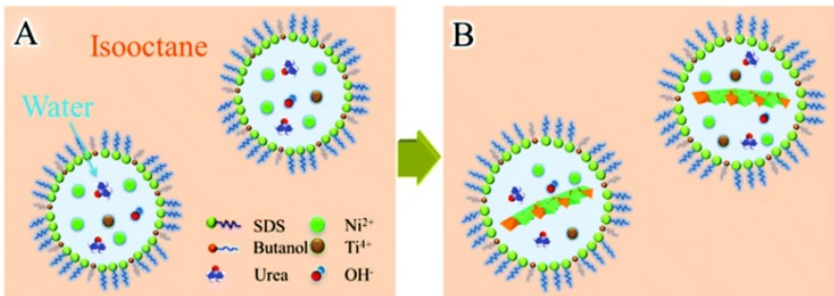

$\mathrm{D}$
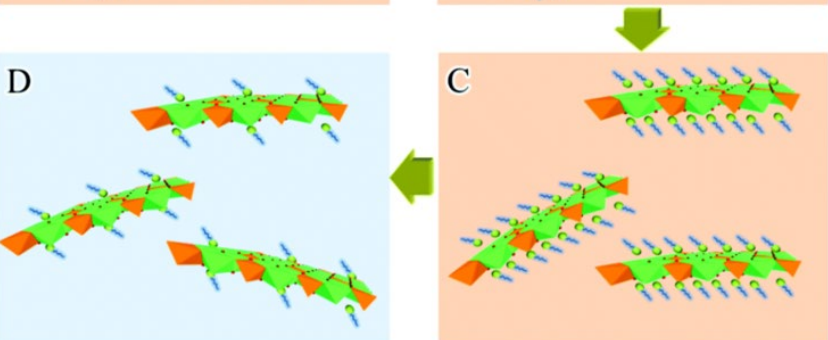

$\mathrm{E}$

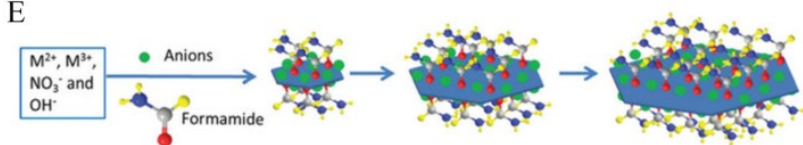

Figure 6. Schematic of the formation of monolayer NiTi-LDH nanosheets in micelles (limited space): (A) metal salts and urea mix in water droplets; (B) LDH starts to form during the hydrolysis of urea; (C) monolayer NiTi-LDH nanosheets form in isooctane; (D) monolayer NiTi-LDH nanosheets are transferred into the water surrounding after cleaning. ${ }^{27}$ Reproduced with permission from ref. ${ }^{27}$, Copyright 2015, The Royal Society of Chemistry; (E) direct growth of MgAl-LDH single-layer nanosheets with the assistance of layer growth inhibitors (i.e., formamide). ${ }^{217}$ Reproduced with permission from ref. ${ }^{217}$, Copyright 2015, The Royal Society of Chemistry

In the top-down pathway, the most prevalent and effective, but meanwhile very demanding, approach is the exfoliation of the layers into individual nanosheets. In this way, inorganic layers with a very high aspect ratio may become thoroughly separated. A summary of exfoliation methods can be found in the literature. ${ }^{6}$, ${ }^{226}$ After exfoliation, various properties of the LDHs usually exhibit a pronounced enhancement compared to those of the pristine LDHs. 221, 222, 227 For instance, Song and Hu demonstrated that the exfoliated CoCo-LDH, NiCo-LDH, and NiFe-LDH single-layer nanosheets exhibited significantly higher oxygen evolution activity than the corresponding bulk LDH in alkaline conditions. ${ }^{221}$ The exfoliated nanosheets from NiFe-LDH and NiCo-LDH outperformed both the activity and stability of a commercial iridium dioxide catalyst. The improvement of the catalytic activity in oxygen evolution reaction is attributed to the more active sites created by exfoliation and the improved electronic conductivity. Sun et al. also confirmed that the ultrathin MgAl-LDH, CoAl-LDH, CoCo-LDH, and NiCo-LDH prepared from exfoliation could exceptionally improve the electronic and hydroxyl ion conductivities. ${ }^{222}$ They found that the above LDH single-layer nanosheets exhibited exceptionally high in-plane hydroxyl ion conductivity approaching $10^{-1} \mathrm{~S} \mathrm{~cm}^{-1}$ (the bulk LDHs generally up to $10^{-3} \mathrm{~S} \mathrm{~cm}^{-1}$ ), which was the highest among anion conductors and comparable to proton conductivity in commercial proton exchange membranes (e.g., Nafion ${ }^{\circ}$. This 2D superionic transport characteristic might have great promises in a variety of applications including alkaline fuel cells and water electrolysis.

\subsubsection{Dimensional morphology regulation}

It is known that the common LDHs synthesized by the conventional methods usually exhibit a plate-like morphology (i.e., 2D morphology). Although LDHs with a 2D morphology possess fascinating functions, tuning their dimensions may endow LDHs with more attractive characteristics. In modern research, 3D hierarchical nanostructures have drawn considerable attention due to their unique properties and potential applications. ${ }^{213}$ The fabrication of LDHs with a 3D morphology has been demonstrated to be an effective means to introduce unique performances to $\mathrm{LDHs}^{228-231} \mathrm{Li}$ and coworkers developed a facile, inexpensive, and self-assembling strategy to massively fabricate a $3 \mathrm{D}$ rosette NiCo$\mathrm{LDH}$ under mild reaction conditions $\left(55^{\circ} \mathrm{C}\right)$ via one-step chemical co-precipitation in metal-ammine mixture solution (Figure 7a). After systematic investigation of various reaction factors including the $\mathrm{Ni} / \mathrm{Co}$ feeding ratio, reaction time, and initial $\mathrm{pH}$ value, the authors managed to regulate the morphologies of NiCo-LDH from nanoparticles and nanosheets to nanopetals, and eventually to rosette microspheres. The resultant 3D NiCo-LDH was demonstrated to have high electrochemical performance with an excellent capacitance value of ca. $2228 \mathrm{Fg}^{-1}\left(1 \mathrm{Ag}^{-1}\right)$. In another instance, $\mathrm{Li}$ et al. prepared a rosette NiAl-LDH using a templatefree and facile self-assembling hydrothermal synthesis method in the existence of poly(sodium-p-styrene-sulfonate). ${ }^{230}$ The prepared 3D rosette NiAl-LDH exhibited excellent energy storage performance, which was much higher than that of the common NiAl-LDH. Apart from rosette 3D morphology, other 3D morphologies, such as cone-shaped ${ }^{232}$ and vertically aligned nanosheets ${ }^{228}$ have also been developed, and these 3D LDHs displayed high performances in various fields. The high performances of 3D LDHs can be ascribed to, but not limited to, some of the following aspects: $137,213,228,229,231$ (1) 3D structures can produce a relatively high specific surface area and/or unique hierarchical porous 3D architectures; (2) the highly oriented and rigid $3 \mathrm{D}$ architecture can help overcome the problem of low conductivity in conventional LDHs; (3) many 3D LDHs are composed of thin LDH nanosheets; (4) 3D LDHs may have higher surface activity than common 2D LDHs.

a
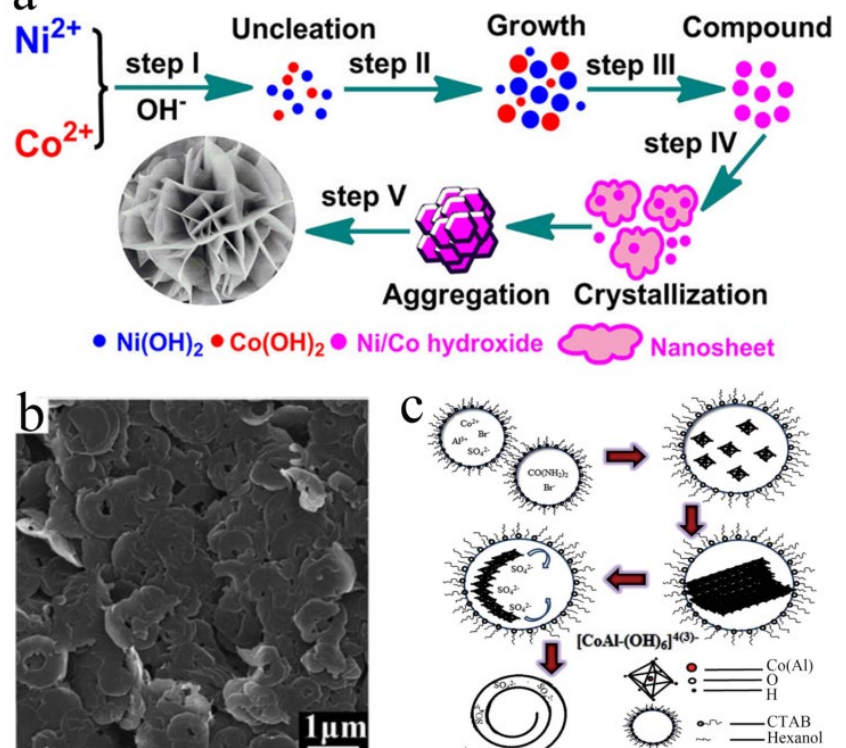

Figure 7. (a) Schematic illustration describing the synthetic procedures of the 3D NiCo-LDH microspheres, ${ }^{229}$ Reproduced with permission from ref. ${ }^{229}$ Copyright 2016, American Chemical Society; (b) SEM image of MgAl-LDH nanorings, ${ }^{233}$ Reproduced with permission from ref ${ }^{233}$, Copyright 2011, The Royal Society of Chemistry; (c) schematic of the nucleation and structural 
evolution process of the CoAl-LDH nanoscrolls, ${ }^{234}$ Reproduced with permission from ref. ${ }^{234}$, Copyright 2015, The Royal Society of Chemistry

In addition to 3D morphologies, other morphologies such as LDH nanorings, ${ }^{233}$ nanoscrolls, ${ }^{234}$ nanorods, ${ }^{235}$ and nanowires ${ }^{236}$ have been reported, offering options to modify the characteristics of LDHs. Yang and coworkers synthesized unique MgAl-LDH nanorings with an external diameter of ca. $750 \mathrm{~nm}$ and an internal diameter of $250 \mathrm{~nm}$ in an organic/water solvent system via a urea hydrolysis method by using $\mathrm{Mg}_{10}(\mathrm{OH})_{18} \mathrm{Cl}_{2} \cdot 5 \mathrm{H}_{2} \mathrm{O}$ nanowires as the precursor (Figure $7 b$ ). ${ }^{233}$ The resultant unique MgAl-LDH nanorings had a higher specific surface area and larger pore volume than the plate-like LDHs. Furthermore, the MgAl-LDH nanorings presented a significantly enhanced catalytic performance in the Knoevenagel reaction between benzaldehyde and diethyl malonate compared to the plate-like LDH. Lv et al. prepared a novel 1D CoAl-LDH, i.e., nanoscrolls, by facile trinal-phase hydrothermal treatment under different pressures (generated by controlling temperature).234 Their study indicated that CoAl-LDH nanosheets formed at first, which subsequently evolved into nanoscrolls (Figure 7c). Notably, their investigation results confirmed that the urea and pressure played key roles in the formation of the 1D CoAl-LDH nanoscrolls. Further observations by scanning electron microscopy and highresolution TEM indicated that the nanoscrolls were derived from nanosheets through a roll-up process, rather than through the control of the crystal growth in one particular direction. Owing to the increased specific surface area and novel structure, the nanoscrolls exhibited high adsorption capacity and excellent reusability in the adsorption of organic contaminant (methyl orange) in aqueous solution. These examples demonstrated that the fabrication of LDHs with special 2D (e.g., nanorings) or $1 \mathrm{D}$ morphology also helps the regulation of physical properties (such as surface area and porosity) of LDHs.

\subsubsection{Hollow and porous structures}

Recently, much attention has been paid to nanostructured materials with a hierarchical architecture due to their large specific surface area, high porosity, high structural stability, as well as significantly enhanced performances, e.g., electro-chemical responses, high ionic transport, enhanced adsorption capacity and catalytic activity, in comparison with their common counterparts. $237,238 \mathrm{LDH}$ is one type of such widely studied nanostructured materials. Fabrication of hierarchical LDHs with a hollow or highly porous structure is currently an active approach to control the properties of LDHs. Various researchers have found that hollow or porous LDHs can be prepared by using a template, ${ }^{237}, 239-242$ applying bubbles, ${ }^{243}$ or employing acid or alkali to etch LDHs. ${ }^{244}$ For example, Shao and coworkers synthesized hierarchical MgFe-LDH microspheres with a tunable interior structure via a facile and cost-effective method by using sodium dodecyl sulfonate (SDS) as the template. ${ }^{237}$ By controlling the concentration of SDS, the structure of the products could be tailored from hierarchical rosette MgFe-LDH solid spheres to yolkshell and then to hollow spheres with different interior space (Figure 8a). The changes in interior space eventually contributed to the changes in specific surface area and pore-size distribution. Specifically, the maximum specific surface area of the hollow MgFe-LDH microspheres $\left(213.6 \mathrm{~m}^{2} / \mathrm{g}\right)$ was much larger than that of the yolk-shell $\left(124.4 \mathrm{~m}^{2} / \mathrm{g}\right)$ and solid $\left(78.8 \mathrm{~m}^{2} / \mathrm{g}\right)$ one. In addition, the pore size analysis based on the isotherms indicated that these samples consisting of a mesoporous distribution in the range of 2-
$6 \mathrm{~nm}$. Their subsequent application results indicated that the hollow MgFe-LDH microspheres exhibited to be most promising in electrocatalytic oxidation of ethanol in alkaline fuel cells, including high activity, enhanced long-term durability and cycling stability. The high performance of the hollow LDH is a result of significantly improved faradaic redox reaction and mass transport contributed by the high specific surface area and hollow and mesoporous structures. In another instance, Rodriguez et al. developed a bubble method to prepare porous MgAl-LDH by the intercalation and decomposition of hydrogen peroxide, in which oxygen nanobubbles were generated and subsequently pierced holes in the galleries of LDH (Figure 8b). ${ }^{243}$ The decomposition of the peroxide can be triggered by microwave radiation or chemically by reaction with iodide $\left(I^{-}\right)$ions. The presence of hydrogen peroxide in the interlayer space and its later decomposition triggered by microwave radiation generated pores in between LDH layers, increasing the specific surface area from $9 \mathrm{~m}^{2} / \mathrm{g}$ to a maximum value of $67 \mathrm{~m}^{2} / \mathrm{g}$. Different from the above strategies, Abushrenta and coworkers prepared a porous LDH by applying alkali to etch the pre-synthesized CoAl-LDH which grew on $\mathrm{Co}(\mathrm{OH})_{2}$ plates (Figure 8c). ${ }^{244}$ The porous structure of the CoAl-LDH significantly favored the ionic diffusion and charge transport, and provided a large contact area owing to its porous structure, leading to a high supercapacitor performance. Clearly, various approaches can be employed to prepare hollow and porous LDHs, and the fabrication of hollow and porous LDHs can usually dramatically improve various properties of LDH thanks to the unique hollow and porous structures, and high specific surface area. a

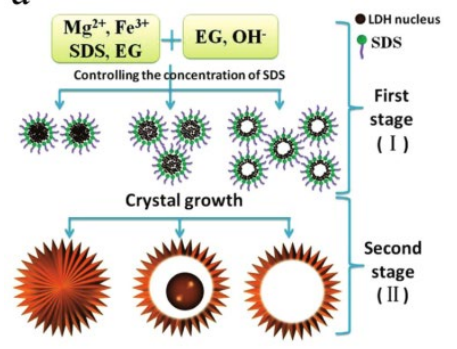

b

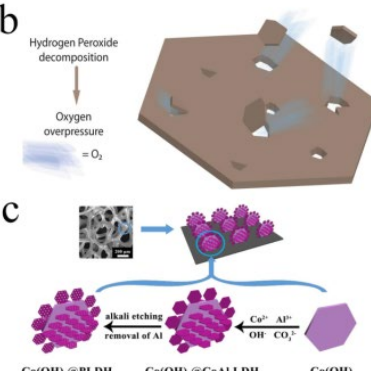

Figure 8. (a) Schematic of the morphological evolution processes of the asobtained hierarchical rosette MgFe-LDH microspheres: (I) formation of LDH precursor-SDS micelles; (II) formation of rosette microspheres with different inner architectures, ${ }^{237}$ Reproduced with permission from ref. ${ }^{237}$, Copyright 2013, WILEY-VCH Verlag GmbH \& Co. KGaA, Weinheim; (b) schematic of the micropore formation process in Mg-Al LDH by using the bubble method, ${ }^{243}$ Reproduced with permission from ref. ${ }^{243}$, Copyright 2017, Springer Nature; (c) schematic of the fabrication process of hierarchical porous CoAl-LDH arrays on $\mathrm{Co}(\mathrm{OH})_{2}$ by alkali etching of $\mathrm{Al}^{244}$ Reproduced with permission from ref. ${ }^{244}$, Copyright 2015 , Springer Nature

\subsection{Defect creation}

While defects are usually highly undesirable in most materials, researchers have sought to intentionally introduce defect sites into traditional LDHs as a means of activating LDHs. For example, it was reported that defect sites (e.g., oxygen vacancies) could decrease the barrier for the adsorption of reactants, and the surface defects would lead to the formation of coordinatively unsaturated metal centers which can serve as active sites and subsequently improve electronic conductivity. ${ }^{245}$ Previous reports also showed that, in the applications of catalysis and photocatalysis, abundant atomic defects in monolayer semiconductors could notably increase the mobility of surface 
electrons and thus significantly enhance catalytic performance. ${ }^{27}$ The formation of defects can usually increase the density of states near the Fermi level, which serve as active centers for catalysis. ${ }^{246}$ In addition, defects can also create new active sites for the adsorption of reactants and increase light absorption through narrowing of the bandgap, synergistically enhancing photocatalytic activity. Therefore, defects can tune the adsorption ability, electronic conductivity, and light absorption performance of LDHs, and create more active sites for LDHs.

The above merits of defects markedly advance the diverse performance of LDHs. For instance, to improve the efficiency of visible-light-driven photocatalytic dinitrogen fixation, Zhao et al. designed an ultrathin CuCr-LDH with a severely distorted structure. $^{219}$ The study showed that the ultrathin CuCr-LDH photocatalyst possessed a remarkable photocatalytic activity for the photoreduction of $\mathrm{N}_{2}$ to $\mathrm{NH}_{3}$ in water at $25^{\circ} \mathrm{C}$ under visiblelight irradiation. It was demonstrated that the CuCr-LDH nanosheets contained abundant oxygen vacancies that enhanced the adsorption and activation of $\mathrm{N}_{2}$ and $\mathrm{H}_{2} \mathrm{O}$, endowing the LDH nanosheets with an excellent photocatalytic activity for transforming $\mathrm{N}_{2}$ to $\mathrm{NH}_{3}$. It was also revealed that the introduction of $\mathrm{Cu}^{2+}$ ions in the $\mathrm{LDH}$ nanosheets imparted additional structural distortions and compressive strain, leading to an increased interaction between the $\mathrm{LDH}$ and $\mathrm{N}_{2}$, thereby promoting $\mathrm{NH}_{3}$ evolution. In another work, they introduced abundant oxygen defects onto ZnAl-LDH nanosheets by controlling the particle size of the nanosheets, and demonstrated that the created abundant oxygen vacancies on the ultrathin ZnAl-LDH nanosheets could serve as trapping sites for efficient adsorption of $\mathrm{CO}_{2}$ and $\mathrm{H}_{2} \mathrm{O}$ molecules, promoting the photo-induced charge separation and significantly improving the catalytic activity for $\mathrm{CO}_{2}$ reduction. ${ }^{215}$ In a report by Liu and coworkers, the defect-rich ultrathin CoFe-LDH nanosheets were proved to be highly effective in overall water splitting. ${ }^{245}$ The defects played a key role in the improvement of water splitting performance. Therefore, creation of defects is a theoretically and practically viable and promising approach to functionalize LDHs.

\section{Applications}

LDHs have found widespread application in the past few decades. After appropriate modification or functionalization LDHs can exhibit new and/or improved function, as briefly discussed in the above section. In the following section, we will discuss a designed functionalization may be performed to achieve a specific property enhancement. For example, because of their unique physiochemical properties, functionalized LDHs are particularly suitable for environmental, energy, catalysis, and biomaterial related applications.

\subsection{Environmental applications}

With rapidly growing industrial development worldwide, the need for a new class of functional materials and techniques for treating various contaminants (e.g., heavy metals, radionuclides, and organic contaminants) remains a major concern to protect the environment. LDHs and particularly functionalized LDHs are emerging as promising materials for environmental remediation, ${ }^{9}$, 247 especially in water systems. ${ }^{9,} 247,248$ Functionalized LDHs can not only provide physical but also chemical means to remove contaminants, which makes them far superior to other common materials such as activated carbons and silicates in environmental remediation. Functionalized LDHs can be used as both an adsorbent and a catalyst, which greatly exploit the physical and chemical properties of functionalized LDHs. When functionalized LDHs are used as an adsorbent, various features of the LDH (e.g., anion exchange ion or basic sites) provide active sites for many adsorbates. The facile manipulation of the adsorption sites (e.g., layer charge density, basic strength and density) by the aforementioned strategies as well as the morphology/pore structure at micron-nano scale offer a possibility to tune the active structure and adsorption kinetics for a specific adsorption process. ${ }^{9}$ Utilizing LDHs as a catalyst, various aspects of LDHs can be regulated to achieve a high catalytic activity for the degradation of contaminants, including the flexible tunability of the metal cations in the layers, the overall morphology and pore structure, the exchangeability of the intercalated anions in the interlayer space, the accessibility of the guest functional species after hybridization (such as conductive materials, semiconductors, and noble metals or rare earth elements), and the providential defect sites. ${ }^{9,} 248$ Herein, we will manly focus on the applications in the removal of heavy metal ions, radionuclide, and organic contaminants by functionalized LDHs.

\subsubsection{Heavy metals removal}

The presence of heavy metal ions (e.g., $\mathrm{Cu}^{2+}, \mathrm{Co}^{2+}, \mathrm{Cd}^{2+}, \mathrm{Ni}^{2+}$, $\mathrm{Zn}^{2+}, \mathrm{Pb}^{2+}, \mathrm{As}^{3+/ 5+}, \mathrm{Cr}^{3+/ 6+}$, and $\left.\mathrm{Hg}^{2+}\right)$ in our environment has raised worldwide health concerns. Heavy metals originate from wastewater and steams from a range of industries such as plastics, battery manufacturing, mining, paper, electroplating, fertilizer, and steel. ${ }^{247}, 249$ Many heavy metal-containing complexes bioaccumulate in living organisms thus ultimately causing a serious threat to human health. ${ }^{247}$ Therefore, the removal of heavy metals from environmental medium such as water remains a key subject of research. Previous studies suggested that functionalized LDHs exhibit very favorable adsorption to heavy metals as measured by high adsorption capacity and selectivity,2, 66, 76, 247, 250-252 which resulted in effective removal of toxic metals to meet increasingly strict environmental regulations. For example, Ma and coworkers found that the intercalation of $\mathrm{MoS}_{4}{ }^{2-}$ into $\mathrm{MgAl}-\mathrm{LDH}$ interlayer space could not only endow MgAl-LDH with the ability to adsorb various heavy metal ions $\left(\mathrm{Co}^{2+}, \mathrm{Ni}^{2+}, \mathrm{Zn}^{2+}, \mathrm{Cd}^{2+}, \mathrm{Pb}^{2+}, \mathrm{Cu}^{2+}, \mathrm{Hg}^{2+}\right.$, and $\mathrm{Ag}^{+}$) rapidly and effectively, but also offer high selectivity for some of these heavy metals. ${ }^{2,} 66$ The intercalation of $\mathrm{MoS}_{4}{ }^{2-}$ produces a 5-8 folds increase of the heavy metal cations capture capacity of the MgAl-LDH compared to that of the nonfunctionalized MgAl-LDH. Recently, Asiabi and coworkers have indicated that the intercalation of functional species into the interlayer space of LDH could endow LDH with a highly selectivity and efficient removal of heavy metals, and the properties (e.g., functional groups) of the intercalants played a key role in the adsorption process. ${ }^{76,251}$

Apart from the functionalized LDHs produced by intercalation, various other types of functionalized LDHs were also showed to be highly effective in heavy metal removal, such as the LDH hybridized with carbon materials, ${ }^{253-255} 3 \mathrm{D}$ LDHs, ${ }^{213}, 255$ core-shell LDHs, ${ }^{256}$ and ultrathin LDHs. ${ }^{257}$ The main factors contributing to the favorable adsorption of heavy metals by the functionalized LDHs include high specific surface area and porosity, unique nanostructure, and the specific functions of the guest species hybridized with $\mathrm{LDH}{ }^{2}{ }^{2,66,213,250,254,255}$

\subsubsection{Radionuclide capture}


Nuclear energy generation is considered to be an important component of an economical and sustainable energy generation strategy. However, the development of improved nuclear energy generation approaches involves developing effective management protocols for the radioactive waste at each part nuclear fuel cycle. ${ }^{258}$ Radioactive nuclides are some of the dangerous contaminants in the environment because of their long half-life, high radioactivity, and biological toxicity. ${ }^{258}$ In recent years, functionalized LDHs have been demonstrated to be potential candidates to remove or immobilize radioactive contaminants (e.g., $\mathrm{U}(\mathrm{VI}),{ }^{129}$, ${ }^{99} \mathrm{Tc}$, and ${ }^{79} \mathrm{Se}$ ) from environmental media. 3 ,66, 259267

Functionalized LDHs can remove or immobilize radioactive contaminants mainly through surface adsorption and/or interlayer anion exchange. ${ }^{267}$ Surface adsorption involves the attachment of a nuclide onto the surfaces of the LDHs or onto the sites of the guest species used to functionalize LDHs, forming a stable molecular or atomic film on the top of the LDH material or an aggregation on the guest species zones. In the surface adsorption process, the adsorption of radionuclide can be induced by the nature of the LDH or the guest species on LDH. The interlayer anion-exchange process involves the exchange of interlayer anions with the targeted nuclide anions and is mainly influenced by the nature of the charge balancing anions in the interlayer space, the layer charge density, and the interlayer distance. ${ }^{3,} 267 \mathrm{Ma}$ and coworkers demonstrated that the intercalation of polysulfide into the galleries of MgAl-LDH provided MgAl-LDH a merit of highly selective and efficient capture of radionuclide $\left(\mathrm{UO}_{2}{ }^{2+}\right) .^{3}$ The polysulfide functionalized LDH showed a high removal capacity $\left(q_{\mathrm{m}}\right.$ $=330 \mathrm{mg} / \mathrm{g})$, large adsorption coeffcient values $\left(10^{4}-10^{6} \mathrm{~mL} / \mathrm{g}\right.$ at $1-$ $300 \mathrm{ppm} U$ concentration), and high removal rates ( $>95 \%$ at $1-100$ $\mathrm{ppm}$, or $\sim 80 \%$ for ppb level seawater) for $\mathrm{UO}_{2}{ }^{2+}$. Their results indicated that under low $U$ concentrations, the functional unit $\left(\mathrm{S}_{4}\right)^{2-}$ coordinated to $\mathrm{UO}_{2}{ }^{2+}$ forming anionic complexes that were retained in the LDH interlayer space, while at high $U$ concentrations, $\left(\mathrm{S}_{4}\right)^{2-}$ binds to $\mathrm{UO}_{2}{ }^{2+}$ to generate neutral $\mathrm{UO}_{2} \mathrm{~S}_{4}$ salts outside the interlayer space. In this example, the immobilization of $U$ on LDH mainly exploits the specific functions of polysulfide. In a further study, Ma and coworkers, intercalated $\mathrm{MoS}_{4}{ }^{2-}$ in $\mathrm{MgAl}-\mathrm{LDH}$ and used it to remove ${ }^{79} \mathrm{Se}\left(\mathrm{SeO}_{4}{ }^{2-}\right.$, and $\mathrm{SeO}_{3}{ }^{2-} / \mathrm{HSeO}_{3}{ }^{-}$). The removal of ${ }^{79} \mathrm{Se}$ preceeded by an interlayer anion-exchange process. ${ }^{66}$ Importantly, the $\mathrm{MoS}_{4}{ }^{2-}$ intercalated MgAl-LDH presented a super high adsorption capacity for $\mathrm{SeO}_{3}{ }^{2-}$ $/ \mathrm{HSeO}_{3}{ }^{-}$reaching $294 \mathrm{mg} / \mathrm{g}$. This adsorption capacity for $\mathrm{SeO}_{3}{ }^{2-}$ $/ \mathrm{HSeO}_{3}{ }^{-}$reached a record value, placing the $\mathrm{MoS}_{4}{ }^{2-}$ intercalated MgAl-LDH amongst the highest-capacity selenite adsorbing materials reported to date. Many other types of functionalized LDHs exhibit impressive performance in the capture of radionuclides, such as core-shell-type $\mathrm{LDHs},{ }^{259} 3 \mathrm{D} \mathrm{LDHs},{ }^{260} \mathrm{LDHs}$ hybridized with carbon or carbon related materials. ${ }^{262,265}$

\subsubsection{Water-soluble organic contaminant removal}

During recent years, functionalized LDHs are increasingly investigated for the remediation of various toxic organic contaminants from wastewater due to their high surface area, outstanding anion-exchange capability, tunability and low toxicity. ${ }^{247}$ Their high surface area and outstanding anion-exchange capacity (AEC, e.g., $272.9 \mathrm{mmol} / 100 \mathrm{~g}$ of $\mathrm{AEC}$ for $\mathrm{Mg}_{4} \mathrm{Al}-\mathrm{LDH}^{56}$ ) make them promising candidates as adsorbents for organic contaminants such as various dyes. ${ }^{247}$ The ease in tuning the components including layered metal compositions and the guest species, e.g., semiconductors, noble metals and rare metal elements, hybridized on LDH enables LDHs to be excellent catalysts to degrade organic contaminants. ${ }^{9,10}$ As such, functionalized LDHs remove organic contaminants mainly via adsorption or catalytic degradation. For example, Zhang et al. functionalized MgAl-LDH by hybridizing surface passivated carbon dots containing abundant oxygen-containing functional groups $(-\mathrm{OH},-\mathrm{COOH}$, and $-\mathrm{C}=\mathrm{O})$ onto the surface of the LDH. ${ }^{268}$ Taking advantage of the combined benefits of the $\mathrm{LDH}$ and the carbon dots, the as-prepared hybrids exhibited high uptake of anionic dye methyl blue $(185 \mathrm{mg} / \mathrm{g})$. The authors proposed that the cooperative contributions of hydrogen bonding between methyl blue and carbon dots, as well as the electrostatic attraction between methyl blue and LDH led to the high performance for dye removal (Figure 9a). The high adsorption performance of functionalized LDHs as adsorbents for organic contaminants has also been well demonstrated by many other researches. ${ }^{247,}$ 269-271
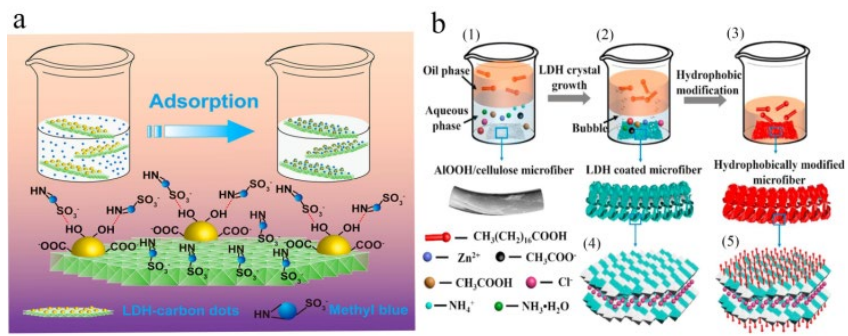

Figure 9. (a) Schematic of methyl blue adsorption onto LDH-carbon dot hybrids, ${ }^{268}$ Reproduced with permission from ref. ${ }^{268}$, Copyright 2014, American Chemical Society; (b) schematic of the preparation of superhydrophobic cellulose/ZnAl-LDH membrane in an open oil/water twophase system, ${ }^{272}$ Reproduced with permission from ref. ${ }^{272}$, Copyright 2017, Elsevier

Besides their high performance in adsorption, various functionalized LDHs possess the ability to remove organic contaminants by catalytic degradation. The LDHs containing transition metals are semiconductors with the potential for photocatalytic environmental catalysts. Furthermore, specific guest species hybridized on LDH further improve catalytic performance in the degradation of organic contaminants. For example, Zhu and coworkers synthesized a semiconducting $\mathrm{ZnTi}$ $\mathrm{LDH}$, and subsequently functionalized it by surface hybridization with $\mathrm{C}_{60 .}{ }^{8}$ Taking the advantages of the hybridization in promoting the electron-hole separation efficiency and enhancing the visiblelight response, the functionalized LDH exhibited a significantly higher efficiency for the photocatalytic degradation of organic dyes compared the pristine LDH in the. Other types of functionalized $\mathrm{LDHs}$, such as semiconductors hybridized $\mathrm{LDHs}^{273}$ intercalated $\mathrm{LDHs}^{274}$ and noble metal and rare earth element hybridized $\mathrm{LDHs},{ }^{178}$ have also been reported to exhibited high performance in the degradation of organic contaminants.

\subsection{Oil pollution elimination}

The removal of oil pollutants from water is frequently required either due to oil spill accidents, or from industrial wastewater. To achieve oil removal from water, superhydrophobic and superoleophilic materials are commonly adopted. ${ }^{275-280}$ Functionalized LDHs have been shown to offer novel opportunities as adsorbents for oil pollution remediation. ${ }^{272,281,282}$ An LDH surface is inherently hydrophilic due to the abundant surface hydroxyl groups. However, the surface of LDHs can be easily modified using a wide scope of functionalization strategies as 
discussed in Section 2. For example, the incorporation of specific organic species on an LDH surface can endow LDHs with hydrophobic properties.281 For example, Yue and coworkers developed a simple and effective strategy to fabricate a superhydrophobic cellulose/ZnAl-LDH membrane in an open oil/water two-phase system, which perfectly integrated the processes of hydrothermal reaction and hydrophobic modification (Figure 9b). ${ }^{272}$ In this reaction system, the two dominant factors to achieve superhydrophobicity, i.e., surface roughness and low surface energy, could be accomplished simultaneously by taking advantage of crystal growth in the aqueous phase and hydrophobic modification in the oil phase. Such membranes exhibited effective separation of multiple types of oil/water mixtures, as well as excellent recyclability and exhibiting stable superhydrophobicity under harsh conditions, making them promising candidates for oily water remediation. Deploying organic surface modifiers to surface-modify LDHs for oil pollution purification has been demonstrated to be a practicable and promising approach. ${ }^{281,282}$

\subsection{Energy related applications}

New energy storage and conversion technologies including hydrogen storage, supercapacitors, batteries, and solar cells have attracted tremendous attention over few decades because of the ever-increasing demand for clean and sustainable energy systems. ${ }^{11}{ }^{14}, 283-285$ Hydrogen is a clean, efficient and renewable energy carrier; it has a high energy density and is environmentally friendly, so it is an ideal alternative to fossil fuels. ${ }^{14}$ Water splitting by electrochemical or photochemical procedures is an environmentally benign and economic route to generate $\mathrm{H}_{2}$ on a large scale. Currently, considerable efforts are being devoted to fabricating robust catalysts and storage media for $\mathrm{H}_{2}$ production and storage, respectively. With respect to other energy storage systems, supercapacitors which are also referred to as electrochemical capacitors, store energy using either ion adsorption (electrochemical double layer capacitors) or fast surface redox reactions (pseudo-capacitors), enabling a rapid charge/discharge process but storing a limited amount of energy. In contrast, batteries release energy via electrochemical reactions in which ions diffuse between electrodes upon discharging. Diffusion is a slow process, but the capacity for energy storage exceeds that of supercapacitors. With regards to solar cells, the energy conversion mechanism is a light-to-electricity conversion process, with the efficiency of solar energy conversion one the main current challenges. Improving the generation and storage efficiencies of $\mathrm{H}_{2}$, energy density of capacitors, power density of batteries, and the quantum efficiency of solar cells are of great interest and necessity. Herein, we give a concise introduction of the contribution of functionalized LDHs in energy field.

\subsubsection{Hydrogen generation}

Nowadays, hydrogen is widely used in chemical processing, petroleum industry, fats and oils, metals, electronics, space exploration, utilities, and glass manufacturing. ${ }^{286,287} \mathrm{Hydrogen}$ has the highest energy content by weight of $33,320 \mathrm{Wh} \mathrm{kg}^{-1}$, which is about 3 and 7 times more than gasoline $\left(12,700 \mathrm{Wh} \mathrm{kg}^{-1}\right)$ and natural gas/coal $\left(13,900 \mathrm{Wh} \mathrm{kg}^{-1}\right)$, respectively. ${ }^{288}$ Its high energy density and environmental friendliness make it an ideal alternative to fossil fuels. The development of more efficient electrochemical or photochemical methodologies to split water into $\mathrm{H}_{2}$ and $\mathrm{O}_{2}$ is one of the grand challenges of modern chemistry. ${ }^{289}$ This requires the development of highly active, low-cost electrocatalysts and photocatalysts with superior durability for both the oxygen evolution reaction (OER) and hydrogen evolution reaction (HER). As summarized in Section 2 and Tables 1-6, various functionalized LDHs have been shown to exhibit excellent charge transfer performance and high catalytic activities for water splitting. LDHs are relatively inexpensive to prepare commercially and since the layered structure significantly favors the diffusion of water molecules and fast release of gaseous products. ${ }^{14}$ The exploration of functionalized LDHs as catalysts for hydrogen generation has been explored.

LDHs can be employed as robust electrocatalysts for water splitting. LDHs are commonly considered as OER catalysts, i.e., $\mathrm{LDHs}$ are $\mathrm{OH}$-acceptors and robust catalysts for oxygen generation. ${ }^{290} \mathrm{Co}^{2+/ 3+_{-}}, \mathrm{Fe}^{3+-}$, and $\mathrm{Ni}^{2+}-$ based $\mathrm{LDH}$ materials can effectively adsorb hydroxyl species and catalyze their dissociation, are well-known as an emerging family of efficient electrocatalysts for oxygen evolution in alkaline media. ${ }^{159}$ Unfortunately, the HER kinetics is disappointingly sluggish in basic solutions, and the HER activity in a base is usually 2 or 3 orders lower than that in an acidic solution. ${ }^{159}$ In addition, LDHs are unstable in acidic media. To improve the HER activity of LDHs in a basic medium, functionalizing them through specific treatments such as anchoring an $\mathrm{H}$-acceptor on their surface and fabrication of unique structures, has been developed. For instance, $\mathrm{Hu}$ and coworkers hybridized $\mathrm{MoS}_{2}$, a strong $\mathrm{H}$-acceptor, on the robust OER catalyst of NiCo-LDH, and demonstrated that the hybridization endowed with a dramatic enhancement of the HER kinetics in alkaline media. ${ }^{159}$ The functionalized NiCo-LDH exhibited an extremely low HER overpotential of $78 \mathrm{mV}$ at $10 \mathrm{~mA} / \mathrm{cm}^{2}$ and a low Tafel slope of $76.6 \mathrm{mV} / \mathrm{dec}$ in $1 \mathrm{M} \mathrm{KOH}$ solution. At a current density of 20 $\mathrm{mA} / \mathrm{cm}^{2}$ or even higher, the $\mathrm{MoS}_{2} / \mathrm{NiCo}-\mathrm{LDH}$ hybrid could operate without degradation for $48 \mathrm{hr}$. This work offers us new opportunities for developing high-performance catalysts in new media. Unlike the strategy of hybridizing $\mathrm{H}$-acceptor onto an LDH, $\mathrm{Yu}$ et al. found that the construction of unique 3D core-shell structures could enhance the HER performance of LDHs. ${ }^{14}$ They fabricated a 3D core-shell LDH by growing only a few-layers of NiFe-LDH on a Cu nanowire cores supported on Cu foams (Figure 10a). Remarkably, benefiting from this $3 D$ hierarchical nanoarchitecture with a large surface area, fast electron transport, and open-channels for effective gas release, the resulting 3D selfstanding catalyst exhibited an outstanding OER activity as well as an excellent HER performance in an alkaline medium. Using it as a bifunctional catalyst for overall water splitting, a current density of $10 \mathrm{~mA} \mathrm{~cm}^{-2}$ was achieved at a voltage of $1.54 \mathrm{~V}$, and $100 \mathrm{~mA} \mathrm{~cm}-2$ at $1.69 \mathrm{~V}$ with excellent durability, which is much higher than the benchmark of $\mathrm{IrO}_{2}(+) / / \mathrm{Pt}(-)$ electrodes. Other strategies, such as producing numerous active exposed edges (e.g., by size refinement) and more accessible active sites, and hybridizing conductive materials to promote charge transfer also showed benefits in enhancing HER performance of LDHs. ${ }^{169,} 291$ 
a

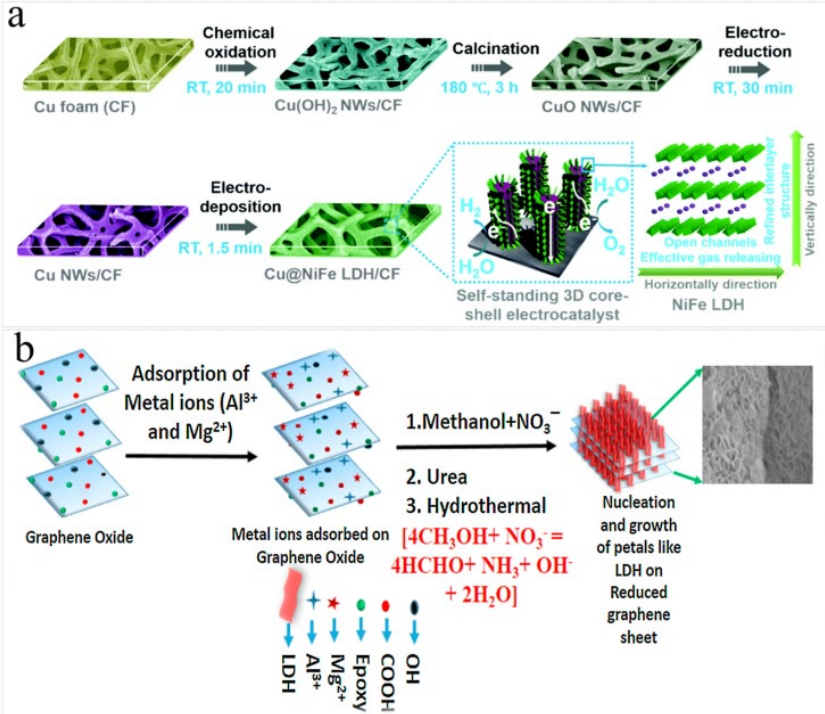

Figure 10. (a) Schematic of the fabrication procedures of the self-standing 3D core-shell Cu@NiFe-LDH electrocatalysts (RT: room temperature), ${ }^{14}$ Reproduced with permission from ref. ${ }^{14}$, Copyright 2017, The Royal Society of Chemistry; (b) schematic of formation of reduced graphene oxide intercalated LDH. ${ }^{292}$ Reproduced with permission from ref. ${ }^{292}$, Copyright 2016, Elsevier

Functionalized LDHs also exhibit very promising photocatalysis under visible light irradiation for $\mathrm{H}_{2}$ generation. Wang and coworkers designed and fabricated a $\mathrm{Cu}_{2} \mathrm{O} @ \mathrm{ZnCr}-\mathrm{LDH}$ core-shell photocatalyst which delivered a high performance in visible-light driven water splitting. ${ }^{98}$ The $\mathrm{Cu}_{2} \mathrm{O} @ \mathrm{ZnCr}-\mathrm{LDH}$ nanostructure exhibited a high activity (with $\mathrm{H}_{2}$ and $\mathrm{O}_{2}$ production rate of 0.90 and $0.44 \mu \mathrm{mol} \mathrm{h} \mathrm{h}^{-1}$, respectively) under visible-light without any sacrificial agent and co-catalyst, which is among the highest level of the reported photocatalysts under the same conditions. Both experimental and computational investigations demonstrated that the $\mathrm{Cu}_{2} \mathrm{O} @ \mathrm{ZnCr}-\mathrm{LDH}$ heterostructure fully exploited the synergistic effect of $\mathrm{Cu}_{2} \mathrm{O}$ and $\mathrm{ZnCr}$ - $\mathrm{LDH}$ in terms of band structure matching. More examples of functionalized LDHs as photocatalysts for $\mathrm{H}_{2}$ generation can be found in Tables 1-6.

\subsubsection{Supercapacitors}

Supercapacitors are an important class of electrochemical energy storage device, they possess the characteristics of high power density, fast charge/discharge rate, excellent cycling life, low cost, and safe operational conditions. ${ }^{293-296}$ However, they present a low energy density, limiting the optimal discharge time to less than a minute, whereas many applications clearly require more. ${ }^{293}, 297,298$ Therefore, one of the challenges posed for supercapacitors is to increase energy density without compromising power density, or, alternatively, to achieve a proper balance between the two. A notable improvement in the performance of supercapacitors has been achieved through advances in the understanding of charge storage mechanisms (such as the ion behavior in small pores) and the development of advanced materials. ${ }^{293}$ According to the surface charge-storage mechanism, two key factors; surface area and electrical conductivity, affect the performance of electrode materials in a supercapacitor. ${ }^{293,} 299$ Given that, numerous efforts have been devoted to exploring advanced electrode materials. Functionalized LDHs have demonstrated to be effective electrode materials in supercapacitor applications owing to their unique structural and electrochemical properties. ${ }^{80,95,99,106,111,113, ~ 292, ~} 300$

As a typical example, Hatui and coworkers functionalized MgAl-LDH by hybridizing it with reduced graphene oxide (RGO) (Figure 10b), and the hybridization endowed the resultant material (named as RGO-MgAl-LDH) with prominent supercapacitor performances, achieving a specific capacitance up to $1334 \mathrm{Fg}^{-1}$ at a current density of $1 \mathrm{Ag}^{-1}$ in a three-electrode cell set up under $1 \mathrm{M}$ aqueous $\mathrm{KOH}$, and $1092.5 \mathrm{Fg}^{-1}$ at a current density of $2 \mathrm{Ag}^{-1}$ in a two-electrode configuration with $1 \mathrm{M}$ tetraethyl-ammonium tetrafluoroborate $\left(\mathrm{TEABF}_{4}\right)$ as electrolyte. ${ }^{292} \mathrm{RGO}-\mathrm{MgAl}-\mathrm{LDH}$ also exhibited a high cyclic stability at a steady current density of $5 \mathrm{Ag}^{-1}$ in a two electrode organic electrolyte system with $87 \%$ retention of specific capacitance after 10000 consecutive charge-discharge cycles. This RGO functionalized LDH demonstrated both high energy and power density, at $388.26 \mathrm{WhKg}^{-1}$ (at a current density of $2 \mathrm{Ag}^{-1}$ ) and $3198.48 \mathrm{WKg}^{-1}$ respectively, in a two-electrode organic electrolyte configuration. The high performance of RGO$\mathrm{MgAl}-\mathrm{LDH}$ in the supercapacitor is ascribed to the large increase in surface area (from 288.3 for the neat LDH to $714.5 \mathrm{~m}^{2} / \mathrm{g}$ for RGOMgAl-LDH), as well as to its unique sandwich-like structure. Such a large enhancement of the surface area allows facile electrolyte accessibility at the interior of the hybrid and significantly shortens ionic transport pathways, facilitating and delivering high capacitance as a result. Concurrently, the sandwich-like structure restricts the restacking of graphene nanosheets and hence improves the accessibility of electrolyte into the interior of the hybrid, making it a more effective electrode material. Yang et al. functionalized NiCoAl-LDH by coupling with NiCo-carbonate hydroxide (NiCo-CH) nanowires, and applied this nanohybrid as the positive electrode for an asymmetric supercapacitor. ${ }^{300}$ The supercapacitor possesses a high energy density of $58.9 \mathrm{Wh} \cdot \mathrm{kg}^{-1}$ at a power density of $0.4 \mathrm{~kW} \cdot \mathrm{kg}^{-1}$, which is based on the total mass of the active materials at a voltage of $1.6 \mathrm{~V}$. An energy density of $14.9 \mathrm{Wh} \cdot \mathrm{kg}^{-1}$ can be retained even at a high power density of 51.5 $\mathrm{kW} \cdot \mathrm{kg}^{-1}$. These results are much better than many other common supercapacitors as shown by the authors. Furthermore, the supercapacitor also exhibits an excellent long cycle life, whereby a specific capacitance of $97 \%$ is retained even after 10,000 cycles. The high performance is ascribed to the fact that the nanowire-like $\mathrm{NiCo}-\mathrm{CH}$ species in the NiCoAl-LDH nanoplate matrix function as a scaffold and support the dispersion of the NiCoAl-LDH nanoplates, resulting in a relatively loose and open structure within the electrode matrix (Figure 11). Various other types of functionalized LDHs, such as intercalated LDH, core-shell structured LDH, and hybridized LDH, also present notable supercapacitor performances with a high specific capacity, stability, and energy and power density, as evidenced by the many examples summarized in Tables 1-6.

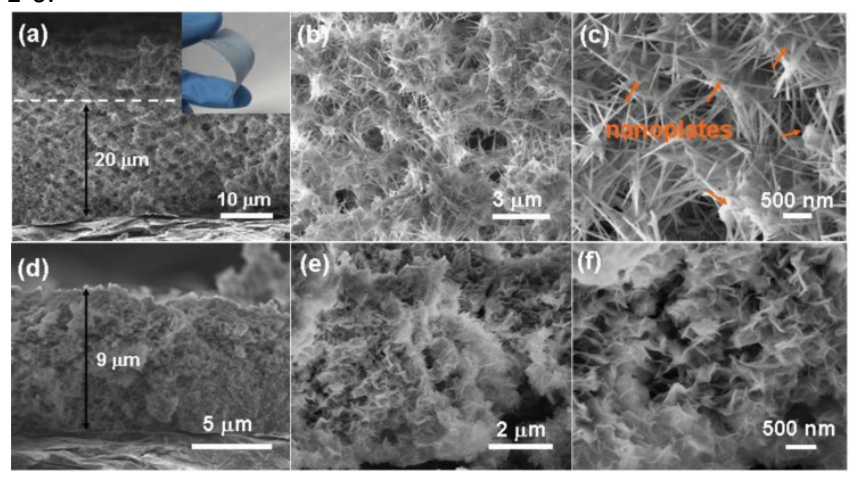

Figure 11. Representative FE-SEM images of the nanohybrids of NiCoAl$\mathrm{LDH}$ and $\mathrm{NiCo}-\mathrm{CH}$ grown at different $\mathrm{Co}^{2+}$ concentrations: $\mathrm{a}-\mathrm{C}$ ) cross-section 
of the as-obtained sample with a $\mathrm{Co} / \mathrm{Ni}$ molar ratio of $1: 1 ; \mathrm{d}-\mathrm{f}$ ) crosssection of the as-obtained sample with a $\mathrm{Co} / \mathrm{Ni}$ molar ratio of 1:3. Reproduced with permission from ref. ${ }^{300}$, Copyright 2014, WILEY-VCH Verlag $\mathrm{GmbH} \&$ Co. KGaA, Weinheim

\subsubsection{Batteries}

Rechargeable batteries, an important class of energy storage device which includes the Li-ion batteries (LIBS), Li-S batteries, metal-oxygen/air batteries, have drawn particular attention. ${ }^{301-303}$ Among these batteries, metal-oxygen/air batteries and Li-S batteries have been considered as promising candidates for the next-generation electro-chemical energy-storage technologies because of their overwhelming advantages in energy density. ${ }^{304-307}$ For example, the theoretical energy density of $\mathrm{Li}^{-\mathrm{O}_{2}}$ (aq) is 3582 Wh kg-1 and for the $\mathrm{Zn}$-air system, the value is still remarkably high at $1086 \mathrm{Wh} \mathrm{kg}^{-1}{ }^{306}$ For metal-oxygen/air batteries, their working principle is that during discharge, oxygen is reduced to hydroxide ions. This reaction is called the oxygen reduction reaction (ORR). During charging, oxygen is formed. This reaction is called the oxygen evolution reaction (OER). Unfortunately, one of the greatest challenges for these types of batteries is the high overpotential at the oxygen/air-cathode, i.e., at the so called gas diffusion electrode, which occurs with both the ORR and the OER. ${ }^{306}$ To reduce the overpotential for the OER and the ORR, respectively, new generation catalysts are needed. As for Li-S batteries, some valuable characteristics of sulfur, such as its high natural abundance, low cost, and nontoxicity, make Li-S batteries even more commercially competitive than the current LIBs. ${ }^{308,309}$ However, practical applications of the rechargeable Li-S batteries are still hindered by a multitude of issues, including low utilization of the active material, short cycle life, fast self-discharge, and poor Columbic efficiency. ${ }^{307,310,311}$ The performance of rechargeable batteries is significantly affected by the properties of the electrode materials. Thus, screening for novel electrode materials with novel structures and surface properties and the optimization of highperformance materials are areas of immense significance to the improvement of rechargeable battery performance.

Functionalized LDHs are potential candidates to the fabrication of metal-oxygen/air batteries ${ }^{304-306}$ and Li-S batteries ${ }^{307}$ with notable strengths, particularly low OER and ORR overpotential for metal-oxygen/air batteries and high stability and high utilization of the active sites for Li-S batteries. For example, Wang and coworkers have prepared a bifunctional electrocatalyst by hybridizing $\mathrm{Co}^{2+}, \mathrm{N}$-doped carbon nanoframes (Co, N-CNF) with $\mathrm{NiFe}-\mathrm{LDH}$, and found that the resultant material displayed a low OER overpotential of $0.312 \mathrm{~V}$ at $10 \mathrm{~mA} \mathrm{~cm}^{-2}$ and an ORR half-wave potential of $0.790 \mathrm{~V}^{304}$ The outstanding performance of the electrocatalyst was attributed to the high electrical conductivity and excellent ORR activity, contributing from the combination of Co, N-CNF and NiFe-LDH. Owing to the excellent OER and ORR performance, the resultant material could be used to fabricate high-performance $\mathrm{Zn}$-air battery which exhibited a low dischargecharge voltage gap $\left(1.0 \mathrm{~V}\right.$ at $\left.25 \mathrm{~mA} \mathrm{~cm}{ }^{-2}\right)$, long-term cycling durability (over $80 \mathrm{~h}$ ), and superior overall performance to a counterpart battery constructed using a mixture of $\mathrm{IrO}_{2}$ and $\mathrm{Pt} / \mathrm{C}$ as the cathode. When hybridized with nickel foam, NiFe-LDH showed an even lower OER overpotential (ultralow as $0.21 \mathrm{~V}$ at 10 $\mathrm{mA} \mathrm{cm}^{-2}$ ), as indicated by Yan and coworkers. ${ }^{305}$ A nickel foam functionalized NiFe-LDH exhibited attractive performance in $\mathrm{Zn}$ oxygen battery with an outstanding stability of over 100 charge/discharge cycles. These reports suggest that rationally- designed functionalized LDHs offer opportunities as active materials for the fabrication of metal-oxygen/air batteries with advantages such as ultralow overpotential and high stability. In addition, Zhang et al. showed that functionalized LDHs displayed remarkable performance in Li-S batteries. ${ }^{307}$ In their study a coreshell-type NiCo-LDH with $\mathrm{Co}(\mathrm{OH})_{2}$ as the inner shell and NiCo-LDH as the outer shell was fabricated and used in Li-S battery. Specifically, the hollow $\mathrm{Co}(\mathrm{OH})_{2} @ N i C o-L D H$ with a complex shell structure not only maximized the advantages of hollow nanostructures for encapsulating a high content of sulfur (75 wt\%), but also provided sufficient self-functionalized surfaces for chemically bonding with polysulfides to suppress their outward dissolution. When evaluated as the cathode material for Li-S batteries, the $\mathrm{Co}(\mathrm{OH})_{2} @ \mathrm{NiCo}-\mathrm{LDH} /$ sulfur cathode was able to maintain excellent cycling stability at both 0.1 and $0.5 \mathrm{C}$ over 100 cycles, and delivered high-rate capacities with relatively high sulfur loading of $3 \mathrm{mg} \mathrm{cm}$. Therefore, functionalized LDHs with rationally designed components and structures also show promise in the construction of Li-S batteries with a high stability and the utilization of active sites.

In addition to metal-oxygen/air batteries and Li-S batteries, various studies ${ }^{159,}, 312-315$ also indicate that functionalized LDHs are of great potential in the construction of $\mathrm{Zn}-\mathrm{Ni}$ secondary batteries.

\subsubsection{Solar cells}

Exploitation of solar energy is an essential component of the renewable energy strategy of the next generation society. There have already been fantastic developments in the cost effectiveness of electricity generation by solar photovoltaic technology. Developments in dye-sensitized solar cells (DSSCs) offer the promise of large quantum efficiency gains and low-cost compared to conventional inorganic photovoltaic devices. However, the present DSSCs still show some severe drawbacks. For example, the liquid electrolyte normally used for the preparation of DSSC devices poses several technical problems such as solvent evaporation, leakage of volatile solvent, and environmental toxicity, and the organic dyes have a relatively low heat stability and narrow absorption bands. ${ }^{316,317}$ To address the drawbacks of liquid electrolyte, methods have been developed such as adding functional materials into the electrolyte to obtain a quasi-solid electrolyte. LDH materials are found to be a highly effective additive for electrolytes. According to Wang et al., LDHs are capable of solidifying the electrolyte against leakage and increasing the solar cell efficiency. ${ }^{318}$ After being modified, LDHs even exhibited enhanced functions. For instance, Bastianini and coworkers found that when high iodide intercalated ZnAl-LDH was added to the electrolyte it had positive effect on the power conversion efficiency of the DSSC compared to the low iodide intercalated and the pristine LDH. ${ }^{316}$ In another example, Du et al. found that stearic intercalated MgAl-LDH could be used as an electrolyte additive to enhance the solar energy conversion efficiency of the fabricated DSSC by $2.17 \% .^{319}$

To address the drawbacks of the relatively low heat stability and narrow absorption bands of the organic dyes, one possible approach is to hybridize them with multi-functional and environmentally friendly inorganic materials such as LDHs, which can provide a stable chemical environment, increase heat or photostability, and improve the inherent light-harvesting ability of the organic dyes. ${ }^{317}$ For example, Lee and coworkers intercalated a light sensitive organic dye (anthraquinone sulfonate anion) into the interlayer space of MgAl-LDH, and subsequently used the 
intercalated LDH as the light sensitizer for DSSC. ${ }^{317}$ The resultant hybrid showed a conspicuous photochromic property under irradiation, and this hybrid sensitized cell showed improved conversion efficiency up to $160 \%$ of the initial value from the anthraquinone sulfonate anion-sensitized cell.

\subsection{Catalysis}

LDH-based nanomaterials have found extensive applications in catalysis because of their intrinsic structural traits and intriguing electronic properties. ${ }^{11,248,320}$ Examples of catalytic applications in environmental and energy related fields (see sections 3.1.3 and 3.2.1) have been discussed above. LDH-based materials have also been applied as catalysts (e.g., photocatalysts, Fenton catalysts, electrocatalysts, etc.) in many other fields, such as $\mathrm{CO}_{2}$ reduction and oxygen evolution. ${ }^{10}, 299$ Rather than introducing various catalytic applications of LDH-based materials, we focus on how to functionalize LDH catalysts herein. The key to functionalizing LDH catalysts is to address their poor electronic conductivity and limited active sites. Various aspects of LDHs can be regulated to achieve a high catalytic activity, including flexible regulation of the metal cations in the layers, overall morphology and pore structure, exchangeability of the intercalated anions in the interlayer space, availability of the interlayer space, accessibility of the functional species after hybridization (such as conductive materials, semiconductors, and noble metals or rare earth elements), and providential defect sites as suggested by Section 2. In summary, functionalization of LDH catalysts can be achieved via the modification of inner surface (interlayer), outer surface, and/or layers of LDHs.

Intercalating functional species into the interlayers of LDHs is one commonly used method to functionalize LDHs by addressing the issues of low electrical conductivity and low availability of the interlayer space. Various studies have demonstrated that catalytic activities of LDHs can be enhanced by introducing guest species into their interlayers. ${ }^{321-324}$ For example, Long and coworkers intercalated graphene into the interlayers of NiFe-LDH to promote electron transport, which resulted in superior electrocatalytic properties of the resultant NiFe-LDH-graphene hybrids for oxygen evolution reaction with an overpotential as low as $210 \mathrm{mV}$. 324 Besides the strategy of intercalation of conductive materials, Li et al. found that the intercalation of formamide to expand the interlayer space of NiFe-LDH could promote the charge transfer of NiFe-LDH. ${ }^{322}$ This is because the expanded interlayer provided more space for diffusion of the reactants, while more inner active sites could be available for reactions. Intercalation can also modify the surface electronic structure, improve electronic conductivity, and create more active sites for LDHs. These findings map out a promising strategy for further improving the activities of LDH catalysts by intercalating various guest species. But note that when intercalating functional species other than conductive materials as active sites, one should consider the space availability of the intercalated species, because the resultant narrow interlayer space may prevent the reactants from entering into the interlayer.

Functionalization via modification of outer surface can be achieved by hybridizing with conductive materials, semiconductors, noble metals/rare earth elements, or other functional species (see Section 2). But several aspects should be considered including but not limited to (i) size, morphology, and pore structure of the LDH-based catalysts. The decrease in size of the hybridized species, thickness and diversification of morphologies of LDHs, and the increase of porosity and specific surface area have significant impacts on the available active sites (including defect sites) and thus the electronic and catalytic properties of the LDH-based catalysts; ${ }^{213-216,219,245}$ (ii) matching of the band structures of LDHs and the hybridized semiconductor when fabrication of heterojunctions. The perfect matching of the band structures can remarkably facilitate the transfer of photogenerated electron-hole pairs during the course of photocatalysis. As a result, the lifetime of electrons and holes is increased and the utilization of photogenic electrons and holes are effectively enhanced; 248,325 (iii) high dispersion and high stability of active sites such as noble metals or rare earth elements. It is suggested that ordered distribution of the hybridized foreign species is important in optimizing photocatalytic activity of LDHs, and the chemical stability can also be significantly improved owing to the ordered structure between the LDH and the foreign species. ${ }^{31} \mathrm{He}$ et al. summarized this as the preferential orientation and dispersion issue of the active sites. ${ }^{320}$ On the other hand, LDH catalysts can also be activated by modifying their layers. The most important characteristic of $\mathrm{LDHs}$ is that $\mathrm{M}^{+1 / 2+}$ and $\mathrm{M}^{\prime 3+/ 4+}$ cations are distributed uniformly within the hydroxide layers. ${ }^{326}$ By replacing the existing metal cations with more active metal elements and decreasing or reducing/oxidizing the existing metal cations, catalysts with a high activity and highly dispersive active sites can be produced. ${ }^{26,114,187-189}$ In addition, active defect sites can also be introduced by these strategies. ${ }^{26}$

\subsection{Biomaterials}

There are extensive studies which indicate that 2D materials merit close attention in biomaterial applications, particularly in drug delivery and controlled release systems. The development of drug delivery systems with controlled release properties based on highly effective and safe carriers is pressing matters in medical research. ${ }^{327,} 328$ Inorganic layers of 2D materials can confine drug molecules in their interspace and thus, drugs such as insulin or enzymes can be protected and gradually released, making 2D materials promising candidates for drug delivery and controlled release. ${ }^{329}$ On the other hand, previous studies also indicated that the intercalation of drugs in the interlayers could reduce their toxicity and enhance bioavailability in a delivery process, which significantly reduced side effects. ${ }^{330}, 331$ In addition to their interlayer sites, studies indicated that their outer surface can also be active sites to immobilize drug molecules. ${ }^{332,333}$

2D LDHs are well known for their peculiar characteristics like good biocompatibility, anion exchange capacity, high chemical stability, and $\mathrm{pH}$-dependent solubility. ${ }^{327}$ These merits make them attractive and safe carriers for drug delivery and controlled release systems in biomaterial fields. ${ }^{327}, 334-337$ The loading of drug molecules on LDHs endows LDHs to function in medical therapy. For example, Xu et al. intercalated pirenoxine sodium (PRN) and chitosan derivatives (chitosan-glutathione (CG), chitosanglutathione-valine (CG-V), and chitosan-glutathione-valine-valine $(\mathrm{CG}-\mathrm{VV})$ ) into the interlayers of MgAl-LDH, and found that the mean residence time and area under the curve $\left(\mathrm{AUC}_{0-6 \mathrm{~h}}\right)$ of $\mathrm{CG}$ PRN/LDH nanocomposite eye drop was respectively up to 2.1-fold and 6.3-fold higher than those of the commercial product of PRN during in vivo precorneal retention study on rabbits. ${ }^{331}$ In addition, in vitro corneal penetration on rabbits demonstrated that the cumulative permeation of CG-VV-PRN/LDH nanocomposite dispersion was increased by 5.2 times compared to that of the commercial product. The authors indicated that the LDH-based 
biomaterials presented prolonged precorneal retention, better corneal permeability, and enhanced ocular bioavailability compared to those of the commercial products. ${ }^{331}$ Zhang et al. demonstrated that MgAl-LDHs were effective adjuvants for protein-based vaccines. ${ }^{338}$ They assembled epitope peptides and CpG (cytosine-phosphate-guanine) onto the surface of LDH nanoparticles, and found that the tyrosinase-related protein 2 peptide functionalized LDH vaccine induced stronger cytotoxic Tlymphocyte responses and significantly inhibited the growth of tumor. Furthermore, the multi-target functionalized LDH vaccine by co-loading of tyrosinase-related protein 2, two mutated epitopes (M27 and M30), and CpG showed remarkable inhibition of melanoma growth. Their results suggested that LDHs are ideal platforms to load multi-antigens and immune stimulants as effective personalized therapeutic cancer vaccines. Kura et al. reported that the intercalated levodopa in the interlayers of LDHs could be released sequentially, controllably, slowly, and $\mathrm{pH}$ dependently with the release lasting for 3-6 days. ${ }^{339}$ This slow releasing property of toxic compounds from the interlayers of LDHs over time is also a factor in suppressing drug toxicity.

Apart from as carries for drug delivery and controlled release systems, LDHs can also be applied in other medical fields such as tissue engineering implants, ${ }^{340}$ antibacterial agents, ${ }^{334,341}$ medical imaging and targeted systems. ${ }^{327}$ For example, Kapusetti et al. demonstrated that LDHs could be employed as bone cement for joint implants after hybridizing with poly(methyl methacrylate). ${ }^{340}$ The bone cement showed superior mechanical strength, stiffness, toughness, fatigue resistance, and thermal stability in comparison with the pure bone cement. Peng et al. also confirmed the feasibility of using LDHs as bone implants. ${ }^{342}$ Chen et al. functionalized an MgAl-LDH by hybridizing silver nanoparticles on the $\mathrm{LDH}$, and found that the resultant material showed excellent antimicrobial activities against planktonic bacteria and inhibited the formation of biofilms. ${ }^{341}$ Kuo et al. activated LDHs by modifying the external surface of LDHs with various organic groups and demonstrated that the resultant materials could enhance organ-specific targeting. ${ }^{343}$ Their studies suggested that surface functionalization of LDH nanoparticles could promote drug targeting.

\section{Summary and outlook}

In this review, we have addressed the currently available strategies to functionalize $\mathrm{LDHs}$ and discussed how these strategies may improve a range of physicochemical properties of LDHs. Currently available functionalization strategies include intercalation, surface modification, hybridization, layered compositions regulation, size and morphology control, and defect creation. We have documented how these strategies contribute significantly to the improvement of a very diverse range of physicochemical responses of an $\mathrm{LDH}$, including adsorptive, catalytic, electronic, electrochemical, and optic performances. The remarkable performances endow functionalized LDHs with great potential across a wide range of applications in the environmental remediation, energy, catalysis, and biomaterial sectors. We have highlighted their potential applications in these fields.

Functionalization of LDHs continues to be a rapidly growing field. We believe future studies could be rewarded by focusing efforts on several fundamental research areas, including:

(i) Using computer modeling to help gain a deeper understanding of LDH functionalization, which will facilitate more effective functionalization of LDHs. To this end, the biggest challenge is to set up proper models for simulation since different functionalization methods may not share a same model.

(ii) New and effective nano-hybridization routes. As both decreasing the size of LDHs and hybridizing LDHs with guest species can lead to dramatic performance improvement of LDHs, the hybridization at the nanoscale may induce new features. Conventionally, ultrathin 2D LDH-based nanomaterials are prepared based on exfoliation technologies followed by layer-by-layer and one-step coassembly methods. But the current exfoliation technologies considerably inhibit the fabrication of large scale and high quality ultrathin 2D LDH-based nanomaterials due to the low exfoliation yield and poor controllability. Therefore, from the material synthesis point of view, the current quality, production rate, and production yield of ultrathin 2D LDH-based nanomaterials are still far from commercialization. One of the major challenges in this hot field is to realize high-yield and massive production of ultrathin 2D nanomaterials to meet the industry requirements. The development of in-situ and/or one-pot synthesis strategies for ultrathin 2D LDH-based hybrid nanomaterials should be one of the future research targets.

(iii) Achieving ordered intercalation and hybridization. The remaining challenges are to maintain the arrangement of the guest species hybridized onto LDHs with defined orientation, to direct the guest species to a spatially defined region, and to order multiple guests on LDH surfaces. Taking functionalization of LDHs by intercalation as an example, key future studies to be conducted include development of more facile intercalation approaches, especially for two or more co-intercalated guest species, as well as further studies over the basic factors that affect intercalation. Intercalation can remarkably enhance the physical and chemical properties of LDHs, rendering LDH materials favorable for a multitude of vital applications. In addition, co-intercalation of different intercalants into one 2D material has been shown to lead to unpredicted properties compared to single matter intercalated LDHs. $^{1}$ Thus, multi-functional species intercalation may give rise to new synergistic properties that are unprecedented with single intercalants. To achieve this goal, more efficient intercalation methods as well as further exploration of the influential factors of co-intercalation are needed. During co-intercalation, the controlled loading of different functional substances at various ratios, stacking forms, and relative position of the functional substances in the LDH layers are key challenge. The intercalation order, intercalation medium, and interactions among different functional species and LDH layers are expected to significantly affect the intercalation process and outcome.

(iv) Investigation of defect structures and linking these to specific LDH functions. Creation of defects is a theoretically and practically viable and promising approach to functionalize LDHs, but the challenge is how to create controllable defects. In addition, it is also critical to identify which type of defects is beneficial or harmful to the specific performance of LDHs. Importantly, how to avoid unfavorable defects and introduce useful defect sites are the biggest challenges for the future researches.

(v) New generation of LDH-based electrochemical energy storage materials. For example, if LDHs can be efficiently developed to serve as the host matrix for the intercalation of 
various earth-abundant cations, a new family of electrochemical energy storage materials can be developed. However, owing to the occupation of the interlayer gallery by anions and the charge repulsion between the positively charged LDH laminate and cations, the intercalation of cations from aqueous solution into the domain of LDHs becomes the major difficulty for the fabrication of this new type of energy storage materials. Recent breakthrough was made by the creation of ordered hydrogen-vacancy on CoFe$\mathrm{LDH}$, and therefore various metal cations (e.g., $\mathrm{Li}^{+}, \mathrm{Na}^{+}, \mathrm{K}^{+}$, $\mathrm{Ca}^{2+}, \mathrm{Mg}^{2+}$, and $\mathrm{Zn}^{2+}$ ) could be intercalated into the interlayers of CoFe-LDH, resulting in high-performance rechargeable cation supercapacitors. ${ }^{344}$ More efforts should be directed to this new area.

\section{Conflicts of interest}

There are no conflicts to declare.

\section{Acknowledgements}

L.S. acknowledges the support from the National Science Foundation (CMMI-1562907). R.Z. acknowledges the support from the National Natural Science Foundation of China (41572031). D.O. acknowledges the support from SCG Chemicals Co. Ltd. M.L. thanks the National Natural Science Foundation of China (41902039), and the China Scholarship Council for offering him a scholarship to conduct research at University of Connecticut.

\section{References}

1. J. Wan, S. D. Lacey, J. Dai, W. Bao, M. S. Fuhrer and L. Hu, Chem. Soc. Rev., 2016, 45, 6742-6765.

2. L. Ma, Q. Wang, S. M. Islam, Y. Liu, S. Ma and M. G. Kanatzidis, J. Am. Chem. Soc., 2016, 138, 2858-2866.

3. S. Ma, L. Huang, L. Ma, Y. Shim, S. M. Islam, P. Wang, L.D. Zhao, S. Wang, G. Sun and X. Yang, J. Am. Chem. Soc., 2015, 137, 3670-3677.

4. Q. Tao, B. J. Reddy, H. He, R. L. Frost, P. Yuan and J. Zhu, Mater. Chem. Phys., 2008, 112, 869-875.

5. Q. Tao, Y. Zhang, X. Zhang, P. Yuan and H. He, J. Solid State Chem., 2006, 179, 708-715.

6. J. Yu, Q. Wang, D. O'Hare and L. Sun, Chem. Soc. Rev., 2017.

7. Q. Tao, H. He, R. L. Frost, P. Yuan and J. Zhu, Appl. Surf. Sci., 2009, 255, 4334-4340.

8. Y. Zhu, M. Laipan, R. Zhu, T. Xu, J. Liu, J. Zhu, Y. Xi, G. Zhu and H. He, Molecular Catalysis, 2017, 427, 54-61.

9. C. Li, M. Wei, D. G. Evans and X. Duan, Small, 2014, 10, 4469-4486.

10. L. Mohapatra and K. Parida, Journal of Materials Chemistry A, 2016, 4, 10744-10766.

11. Q. Wang and D. O'Hare, Chem. Rev., 2012, 112, 41244155.

12. Q.-S. Yao, Z.-C. Li, Z.-M. Qiu, F. Zhang, X.-B. Chen, D.-C. Chen, S.-K. Guan and R.-C. Zeng, Rare Met. , 2019, 38, 629-641.

13. M. Laipan, R. Zhu, J. Zhu and H. He, J. Mol. Catal. A: Chem., 2016, 415, 9-16.

14. L. Yu, H. Zhou, J. Sun, F. Qin, F. Yu, J. Bao, Y. Yu, S. Chen and Z. Ren, Energy Environ. Sci. , 2017, 10, 1820-1827.

15. G. Nagaraju, G. S. R. Raju, Y. H. Ko and J. S. Yu, Nanoscale,
2016, 8, 812-825.

16. Y. Ao, D. Wang, P. Wang, C. Wang, J. Hou and J. Qian, RSC Advances, 2015, 5, 54613-54621.

17. S. Mancipe, F. Tzompantzi and R. Gómez, Appl. Clay Sci., 2017, 136, 67-74.

18. J. Zhu, P. Yuan, H. He, R. Frost, Q. Tao, W. Shen and T. Bostrom, J. Colloid Interface Sci., 2008, 319, 498-504.

19. W. Guan, S. Wang, C. Lu and B. Z. Tang, Nature communications, 2016, 7.

20. X. Gao, X. Liu, D. Wu, B. Qian, Z. Kou, Z. Pan, Y. Pang, L. Miao and J. Wang, Adv. Funct. Mater., 2019, 29.

21. B. Wang, H. Zhang, D. G. Evans and X. Duan, Mater. Chem. Phys., 2005, 92, 190-196.

22. J. Wang, Y. Zhang, J. Zhu, J. Hou, J. Liu and B. Van der Bruggen, J. Membr. Sci., 2016, 510, 27-37.

23. F. Ning, M. Shao, S. Xu, Y. Fu, R. Zhang, M. Wei, D. G. Evans and X. Duan, Energy Environ. Sci. , 2016, 9, 26332643.

24. Z. Gu, J. J. Atherton and Z. P. Xu, Chem. Commun., 2015, 51, 3024-3036.

25. M. Gong, Y. Li, H. Zhang, B. Zhang, W. Zhou, J. Feng, H. Wang, Y. Liang, Z. Fan and J. Liu, Energy Environ. Sci. , 2014, 7, 2025-2032.

26. H. Liu, Y. Wang, X. Lu, Y. Hu, G. Zhu, R. Chen, L. Ma, H. Zhu, Z. Tie and J. Liu, Nano Energy, 2017, 35, 350-357.

27. Y. Zhao, Q. Wang, T. Bian, H. Yu, H. Fan, C. Zhou, L.-Z. Wu, C.-H. Tung, D. O'Hare and T. Zhang, Nanoscale, 2015, 7, 7168-7173.

28. F. Yang, B. Wang, H. Su, S. Zhou and Y. Kong, Materials Chemistry Frontiers, 2017.

29. J. L. Gunjakar, I. Y. Kim, J. M. Lee, N.-S. Lee and S.-J. Hwang, Energy Environ. Sci. , 2013, 6, 1008-1017.

30. M. Shao, M. Wei, D. G. Evans and X. Duan, Chemistry-A European Journal, 2013, 19, 4100-4108.

31. J. L. Gunjakar, T. W. Kim, H. N. Kim, I. Y. Kim and S.-J. Hwang, J. Am. Chem. Soc., 2011, 133, 14998-15007.

32. M. Yu, S. Zhou, Z. Wang, J. Zhao and J. Qiu, Nano Energy, 2018, 44, 181-190.

33. J. Xu, S. Gai, F. He, N. Niu, P. Gao, Y. Chen and P. Yang, Journal of Materials Chemistry A, 2014, 2, 1022-1031.

34. C. Yu, J. Yang, C. Zhao, X. Fan, G. Wang and J. Qiu, Nanoscale, 2014, 6, 3097-3104.

35. H. Hu, X. Wang, S. Xu, W. Yang, F. Xu, J. Shen and C. Mao, J. Mater. Chem., 2012, 22, 15362-15369.

36. H. Hu, K. Xiu, S. Xu, W. Yang and F. Xu, Bioconjugate Chem., 2013, 24, 968-978.

37. C. I. Ezeh, X. Huang, X. Yang, C.-g. Sun and J. Wang, Ultrason. Sonochem., 2017, 39, 330-343.

38. Y. Xu, W. Huang, X. Chen, F. Ge, R. Zhu and L. Sun, Appl. Catal., A 2018, 550, 8.

39. L. Zhang, K. N. Hui, K. San Hui and H. Lee, Electrochim. Acta, 2015, 186, 522-529.

40. J. Cheng, J. Fang, M. Li, W. Zhang, F. Liu and X. Zhang, Electrochim. Acta, 2013, 114, 68-75.

41. F. Lai, Y. Huang, Y.-E. Miao and T. Liu, Electrochim. Acta, 2015, 174, 456-463.

42. M. Tian, C. Liu, Z. G. Neale, J. Zheng, D. Long and G. Cao, ACS Appl. Mat. Interfaces 2019, 11, 35977-35986.

43. S. Fu, G. Fan, L. Yang and F. Li, Electrochim. Acta, 2015, 152, 146-154.

44. X. Han, C. Yu, J. Yang, C. Zhao, H. Huang, Z. Liu, P. M. Ajayan and J. Qiu, Adv. Mater. Interfaces, 2016, 3. 
45

C. Yu, X. Han, Z. Liu, C. Zhao, H. Huang, J. Yang, Y. Niu and J. Qiu, Carbon, 2018, 126, 437-442.

46. J. W. Mellor, Nature (London, U. K.), 1917, 100, 88-89.

47. A. Weiss and A. Weiss, Angew. Chem., 1960, 72, 413415.

48. D. W. Bruce, D. O'Hare and Editors, Inorganic Materials, Wiley, 1992.

49. K. Fredenhagen and G. Cadenbach, Z. Anorg. Allg. Chem., $1926,158,249-263$.

50. A. Clearfield, in Progress in Intercalation Research, eds. W. Müller-Warmuth and R. Schöllhorn, Kluwer Academic Publisher, Dordrecht, The Netherlands, 1994, pp. 240263.

51. D. O'Hare, in Inorg. Mater., eds. D. W. Bruce and D. O'Hare, John Wiley \& Sons, West Sussex, 1992, pp. 165235.

52. A. Clearfield and U. Costantino, in Comprehensive Supramolecular Chemistry, eds. G. Alberti and T. Bein, Elsevier, Oxford, UK, 1996, vol. 7, pp. 107-149.

53. J. Yu, L. Xiang, B. R. Martin, A. Clearfield and L. Sun, Chem. Commun., 2015, 51, 11398-11400.

54. J. Yu, J. E. Sims and L. Sun, J. Mater. Sci., 2017, 52, 66476655.

55. M. Laipan, H. Fu, R. Zhu, L. Sun, J. Zhu and H. He, Scientific Reports, 2017, 7.

56. M. Laipan, R. Zhu, Q. Chen, J. Zhu, Y. Xi, G. A. Ayoko and H. He, J. Hazard. Mater., 2015, 300, 572-580.

57. W. J. Boo, L. Sun, J. Liu, A. Clearfield and H.-J. Sue, J. Phys. Chem. C, 2007, 111, 10377-10381.

58. H. Hu, J. C. Martin, M. Xiao, C. S. Southworth, Y. Meng and L. Sun, J. Phys. Chem. C, 2011, 115, 5509-5514.

59.

L. Sun, J. Y. O'Reilly, D. Kong, J. Y. Su, W. J. Boo, H. J. Sue and A. Clearfield, J. Colloid Interface Sci., 2009, 333, 503509.

60. H. He, L. Ma, J. Zhu, R. L. Frost, B. K. Theng and F. Bergaya, Appl. Clay Sci., 2014, 100, 22-28.

61. J. Zhu, K. Wen, P. Zhang, Y. Wang, L. Ma, Y. Xi, R. Zhu, H. Liu and H. He, Microporous Mesoporous Mater., 2017, 242, 256-263.

62. J. Zhu, P. Zhang, Y. Qing, K. Wen, X. Su, L. Ma, J. Wei, H. Liu, H. He and Y. Xi, Appl. Clay Sci., 2017, 141, 265-271.

63. Q. Tao, J. Zhu, R. L. Frost, T. E. Bostrom, R. M. Wellard, J. Wei, P. Yuan and H. He, Langmuir, 2009, 26, 2769-2773.

64. S. M. Xu, Q. C. Zhu, J. Long, H. H. Wang, X. F. Xie, K. X. Wang and J. S. Chen, Adv. Funct. Mater., 2016, 26, 13651374.

65.

S. Omwoma, W. Chen, R. Tsunashima and Y.-F. Song, Coord. Chem. Rev., 2014, 258, 58-71.

66. L. Ma, S. M. Islam, C. Xiao, J. Zhao, H. Liu, M. Yuan, G. Sun, H. Li, S. Ma and M. G. Kanatzidis, J. Am. Chem. Soc., 2017, 139, 12745-12757.

67. Q. Zhou, F. Chen, W. Wu, R. Bu, W. Li and F. Yang, Chem. Eng. J., 2016, 285, 198-206.

68. N. Wang, J. Sun, H. Fan and S. Ai, Talanta, 2016, 148, 301-307.

69.

Y. Jia, Y. Fang, Y. Zhang, H. N. Miras and Y. F. Song, Chemistry-A European Journal, 2015, 21, 14862-14870.

70. Y. Chen, Z. Yao, H. N. Miras and Y. F. Song, Chemistry-A European Journal, 2015, 21, 10812-10820.

71. W. Lv, L. Yang, B. Fan, Y. Zhao, Y. Chen, N. Lu and R. Li, Chem. Eng. J., 2015, 263, 309-316.

72.
M. Asif, A. Aziz, A. Q. Dao, A. Hakeem, H. Wang, S. Dong,
G. Zhang, F. Xiao and H. Liu, Anal. Chim. Acta, 2015, 898, 34-41.

73. F.-N. Xiao, K. Wang, F.-B. Wang and X.-H. Xia, Anal. Chem., 2015, 87, 4530-4537.

74. J. Wu, D. Peng, Y. He, X. Du, Z. Zhang, B. Zhang, X. Li and Y. Huang, Materials, 2017, 10, 426.

75. Y. Zhao, H. Hu, X. Yang, D. Yan and Q. Dai, Small, 2016, 12, 4471-4476.

76. H. Asiabi, Y. Yamini, M. Shamsayei and E. Tahmasebi, Chem. Eng. J., 2017, 323, 212-223.

77. A. C. Thenuwara, N. H. Attanayake, J. Yu, J. P. Perdew, E. J. Elzinga, Q. Yan and D. R. Strongin, The Journal of Physical Chemistry B, 2017.

78. C. Zhang, T. Tsuboi, H. Namba, Y. Einaga and T. Yamamoto, Dalton Trans., 2016, 45, 13324-13331.

79. C. Wang, X. Zhang, Z. Xu, X. Sun and Y. Ma, ACS Appl. Mat. Interfaces 2015, 7, 19601-19610.

80. W. Quan, C. Jiang, S. Wang, Y. Li, Z. Zhang, Z. Tang and F. Favier, Electrochim. Acta, 2017, 247, 1072-1079.

81. J. M. Oh, S. J. Choi, G. E. Lee, S. H. Han and J. H. Choy, Adv. Funct. Mater., 2009, 19, 1617-1624.

82. L. Li, G. Qi, B. Wang, D. Yue, Y. Wang and T. Sato, J. Hazard. Mater., 2018, 343, 19-28.

83. E. Lima, M. a. d. J. s. Martínez-Ortiz, R. I. G. r. Reyes and M. Vera, Inorg. Chem., 2012, 51, 7774-7781.

84. A. M. El-Toni, M. A. Habila, J. P. Labis, Z. A. ALOthman, M. Alhoshan, A. A. Elzatahry and F. Zhang, Nanoscale, 2016, 8, 2510-2531.

85. M. Shao, F. Ning, Y. Zhao, J. Zhao, M. Wei, D. G. Evans and X. Duan, Chem. Mater., 2012, 24, 1192-1197.

86. R. G. Chaudhuri and S. Paria, Chem. Rev, 2012, 112, 2373-2433.

87. J. Han, Y. Dou, J. Zhao, M. Wei, D. G. Evans and X. Duan, Small, 2013, 9, 98-106.

88. M. B. Gawande, A. Goswami, T. Asefa, H. Guo, A. V. Biradar, D.-L. Peng, R. Zboril and R. S. Varma, Chem. Soc. Rev., 2015, 44, 7540-7590.

89. M. Asif, H. Liu, A. Aziz, H. Wang, Z. Wang, M. Ajmal, F. Xiao and $\mathrm{H}$. Liu, Biosens. Bioelectron., 2017.

90. Y. Li, H.-Y. Bi, H. Li, X.-M. Mao and Y.-Q. Liang, Materials Science and Engineering: C, 2017, 78, 886-891.

91. L.-g. Yan, K. Yang, R.-r. Shan, T. Yan, J. Wei, S.-j. Yu, H.-q. Yu and B. Du, J. Colloid Interface Sci., 2015, 448, 508516.

92. X. Li, Z. Yang, W. Qi, Y. Li, Y. Wu, S. Zhou, S. Huang, J. Wei, H. Li and P. Yao, Appl. Surf. Sci., 2016, 363, 381-388.

93. X. He, Q. Liu, J. Liu, R. Li, H. Zhang, R. Chen and J. Wang, J. Alloys Compd., 2017, 724, 130-138.

94. Q. Guo, Q. Zhang, H. Wang, Z. Liu and Z. Zhao, Catal. Commun., 2016, 77, 118-122.

95. Z. Li, M. Shao, L. Zhou, R. Zhang, C. Zhang, J. Han, M. Wei, D. G. Evans and X. Duan, Nano Energy, 2016, 20, 294-304.

96. W. Chen, T. Wang, J. Xue, S. Li, Z. Wang and S. Sun, Small, 2017, 13.

97. X. Zhou, X. Wang, R. Tong, L. Xiao, Z. Zheng, X. Peng, H. Wang and $\mathrm{H}$. Wang, Int. J. Energy Res. , 2017.

98. C. Wang, B. Ma, S. Xu, D. Li, S. He, Y. Zhao, J. Han, M. Wei, D. G. Evans and X. Duan, Nano Energy, 2017, 32, 463-469.

99. A. S. Oliveira, A. C. Alcântara and S. B. Pergher, Materials Science and Engineering: C, 2017, 75, 1250-1258. 
100. X. Fan, B. Gao, T. Wang, X. Huang, H. Gong, H. Xue, H. Guo, L. Song, W. Xia and J. He, Appl. Catal., A 2016, 528, 52-58.

101. Y. Zhu, J. Ren, X. Yang, G. Chang, Y. Bu, G. Wei, W. Han and D. Yang, Journal of Materials Chemistry A, 2017, 5, 9952-9959.

102. Y. Wang, Y. Zhou, T. Zhang, M. He and X. Bu, Chem. Eng. J., 2015, 266, 199-202.

103. C. Chen, R. Felton, J.-C. Buffet and D. O'Hare, Chem. Commun., 2015, 51, 3462-3465.

104. L. Guo, X. Zhang, Q. Chen, C. Ruan and Y. Leng, Environmental Science and Pollution Research, 2016, 23, 6749-6757.

105. J. Xing, J. Du, X. Zhang, Y. Shao, T. Zhang and C. Xu, Dalton Trans., 2017, 46, 10064-10072.

106. S. Wang, Z. Huang, R. Li, X. Zheng, F. Lu and T. He, Electrochim. Acta, 2016, 204, 160-168.

107. Q. Zhou, M. Lei, J. Li, K. Zhao and Y. Liu, Sep. Purif. Technol., 2017, 182, 78-86.

108. L. Yu, H. Zhou, J. Sun, F. Qin, D. Luo, L. Xie, F. Yu, J. Bao, Y. Li and Y. Yu, Nano Energy, 2017.

109. Y. Ni, L. Yao, Y. Wang, B. Liu, M. Cao and C. Hu, Nanoscale, 2017, 9, 11596-11604.

110. J. Xu, C. Ma, J. Cao and Z. Chen, Dalton Trans., 2017, 46, 3276-3283.

111. S. Wu, K. S. Hui, K. N. Hui and K. H. Kim, ACS Appl. Mat. Interfaces 2016, 9, 1395-1406.

112. P.-F. Liu, K. Tao, G.-C. Li, M.-K. Wu, S.-R. Zhu, F.-Y. Yi, W.-N. Zhao and L. Han, Dalton Trans., 2016, 45, 12632-12635.

113. H. Ma, J. He, D.-B. Xiong, J. Wu, Q. Li, V. Dravid and Y. Zhao, ACS Appl. Mat. Interfaces 2016, 8, 1992-2000.

114. S. Zhang, J. Liu, P. Huang, H. Wang, C. Cao and W. Song, Science Bulletin, 2017.

115. A. N. Ay, H. Akar, A. Zaulet, C. Viňas, F. Teixidor and B. Zumreoglu-Karan, Dalton Trans., 2017, 46, 3303-3310.

116. L. Qian, W. Zhang, J. Yan, L. Han, Y. Chen, D. Ouyang and M. Chen, Environ. Pollut., 2017, 223, 153-160.

117. W. Zhu, L. Liu, Z. Yue, W. Zhang, X. Yue, J. Wang, S. Yu, L. Wang and J. Wang, ACS Appl. Mat. Interfaces 2017.

118. Y. Tao, L. Ruiyi, Y. Tingting and L. Zaijun, Electrochim. Acta, 2015, 152, 530-537.

119. J. Yang, C. Yu, X. Fan, Z. Ling, J. Qiu and Y. Gogotsi, J. Mater. Chem. A, 2013, 1, 1963-1968.

120. Z. Liu, C. Yu, X. Han, J. Yang, C. Zhao, H. Huang and J. Qiu, ChemElectroChem, 2016, 3, 906-912.

121. K. Le, Z. Wang, F. Wang, Q. Wang, Q. Shao, V. Murugadoss, S. Wu, W. Liu, J. Liu and Q. Gao, Dalton Trans., 2019, 48, 5193-5202.

122. X. Liu, C. Wang, Y. Dou, A. Zhou, T. Pan, J. Han and M. Wei, Journal of Materials Chemistry A, 2014, 2, 16821685.

123. J. Yang, C. Yu, C. Hu, M. Wang, S. Li, H. Huang, K. Bustillo, X. Han, C. Zhao and W. Guo, Adv. Funct. Mater., 2018, 28, 1803272.

124. Y. Tang, R. Wang, Y. Yang, D. Yan and X. Xiang, ACS Appl. Mat. Interfaces 2016, 8, 19446-19455.

125. G. Zhang, B. Lin, Y. Qiu, L. He, Y. Chen and B. Gao, Int. J. Hydrogen Energy, 2015, 40, 4758-4765.

126. G. Mikami, F. Grosu, S. Kawamura, Y. Yoshida, G. Carja and Y. Izumi, Appl. Catal., B 2016, 199, 260-271.

127. X. Cai, X. Shen, L. Ma, Z. Ji, C. Xu and A. Yuan, Chem. Eng. J., 2015, 268, 251-259.
128. F. Lai, Y. E. Miao, L. Zuo, H. Lu, Y. Huang and T. Liu, Small, 2016, 12, 3235-3244.

129. C. Wang, X. Zhang, X. Sun and Y. Ma, Electrochim. Acta, 2016, 191, 329-336.

130. C. Xing, F. Musharavati, H. Li, E. Zalezhad, O. K. Hui, S. Bae and B.-Y. Cho, RSC Advances, 2017, 7, 38945-38950.

131. X. Bai, Q. Liu, H. Zhang, J. Liu, Z. Li, X. Jing, Y. Yuan, L. Liu and J. Wang, Electrochim. Acta, 2016, 215, 492-499.

132. F. Wang, S. Sun, Y. Xu, T. Wang, R. Yu and H. Li, Scientific Reports, 2017, 7.

133. X. Yu, M. Zhang, W. Yuan and G. Shi, Journal of Materials Chemistry A, 2015, 3, 6921-6928.

134. W. Ma, R. Ma, C. Wang, J. Liang, X. Liu, K. Zhou and T. Sasaki, ACS Nano, 2015, 9, 1977-1984.

135. R. Chen, G. Sun, C. Yang, L. Zhang, J. Miao, H. Tao, H. Yang, J. Chen, P. Chen and B. Liu, Nanoscale Horizons, 2016, 1, 156-160.

136. D. H. Youn, Y. B. Park, J. Y. Kim, G. Magesh, Y. J. Jang and J. S. Lee, J. Power Sources, 2015, 294, 437-443.

137. Y. Lu, B. Jiang, L. Fang, F. Ling, F. Wu, B. Hu, F. Meng, K. Niu, F. Lin and H. Zheng, J. Alloys Compd., 2017, 714, 6370.

138. M. Li, F. Liu, J. Cheng, J. Ying and X. Zhang, J. Alloys Compd., 2015, 635, 225-232.

139. L. Zhang, R. Chen, K. N. Hui, K. San Hui and H. Lee, Chem. Eng. J., 2017.

140. L. Zhang, K. N. Hui, K. San Hui and H. Lee, J. Power Sources, 2016, 318, 76-85.

141. X. Ge, C. Gu, Z. Yin, X. Wang, J. Tu and J. Li, Nano Energy, 2016, 20, 185-193.

142. L. Zhang, K. Hui, K. Hui, X. Chen, R. Chen and H. Lee, Int. J. Hydrogen Energy, 2016, 41, 9443-9453.

143. B. Hai and Y. Zou, Sens. Actuators, B 2015, 208, 143-150.

144. Y. Wang, H. Dou, J. Wang, B. Ding, Y. Xu, Z. Chang and X. Hao, J. Power Sources, 2016, 327, 221-228.

145. P. Huang, C. Cao, Y. Sun, S. Yang, F. Wei and W. Song, Journal of Materials Chemistry A, 2015, 3, 10858-10863.

146. C.-H. Zheng, T. Yao, T.-R. Xu, H.-A. Wang, P.-F. Huang, Y. Yan and D.-L. Fang, J. Alloys Compd., 2016, 678, 93-101.

147. X. L. Guo, X. Y. Liu, X. D. Hao, S. J. Zhu, F. Dong, Z. Q. Wen and Y. X. Zhang, Electrochim. Acta, 2016, 194, 179-186.

148. H. Chen, Y. Ai, F. Liu, X. Chang, Y. Xue, Q. Huang, C. Wang, H. Lin and S. Han, Electrochim. Acta, 2016, 213, 55-65.

149. M. Yu, R. Liu, J. Liu, S. Li and Y. Ma, Small, 2017.

150. W. Ma, R. Ma, J. Wu, P. Sun, X. Liu, K. Zhou and T. Sasaki, Nanoscale, 2016, 8, 10425-10432.

151. L. Huang, B. Liu, H. Hou, L. Wu, X. Zhu, J. Hu and J. Yang, J. Alloys Compd., 2017.

152. M. Padmini, S. K. Kiran, N. Lakshminarasimhan, M. Sathish and P. Elumalai, Electrochim. Acta, 2017, 236, 359-370.

153. M. Li, J. Cheng, J. Wang, F. Liu and X. Zhang, Electrochim. Acta, 2016, 206, 108-115.

154. J. Ping, Y. Wang, Q. Lu, B. Chen, J. Chen, Y. Huang, Q. Ma, C. Tan, J. Yang and X. Cao, Adv. Mater. , 2016, 28, 76407645.

155. A. Zhang, C. Wang, Q. Xu, H. Liu, Y. Wang and Y. Xia, Rsc Advances, 2015, 5, 26017-26026.

156. W. Peng, H. Li and S. Song, ACS Appl. Mat. Interfaces 2017, 9, 5204-5212.

157. Z. Huang, S. Wang, J. Wang, Y. Yu, J. Wen and R. Li, Electrochim. Acta, 2015, 152, 117-125. 
158. K. Ma, J. Cheng, F. Liu and X. Zhang, J. Alloys Compd., 2016, 679, 277-284.

159. J. Hu, C. Zhang, L. Jiang, H. Lin, Y. An, D. Zhou, M. K. Leung and S. Yang, Joule, 2017, 1, 383-393.

160. R. Zhang, M. Shao, S. Xu, F. Ning, L. Zhou and M. Wei, Nano Energy, 2017, 33, 21-28.

161. L. Mohapatra, D. Patra, K. Parida and S. J. Zaidi, Eur. J. Inorg. Chem., 2017, 2017, 723-733.

162. M. Mureseanu, T. Radu, R.-D. Andrei, M. Darie and G. Carja, Appl. Clay Sci., 2017, 141, 1-12.

163. Z. Li, M. Chen, Q. Zhang, J. Qu, Z. Ai and Y. Li, Appl. Clay Sci., 2017, 144, 115-120.

164. M. Hadnadjev-Kostic, T. Vulic, R. Marinkovic-Neducin, D. Lončarević, J. Dostanić, S. Markov and D. Jovanović, Journal of Cleaner Production, 2017, 164, 1-18.

165. T. Vulic, O. Rudic, S. Vucetic, D. Lazar and J. Ranogajec, Cem. Concr. Compos. , 2015, 58, 50-58.

166. Y. Hou, Z. Wen, S. Cui, X. Feng and J. Chen, Nano Lett., 2016, 16, 2268-2277.

167. S. Nayak, L. Mohapatra and K. Parida, Journal of Materials Chemistry A, 2015, 3, 18622-18635.

168. J. Ma, J. Ding, L. Yu, L. Li, Y. Kong and S. Komarneni, Appl. Clay Sci., 2015, 109, 76-82.

169. Z. Wang, S. Zeng, W. Liu, X. Wang, Q. Li, Z. Zhao and F. Geng, ACS Appl. Mat. Interfaces 2017, 9, 1488-1495.

170. S. Kumar, M. A. Isaacs, R. Trofimovaite, L. Durndell, C. M. Parlett, R. E. Douthwaite, B. Coulson, M. C. Cockett, K. Wilson and A. F. Lee, Appl. Catal., B 2017, 209, 394-404.

171. Y. Fu, F. Ning, S. Xu, H. An, M. Shao and M. Wei, Journal of Materials Chemistry A, 2016, 4, 3907-3913.

172. K. Mori, T. Taga and H. Yamashita, ACS Catalysis, 2017, 7, 3147-3151.

173. E. Seftel, M. Puscasu, M. Mertens, P. Cool and G. Carja, Appl. Catal., B 2015, 164, 251-260.

174. S. Nayak and K. Parida, Int. J. Hydrogen Energy, 2016, 41, 21166-21180.

175. Y. Chen, Y. Bao and X. Wang, Journal of fluorescence, 2016, 26, 813-820.

176. X. Jin, Y. Koizumi, K. Yamaguchi, K. Nozaki and N. Mizuno, J. Am. Chem. Soc., 2017.

177. S. M. de Rezende, C. A. Franchini, M. L. Dieuzeide, A. M. D. de Farias, N. Amadeo and M. A. Fraga, Chem. Eng. J., 2015, 272, 108-118.

178. K. Iqbal, A. Iqbal, A. M. Kirillov, B. Wang, W. Liu and Y. Tang, Journal of Materials Chemistry A, 2017, 5, 67166724.

179. L. Sobhana, M. Sarakha, V. Prevot and P. Fardim, Appl. Clay Sci., 2016, 134, 120-127.

180. Z. Gao, R. Xie, G. Fan, L. Yang and F. Li, ACS Sustainable Chemistry \& Engineering, 2017.

181. M. Suarez-Quezada, G. Romero-Ortiz, V. Suárez, G. Morales-Mendoza, L. Lartundo-Rojas, E. Navarro-Cerón, F. Tzompantzi, S. Robles, R. Gómez and A. Mantilla, Catal. Today, 2016, 271, 213-219.

182. Y. Zhu, R. Zhu, G. Zhu, M. Wang, Y. Chen, J. Zhu, Y. Xi and H. He, Appl. Surf. Sci., 2017.

183. S. Kawamura, M. C. Puscasu, Y. Yoshida, Y. Izumi and G. Carja, Appl. Catal., A 2015, 504, 238-247.

184. Y. Wei, S. Chen, F. Li, Y. Lin, Y. Zhang and L. Liu, ACS Appl. Mat. Interfaces 2015, 7, 14182-14191.

185. X. Duan and D. G. Evans, Layered double hydroxides, Springer Science \& Business Media, 2006.
186. J. Liang, R. Ma, N. Iyi, Y. Ebina, K. Takada and T. Sasaki, Chem. Mater., 2009, 22, 371-378.

187. Z. Lu, L. Qian, Y. Tian, Y. Li, X. Sun and X. Duan, Chem. Commun., 2016, 52, 908-911.

188. X. Li, M. Xin, S. Guo, T. Cai, D. Du, W. Xing, L. Zhao, W. Guo, Q. Xue and Z. Yan, Electrochim. Acta, 2017, 253, 302-310

189. K. Parida, M. Satpathy and L. Mohapatra, J. Mater. Chem., 2012, 22, 7350-7357.

190. T. Kameda, E. Kondo and T. Yoshioka, Sep. Purif. Technol., 2014, 122, 12-16.

191. X. Wang, Y. Lin, Y. Su, B. Zhang, C. Li, H. Wang and L. Wang, Electrochim. Acta, 2017, 225, 263-271.

192. M. Dinari, M. M. Momeni and Y. Ghayeb, J. Mater. Sci.: Mater. Electron., 2016, 27, 9861-9869.

193. S. Kim, J. Fahel, P. Durand, E. André and C. Carteret, Eur. J. Inorg. Chem., 2017, 2017, 669-678.

194. K. Grover, S. Komarneni and H. Katsuki, Appl. Clay Sci., 2010, 48, 631-637.

195. M. Sui, Y. Zhou, L. Sheng and B. Duan, Chem. Eng. J., 2012, 210, 451-460.

196. S. Kim, S. G. Jeon and K. B. Lee, ACS Appl. Mat. Interfaces 2016, 8, 5763-5767.

197. E. Dore and F. Frau, Environmental Science and Pollution Research, 2017, 1-14.

198. T. Lv, W. Ma, G. Xin, R. Wang, J. Xu, D. Liu, F. Liu and D. Pan, J. Hazard. Mater., 2012, 237, 121-132.

199. A. A. A. Ahmed, Z. A. Talib, M. Z. bin Hussein and A. Zakaria, J. Solid State Chem., 2012, 191, 271-278.

200. Y. Yang, X. Yan, X. Hu, R. Feng and M. Zhou, J. Colloid Interface Sci., 2017.

201. M. Shao, J. Han, M. Wei, D. G. Evans and X. Duan, Chem. Eng. J., 2011, 168, 519-524.

202. Y. Zhao, B. Li, Q. Wang, W. Gao, C. J. Wang, M. Wei, D. G. Evans, X. Duan and D. O'Hare, Chemical Science, 2014, 5, 951-958.

203. L.-J. Zhou, X. Huang, H. Chen, P. Jin, G.-D. Li and X. Zou, Dalton Trans., 2015, 44, 11592-11600.

204. J. Zhang, J. Cheng, M. Li, L. Liu, F. Liu and X. Zhang, J. Electroanal. Chem., 2015, 743, 38-45.

205. A. Sumboja, J. Chen, Y. Zong, P. S. Lee and Z. Liu, Nanoscale, 2017, 9, 774-780.

206. F. Ling, L. Fang, Y. Lu, J. Gao, F. Wu, M. Zhou and B. Hu, Microporous Mesoporous Mater., 2016, 234, 230-238.

207. K. Ma, J. Cheng, J. Zhang, M. Li, F. Liu and X. Zhang, Electrochim. Acta, 2016, 198, 231-240.

208. M. A. Woo, M.-S. Song, T. W. Kim, I. Y. Kim, J.-Y. Ju, Y. S. Lee, S. J. Kim, J.-H. Choy and S.-J. Hwang, J. Mater. Chem., 2011, 21, 4286-4292.

209. J. Gou, S. Xie, Y. Liu and C. Liu, Electrochim. Acta, 2016, 210, 915-924.

210. L. Qian, Z. Lu, T. Xu, X. Wu, Y. Tian, Y. Li, Z. Huo, X. Sun and $X$. Duan, Advanced Energy Materials, 2015, 5.

211. Q. Liu, H. Wang, X. Wang, R. Tong, X. Zhou, X. Peng, H. Wang, H. Tao and Z. Zhang, Int. J. Hydrogen Energy, 2017, 42, 5560-5568.

212. P. Li, Q. Xie, L. Zheng, G. Feng, Y. Li, Z. Cai, Y. Bi, Y. Li, Y. Kuang and X. Sun, Nano Research, 2017, 10, 2988-2997.

213. X.-Y. Yu, T. Luo, Y. Jia, R.-X. Xu, C. Gao, Y.-X. Zhang, J.-H. Liu and X.-J. Huang, Nanoscale, 2012, 4, 3466-3474.

214. Y. Sun, S. Gao and Y. Xie, Chem. Soc. Rev., 2014, 43, 530546. 
215. Y. Zhao, G. Chen, T. Bian, C. Zhou, G. I. Waterhouse, L. Z. Wu, C. H. Tung, L. J. Smith, D. O'Hare and T. Zhang, Adv. Mater. , 2015, 27, 7824-7831.

216. Y. Zhao, Y. Zhao, G. I. Waterhouse, L. Zheng, X. Cao, F. Teng, L. Z. Wu, C. H. Tung, D. O'Hare and T. Zhang, Adv. Mater. , 2017.

217. J. Yu, B. R. Martin, A. Clearfield, Z. Luo and L. Sun, Nanoscale, 2015, 7, 9448-9451.

218. J. Yu, J. Liu, A. Clearfield, J. E. Sims, M. T. Speiegle, S. L. Suib and L. Sun, Inorg. Chem., 2016, 55, 12036-12041.

219. Y. Zhao, Y. Zhao, G. I. N. Waterhouse, L. Zheng, X. Cao, F. Teng, L.-Z. Wu, C.-H. Tung, D. O'Hare and T. Zhang, Advanced materials (Deerfield Beach, Fla.), 2017, DOI: 10.1002/adma.201703828.

220. Y. Sun, S. Gao, F. Lei, C. Xiao and Y. Xie, Acc. Chem. Res., 2014, 48, 3-12.

221. F. Song and X. Hu, Nature communications, 2014, 5 .

222. P. Sun, R. Ma, X. Bai, K. Wang, H. Zhu and T. Sasaki, Science Advances, 2017, 3, e1602629.

223. G. Hu, N. Wang, D. O'Hare and J. Davis, J. Mater. Chem., 2007, 17, 2257-2266.

224. G. Hu and D. O'Hare, J. Am. Chem. Soc., 2005, 127, 17808-17813.

225. Q. Wang, S. V. Y. Tang, E. Lester and D. O'Hare, Nanoscale, 2013, 5, 114-117.

226. V. Nicolosi, M. Chhowalla, M. G. Kanatzidis, M. S. Strano and J. N. Coleman, Science, 2013, 340, 1226419.

227. H. Liang, F. Meng, M. СabГY̌n-Acevedo, L. Li, A. Forticaux, L. Xiu, Z. Wang and S. Jin, Nano Lett., 2015, 15, 1421.

228. Z. Lu, W. Xu, W. Zhu, Q. Yang, X. Lei, J. Liu, Y. Li, X. Sun and X. Duan, Chem. Commun., 2014, 50, 6479-6482.

229. T. Li, G. Li, L. Li, L. Liu, Y. Xu, H. Ding and T. Zhang, ACS Appl. Mat. Interfaces 2016, 8, 2562-2572.

230. H. Li, Z. Chen, Y. Wang, J. Zhang and X. Yan, Electrochim. Acta, 2016, 210, 15-22.

231. T. Li, R. Li and H. Luo, Journal of Materials Chemistry A, 2016, 4, 18922-18930.

232. K. Dutta and A. Pramanik, Chem. Commun., 2013, 49, 6427-6429.

233. M. Yang, J. Liu, Z. Chang, G. R. Williams, D. O'Hare, X. Zheng, X. Sun and X. Duan, J. Mater. Chem., 2011, 21, 14741-14746.

234. W. Lv, M. Du, W. Ye and Q. Zheng, Journal of Materials Chemistry A, 2015, 3, 23395-23402.

235. C. J. Wang and D. O'Hare, J. Mater. Chem., 2012, 22, 23064-23070.

236. L. Chen, C. Li, Y. Wei, G. Zhou, A. Pan, W. Wei and B. Huang, J. Alloys Compd., 2016, 687, 499-505.

237. M. Shao, F. Ning, J. Zhao, M. Wei, D. G. Evans and X. Duan, Adv. Funct. Mater., 2013, 23, 3513-3518.

238. Z. Li, B. Yang, S. Zhang, B. Wang and B. Xue, Journal of Materials Chemistry A, 2014, 2, 10202-10210.

239. T. Zhang, Z. Mei, Y. Zhou, X. Bu, Y. Wang, Q. Li and X. Yang, CrystEngComm, 2014, 16, 1793-1801.

240. L. Li, R. Ma, N. Iyi, Y. Ebina, K. Takada and T. Sasaki, Chem. Commun., 2006, 3125-3127.

241. C. Zhang, M. Shao, L. Zhou, Z. Li, K. Xiao and M. Wei, ACS Appl. Mat. Interfaces 2016, 8, 33697-33703.

242. E. Géraud, S. Rafqah, M. Sarakha, C. Forano, V. Prevot and F. Leroux, Chem. Mater., 2007, 20, 1116-1125.

243. P. G. Rodriguez, M. de Ruiter, T. Wijnands and J. Ten Elshof, Scientific reports, 2017, 7.
244. N. Abushrenta, X. Wu, J. Wang, J. Liu and X. Sun, Scientific reports, 2015, 5.

245. P. F. Liu, S. Yang, B. Zhang and H. G. Yang, ACS Appl. Mat. Interfaces 2016, 8, 34474-34481.

246. Y. Sun, Q. Liu, S. Gao, H. Cheng, F. Lei, Z. Sun, Y. Jiang, H. Su, S. Wei and Y. Xie, Nature communications, 2013, 4, 2899.

247. M. Zubair, M. Daud, G. McKay, F. Shehzad and M. A. AlHarthi, Appl. Clay Sci., 2017, 143, 279-292.

248. G. Fan, F. Li, D. G. Evans and X. Duan, Chem. Soc. Rev., 2014, 43, 7040-7066.

249. S. M. Shaheen, N. K. Niazi, N. E. Hassan, I. Bibi, H. Wang, D. C. Tsang, Y. S. Ok, N. Bolan and J. Rinklebe, Int. Mater. Rev., 2019, 64, 216-247.

250. M. González, I. Pavlovic, R. Rojas-Delgado and C. Barriga, Chem. Eng. J., 2014, 254, 605-611.

251. H. Asiabi, Y. Yamini and M. Shamsayei, J. Hazard. Mater., 2017, 339, 239-247.

252. M. W. Laipan, H. Y. Fu, R. L. Zhu, L. Y. Sun, R. M. Steel, S. J. Ye, J. X. Zhu and H. P. He, Appl. Clay Sci., 2018, 153, 4653.

253. J. Gong, T. Liu, X. Wang, X. Hu and L. Zhang, Environ. Sci. Technol., 2011, 45, 6181-6187.

254. T. Wen, X. Wu, X. Tan, X. Wang and A. Xu, ACS Appl. Mat. Interfaces 2013, 5, 3304-3311.

255. G. B. B. B. Varadwaj, O. A. Oyetade, S. Rana, B. S. Martincigh, S. B. Jonnalagadda and V. O. Nyamori, ACS Appl. Mat. Interfaces 2017.

256. G. Sheng, J. Hu, H. Li, J. Li and Y. Huang, Chemosphere, 2016, 148, 227-232.

257. B. Zhang, L. Luan, R. Gao, F. Li, Y. Li and T. Wu, Colloids Surf., A 2017, 520, 399-408.

258. S. U. Nandanwar, K. Coldsnow, V. Utgikar, P. Sabharwall and D. E. Aston, Chem. Eng. J., 2016, 306, 369-381.

259. X. Zhang, J. Wang, R. Li, Q. Dai, R. Gao, Q. Liu and M. Zhang, Ind. Eng. Chem. Res., 2013, 52, 10152-10159.

260. L. Tan, Y. Wang, Q. Liu, J. Wang, X. Jing, L. Liu, J. Liu and D. Song, Chem. Eng. J., 2015, 259, 752-760.

261. G. Sheng, Y. Tang, W. Linghu, L. Wang, J. Li, H. Li, X. Wang and Y. Huang, Appl. Catal., B 2016, 192, 268-276.

262. W. Linghu, H. Yang, Y. Sun, G. Sheng and Y. Huang, ACS Sustainable Chemistry \& Engineering, 2017.

263. Y. Zou, Y. Liu, X. Wang, G. Sheng, S. Wang, Y. Ai, Y. Ji, Y. Liu, T. Hayat and X. Wang, ACS Sustainable Chemistry \& Engineering, 2017, 5, 3583-3595.

264. W. Yao, X. Wang, Y. Liang, S. Yu, P. Gu, Y. Sun, C. Xu, J. Chen, T. Hayat and A. Alsaedi, Chem. Eng. J., 2018, 332, 775-786.

265. Y. Zou, P. Wang, W. Yao, X. Wang, Y. Liu, D. Yang, L. Wang, J. Hou, A. Alsaedi and T. Hayat, Chem. Eng. J., 2017, 330, 573-584.

266. T. G. Levitskaia, S. Chatterjee, B. W. Arey, E. L. Campbell, Y. Hong, L. Kovarik, J. M. Peterson, N. K. Pence, J. Romero and V. Shutthanandan, RSC Advances, 2016, 6, 7604276055.

267. D. Banerjee, D. Kim, M. J. Schweiger, A. A. Kruger and P. K. Thallapally, Chem. Soc. Rev., 2016, 45, 2724-2739.

268. M. Zhang, Q. Yao, C. Lu, Z. Li and W. Wang, ACS Appl. Mat. Interfaces 2014, 6, 20225-20233.

269. P. Zhao, X. Liu, W. Tian, D. Yan, X. Sun and X. Lei, Chem. Eng. J., 2015, 279, 597-604.

270. S. Yu, X. Wang, Z. Chen, J. Wang, S. Wang, T. Hayat and X. 
Wang, J. Hazard. Mater., 2017, 321, 111-120.

271. D. Bharali and R. C. Deka, Colloids Surf., A 2017, 525, 6476.

272. X. Yue, J. Li, T. Zhang, F. Qiu, D. Yang and M. Xue, Chem. Eng. J., 2017, 328, 117-123.

273. G. Carja, E. F. Grosu, M. Mureseanu and D. Lutic, Catalysis Science \& Technology, 2017.

274. Y. Meng, W. Luo, S. Xia and Z. Ni, Catalysts, 2017, 7, 143.

275. J. Yuan, X. Liu, O. Akbulut, J. Hu, S. L. Suib, J. Kong and F. Stellacci, Nat. Nanotechnol., 2008, 3, 332-336.

276. Q. Wang, G. Chen, J. Tian, Z. Yu, Q. Deng and M. Yu, Mater. Lett., 2018, 230, 84-87.

277. Q. Wang, M. Yu, G. Chen, Q. Chen and J. Tian, J. Mater. Sci., 2017, 52, 2549-2559.

278. Q. Wang, M. Yu, G. Chen, Q. Chen and J. Tai, BioResources, 2017, 12, 643-654.

279. Q. Wang, J. Xiong, G. Chen, O. Xinping, Z. Yu, Q. Chen and M. Yu, Materials, 2019, 12, 1393.

280. Y. Lin, P. Yi, M. Yu and G. Li, Mater. Lett., 2018, 230, 219223.

281. X. Liu, L. Ge, W. Li, X. Wang and F. Li, ACS Appl. Mat. Interfaces 2014, 7, 791-800.

282. S. S. Elanchezhiyan and S. Meenakshi, Int. J. Biol. Macromol., 2017.

283. J. Luo, W. Zhang, H. Yuan, C. Jin, L. Zhang, H. Huang, C. Liang, Y. Xia, J. Zhang and Y. Gan, ACS Nano, 2017, 11, 2459-2469.

284. C. Eames and M. S. Islam, J. Am. Chem. Soc., 2014, 136, 16270-16276.

285. G. G. Yadav, J. W. Gallaway, D. E. Turney, M. Nyce, J. Huang, X. Wei and S. Banerjee, Nature Communications, 2017, 8 .

286. J. Zhang, Z. Zhang, Y. Yao, X. Ma, Y. Yang, Y. Chen and Z. Cheng, Appl. Surf. Sci., 2019.

287. C. Peng, P. Wei, X. Li, Y. Liu, Y. Cao, H. Wang, H. Yu, F. Peng, L. Zhang and B. Zhang, Nano energy, 2018, 53, 97107.

288. B. G. Pollet, I. Staffell and J. L. Shang, Electrochim. Acta, 2012, 84, 235-249.

289. X. Luo, Q. Zhou, S. Du, J. Li, L. Zhang, K. Lin, H. Li, B. Chen, T. Wu and D. Chen, ACS Appl. Mat. Interfaces 2018, 10, 42335-42347.

290. X. Long, Z. Wang, S. Xiao, Y. An and S. Yang, Mater. Today 2016, 19, 213-226.

291. Y. Jia, L. Zhang, G. Gao, H. Chen, B. Wang, J. Zhou, M. T. Soo, M. Hong, X. Yan and G. Qian, Adv. Mater. , 2017, 29.

292. G. Hatui, G. C. Nayak and G. Udayabhanu, Electrochim. Acta, 2016, 219, 214-226.

293. P. Simon and Y. Gogotsi, Nat. Mater., 2008, 7, 845-854.

294. J. Han, Y. Ping, J. Li, Z. Liu, B. Xiong, P. Fang and C. He, Diamond Relat. Mater., 2019, 96, 176-181.

295. Q. Zhou, T. Fan, Y. Li, D. Chen, S. Liu and X. Li, J. Power Sources, 2019, 426, 111-115.

296. S. Zhang, C. Wu, W. Wu, C. Zhou, Z. Xi, Y. Deng, X. Wang, P. Quan, X. Li and Y. Luo, J. Power Sources, 2019, 424, 17.

297. M. Yao, X. Zhao, J. Zhang, W. Tan, J. Luo, J. Dong and Q. Zhang, Nanotechnology, 2018, 30, 085404.

298. P. Ou, Q. Zhou, J. Li, W. Chen, J. Huang, L. Yang, J. Liao and M. Sheng, Materials Research Express, 2019, 6, 095044.

299. C. Tan, X. Cao, X.-J. Wu, Q. He, J. Yang, X. Zhang, J. Chen,
W. Zhao, S. Han and G.-H. Nam, Chem. Rev., 2017, 117, 6225-6331.

300. J. Yang, C. Yu, X. Fan and J. Qiu, Adv. Energy Mater., 2014, 4, 1400761.

301. B. Zhu, G. Guo, G. Wu, Y. Zhang, A. Dong, J. Hu and D. Yang, J. Alloys Compd., 2019, 775, 776-783.

302. F. Wang, C. Wang, H. Chen, W. Zhang, R. Jiang, Z. Yan, Z. Huang, H. Zhou and Y. Kuang, Nanotechnology, 2019, 30, 335701.

303. P. Liang, L. Zhang, D. Wang, X. Man, H. Shu, L. Wang, H. Wan, X. Du and H. Wang, Appl. Surf. Sci., 2019.

304. Q. Wang, L. Shang, R. Shi, X. Zhang, Y. Zhao, G. I. Waterhouse, L. Z. Wu, C. H. Tung and T. Zhang, Advanced Energy Materials, 2017, 7.

305. Z. Yan, E. Wang, J. Gao, J. Yang, C. Wu, L. Jiang, M. Zhu and G. Sun, ChemElectroChem.

306. A. Flegler, S. Müssig, J. Prieschl, K. Mandel and G. Sextl, Electrochim. Acta, 2017, 231, 216-222.

307. J. Zhang, H. Hu, Z. Li and X. W. D. Lou, Angew. Chem. Int. Ed. , 2016, 55, 3982-3986.

308. P. G. Bruce, S. A. Freunberger, L. J. Hardwick and J.-M. Tarascon, Nat. Mater., 2012, 11, 19-29.

309. X. Ji and L. F. Nazar, J. Mater. Chem., 2010, 20, 98219826.

310. A. Manthiram, Y. Fu, S.-H. Chung, C. Zu and Y.-S. Su, Chem. Rev., 2014, 114, 11751-11787.

311. S. Evers and L. F. Nazar, Acc. Chem. Res., 2012, 46, 11351143.

312. X. Wen, Z. Yang, X. Xie, Z. Feng and J. Huang, Electrochim. Acta, 2015, 180, 451-459.

313. Y. Liu and Z. Yang, RSC Advances, 2016, 6, 68584-68591.

314. J. Long, Z. Yang, J. Huang and X. Zeng, J. Power Sources, 2017, 359, 111-118.

315. X. Zeng, Z. Yang, F. Liu, J. Long, Z. Feng and M. Fan, RSC Advances, 2017, 7, 44514-44522.

316. M. Bastianini, R. Vivani, M. Nocchetti, D. Costenaro, C. Bisio, F. Oswald, T. B. Meyer and L. Marchese, Sol. Energy 2014, 107, 692-699.

317. J. H. Lee, J. Chang, J. H. Cha, D. Y. Jung, S. S. Kim and J. M. Kim, Chemistry-A European Journal, 2010, 16, 82968299.

318. X. Wang, R. Deng, S. A. Kulkarni, X. Wang, S. S. Pramana, C. C. Wong, M. Grätzel, S. Uchida and S. G. Mhaisalkar, Journal of Materials Chemistry A, 2013, 1, 4345-4351.

319. T. Du, J. Zhu, N. Wang, H. Chen and H. He, J. Electrochem. Soc., 2015, 162, H518-H521.

320. C. Li, M. Wei, D. G. Evans and X. Duan, Small, 2014, 10, 4469-4486.

321. M. Luo, Z. Cai, C. Wang, Y. Bi, L. Qian, Y. Hao, L. Li, Y. Kuang, Y. Li and X. Lei, Nano Research, 2017, 10, 17321739.

322. X. Li, X. Hao, Z. Wang, A. Abudula and G. Guan, J. Power Sources, 2017, 347, 193-200.

323. N. Han, F. Zhao and Y. Li, Journal of Materials Chemistry A, 2015, 3, 16348-16353.

324. X. Long, J. Li, S. Xiao, K. Yan, Z. Wang, H. Chen and S. Yang, Angew. Chem., 2014, 126, 7714-7718.

325. M. Wang, M. Shen, L. Zhang, J. Tian, X. Jin, Y. Zhou and J. Shi, Carbon, 2017, 120, 23-31.

326. S. He, Z. An, M. Wei, D. G. Evans and X. Duan, Chem. Commun., 2013, 49, 5912-5920.

327. Y. Kuthati, R. K. Kankala and C.-H. Lee, Appl. Clay Sci., 
2015, 112, 100-116.

328. P. Wang, J. Wang, H. Tan, S. Weng, L. Cheng, Z. Zhou and S. Wen, Biomaterials science, 2018, 6, 1262-1270.

329. A. Díaz, A. David, R. Pérez, M. L. González, A. Báez, S. E. Wark, P. Zhang, A. Clearfield and J. L. Colón, Biomacromolecules, 2010, 11, 2465-2470.

330. Y. Zhang, M. Long, P. Huang, H. Yang, S. Chang, Y. Hu, A. Tang and L. Mao, Nano Research, 2017, 1-11.

331. T. Xu, J. Zhang, H. Chi and F. Cao, Acta Biomater., 2016, 36, 152-163.

332. S. T. Frey, S. L. Guilmet, R. G. Egan III, A. Bennett, S. R. Soltau and R. C. Holz, ACS Appl. Mat. Interfaces 2010, 2, 2828-2832.

333. A. Li, L. Qin, D. Zhu, R. Zhu, J. Sun and S. Wang, Biomaterials, 2010, 31, 748-756.

334. G. Mishra, B. Dash and S. Pandey, Appl. Clay Sci., 2018, 153, 172-186.

335. A. Li, L. Qin, W. Wang, R. Zhu, Y. Yu, H. Liu and S. Wang, Biomaterials, 2011, 32, 469-477.

336. J.-H. Choy, S.-J. Choi, J.-M. Oh and T. Park, Appl. Clay Sci.,
2007, 36, 122-132.

337. S.-J. Choi and J.-H. Choy, Nanomedicine, 2011, 6, 803814.

338. L.-x. Zhang, X.-x. Xie, D.-q. Liu, Z. P. Xu and R.-t. Liu, Biomaterials, 2018, 174, 54-66.

339. A. U. Kura, S. H. H. Al Ali, M. Z. Hussein, S. Fakurazi and P. Arulselvan, Int. J. Nanomedicine, 2013, 8, 1103.

340. G. Kapusetti, N. Misra, V. Singh, R. Kushwaha and P. Maiti, Journal of Biomedical Materials Research Part A, 2012, 100, 3363-3373.

341. C. Chen, P. Gunawan, X. W. Lou and R. Xu, Adv. Funct. Mater., 2012, 22, 780-787.

342. F. Peng, D. Wang, D. Zhang, H. Cao and X. Liu, Appl. Clay Sci., 2018, 165, 179-187.

343. Y.-M. Kuo, Y. Kuthati, R. K. Kankala, P.-R. Wei, C.-F. Weng, C.-L. Liu, P.-J. Sung, C.-Y. Mou and C.-H. Lee, Journal of Materials Chemistry B, 2015, 3, 3447-3458.

344. Z. Li, H. Duan, M. Shao, J. Li, D. O'Hare, M. Wei and Z. L. Wang, Chem, 2018, 4, 2168-2179. 


\section{ARTICLE}

\section{Table of contents entry}

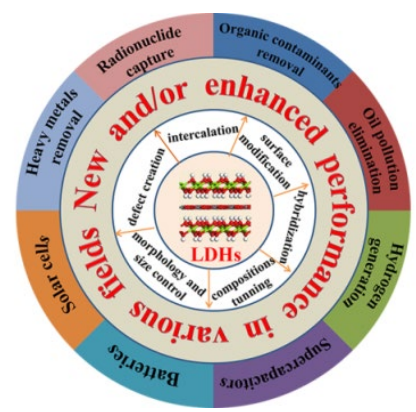

Functionalization strategies are powerful for generating new or enhanced properties of LDHs, offering unique perspectives and advantages for preparing novel materials. 